Aus der Abteilung Präventive Zahnmedizin, Parodontologie und Kariologie

(Komm. Direktor: Prof. Dr. med. dent. M. Hülsmann)

im Zentrum Zahn-, Mund- und Kieferheilkunde

der Medizinischen Fakultät der Universität Göttingen

\title{
Vergleichende Untersuchung zur Reinigungswirkung von Handspülung, Ultraschallspülung und RinsEndo bei Wurzelkanälen mit unterschiedlicher apikaler Präparationsgröße
}

\author{
INAUGURAL - DISSERTATION \\ zur Erlangung des Doktorgrades \\ für Zahnheilkunde \\ der Medizinischen Fakultät \\ der Georg-August-Universität zu Göttingen \\ vorgelegt von \\ Mohammad Bagher Sedghi Shabestari \\ aus \\ Teheran/Iran
}

Göttingen 2010 
Dekan:

1. Berichterstatter:

2. Berichterstatter/-in:

3. Berichterstatter/-in:
Prof. Dr. med. C. Frömmel

Prof. Dr. med. dent. M. Hülsmann

Prof. Dr. med. dent. R. Sadat-Khonsari

Prof. Dr. med. M. Oppermann

Tag der mündlichen Prüfung: 2011-03-29 
Die vorliegende Promotionsschrift war die Grundlage für folgende Veröffentlichung:

Rödig T, Sedghi M, Konietschke F, Lange K, Ziebolz D, Hülsmann M (2010):

Efficacy of syringe irrigation, RinsEndo and passive ultrasonic irrigation in removing debris from irregularities in root canals with different apical sizes

Int Endod J 느, 581-589 


\section{Inhaltsverzeichnis}

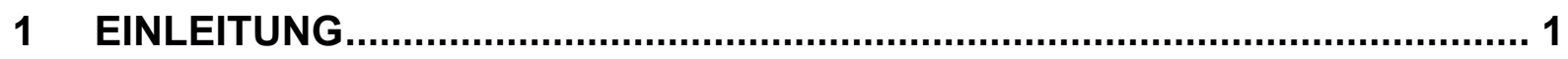

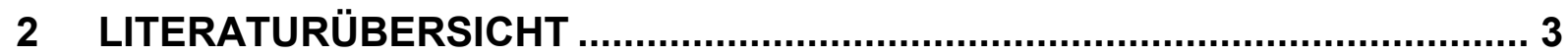

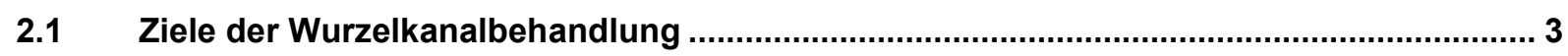

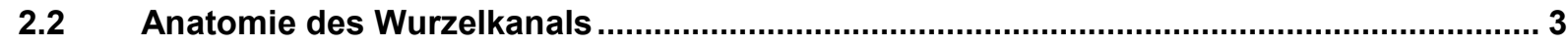

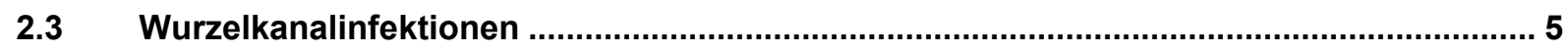

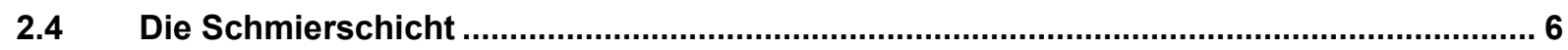

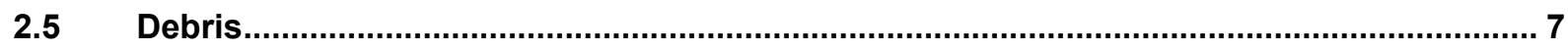

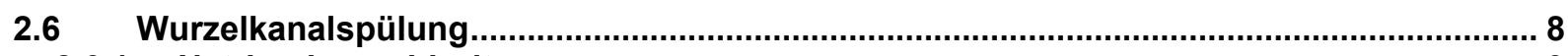

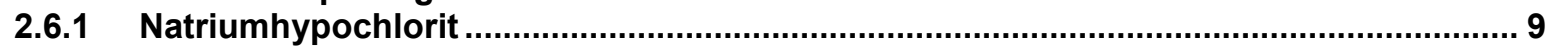

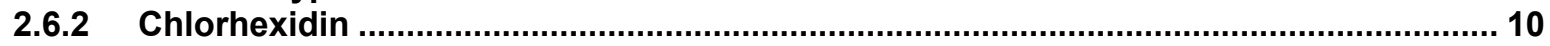

2.6.3 EDTA

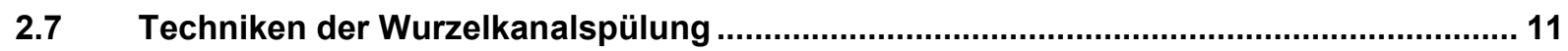

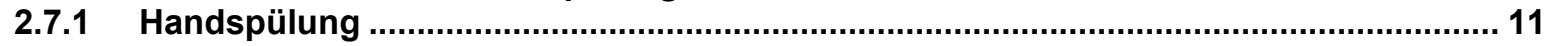

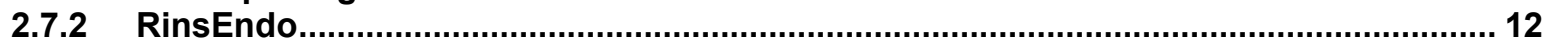

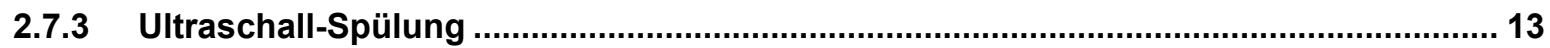

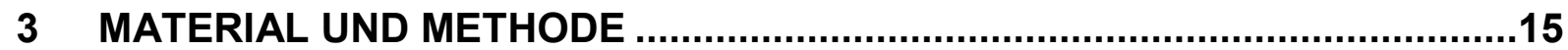

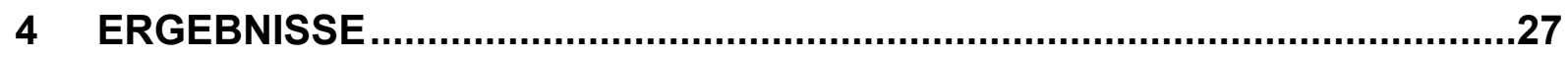

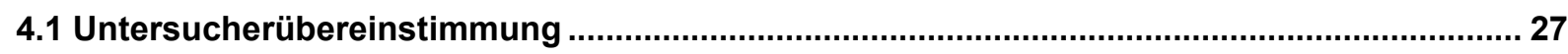

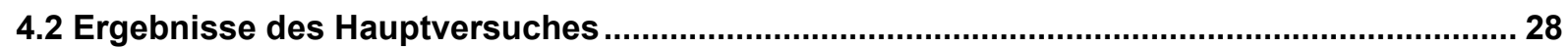

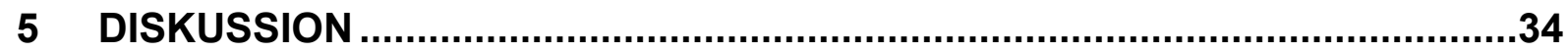

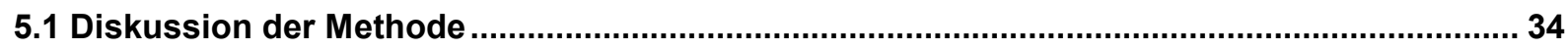

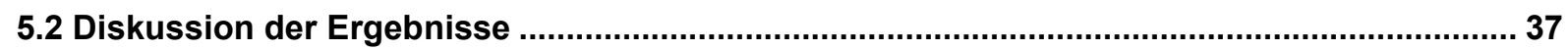

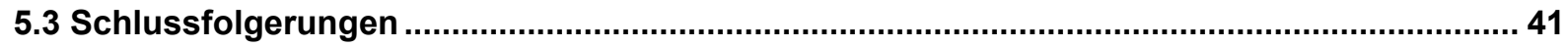

6 ZUSAMMENFASSUNG .....................................................................43

$7 \quad$ LITERATURVERZEICHNIS ...............................................................45

8 ANHANG: BIOMETRISCHE AUSWERTUNG ..........................................69 
Tabellenverzeichnis:

Tab. 3.1 Standardisierte Reihenfolge der Arbeitsschritte mit den 17

FlexMaster-Instrumenten

Tab. 4.1.1 Interindividuelle Übereinstimmung 27

Tab. 4.1.2 Intraindividuelle Reproduzierbarkeit Untersucher $1 \quad 27$

$\begin{array}{lll}\text { Tab. 4.1.3 Intraindividuelle Reproduzierbarkeit Untersucher } 2 & 27\end{array}$

Tab. 4.2.1 Spezielle nichtparametrische Kovarianzanalyse der 28 Effekte

Tab. 4.2.2 Spezielle nichtparametrische Kovarianzanalyse für 31

Tab. 4.2.3 Paarvergleich der Spülmethoden - Größe 30-Gruppe 32

Tab. 4.2.4 Paarvergleich der Spülmethoden - Größe 40-Gruppe 32

Tab. 4.2.5 Paarvergleich der Spülmethoden - Größe 50-Gruppe 33

Abbildungsverzeichnis:

Abb. 2.1 Aufzweigungen des Wurzelkanalsystems 4

Abb. 2.2 Schematische Darstellung von Wurzelkanälen 4

Abb. 3.1 Versuchsaufbau 16

Abb. 3.2 Retentionskerben 19

Abb. 3.3 Ausbuchtungen 19

Abb. 3.4 Sichtfenster 19

Abb. 3.5 Gruben 19

Abb. 3.6 Bohrlöcher 19

Abb. 3.7 Vorrichtung zur Präparation der Gruben und Bohrlöcher 20

Abb. 3.8 Eingebettete Wurzelhälfte und Silaplastschlüssel 21

Abb. 3.9 Handspritze mit Navi-Tip 22

Abb. 3.10 Rins-Endo-Handstück 22

Abb. 3.11 Zahnhälfte A: Score $0 \quad 24$

Abb. 3.12 Zahnhälfte A: Score 1

Abb. 3.13 Zahnhälfte A: Score 2

Abb. 3.14 Zahnhälfte A: Score 3

Abb. 3.15 Zahnhälfte B: Score $0 \quad 25$

Abb. 3.16 Zahnhälfte B: Score 1

Abb. 3.17 Zahnhälfte B: Score 2

Abb. 3.18 Zahnhälfte B: Score 3

Abb. 4.2.1 Grafische Darstellung der Spüleffektivität für jede 29

Präparationsgröße und Spülmethode der Zahnhälften a (Bohrlöcher) und b (Gruben)

Abb. 4.2.2 Grafische Übersicht der Spüleffektivität für Zahnhälfte a 30 (Bohrlöcher) und Zahnhälfte b (Gruben) in Abhängigkeit der Präparationsgröße und der Spülmethode

Abb. 4.2.3 Mittelwertplot für den relativen Effekt - Größe 30-Gruppe 33

Abb. 4.2.4 Mittelwertplot für den relativen Effekt - Größe 40-Gruppe 33

Abb. 4.2.5 Mittelwertplot für den relativen Effekt - Größe 50-Gruppe 33 


\section{Einleitung}

Etwa bis Mitte des 19. Jahrhunderts bestand die Therapie eines schmerzenden Zahnes hauptsächlich in dessen Extraktion. Daraus resultierten Einbußen in der Kaufunktion und in der Ästhetik. Erst mit Einführung spezieller Methoden und prophylaktischer Maßnahmen zur Erhaltung der Zähne gewann die Endodontie eine zunehmend größere Bedeutung. Diese Entwicklung dauert bis zum heutigen Tag an.

Die Fortschritte der endodontischen Therapie begründeten sich vor allem auf neuen Erkenntnissen bezüglich der Mikrobiologie der infizierten Zahnpulpa und des infizierten apikalen Gewebes. So erkannte man die Bedeutung der Reinigung und Desinfektion des Wurzelkanals und die Wichtigkeit eines bakteriendichten Verschlusses des Kanalsystems für eine erfolgreiche Wurzelkanalbehandlung. Außerdem gewann das aseptische Arbeiten unter Kofferdamisolierung immer mehr an Bedeutung. Das Ziel einer endodontischen Therapie ist der langfristige Erhalt der Funktion eines avitalen Zahnes als funktionierende Kaueinheit. Die systematische Wurzelkanalbehandlung gliedert sich hauptsächlich in zwei Arbeitsschritte: die Wurzelkanalpräparation und die Wurzelkanalfüllung.

Ziel der Wurzelkanalpräparation ist eine gründliche Reinigung und Desinfektion des Wurzelkanals sowie die Erweiterung und Formgebung des Kanals zur Entfernung des infizierten Dentins und zur besseren Aufnahme des Füllmaterials. Oberste Priorität in diesem ersten Arbeitsschritt hat die Entfernung von vitalen und nekrotischen Geweberesten sowie von Bakterien und deren Endotoxinen.

In den vergangenen Jahren haben sich die wissenschaftlichen Untersuchungen nicht nur auf die Methoden der Spülung, sondern auch auf die chemische Reinigungs- und Desinfektionswirkung der verschiedenen Spüllösungen konzentriert. Bedeutsam sind hierfür hauptsächlich Natriumhypochlorit $(\mathrm{NaOCl})$, Ethylendiamintetraessigsäure (EDTA) und Wasserstoffperoxid $\left(\mathrm{H}_{2} \mathrm{O}_{2}\right)$, wobei $\mathrm{NaOCl}$ wegen seiner Fähigkeit organisches Material aufzulösen und den Wurzelkanal zu desinfizieren, zur bevorzugten Standardlösung geworden ist (Grossmann und Meimann 1941). Die vermehrte zytotoxische Wirkung bei erhöhter Konzentration von $\mathrm{NaOCl}$ ist hierbei jedoch zu beachten (Lamers et al. 1980). 
Wie Ram (1977) bereits feststellte, gelangen Spüllösungen mit herkömmlichen Methoden nur einen Millimeter tiefer als die Spitze der Kanüle in das Wurzelkanallumen.

Daher galt es, Systeme zu entwickeln, die die Spüllösungen über die gesamte Wurzelkanallänge in alle Verzweigungen und bis zum Apex hin transportieren können. Die neueren Entwicklungen, insbesondere die verschiedenen UltraschallSysteme (EMS, Nyon, Schweiz), zeigten bei Überprüfung ihrer Effektivität gute Resultate. Martin et al. (1980) und Martin und Cunningham (1983, 1985) fanden heraus, dass sich z. B. Ultraschall und $\mathrm{NaOCl}$ gegenseitig in ihrer Wirkung verstärken.

Das Ziel der vorliegenden Arbeit war es, anhand des neu entwickelten hydrodynamischen Spülsystems RinsEndo (Dürr Dental, Bietigheim-Bissingen, Deutschland), die Effektivität einer maschinengetriebenen Spülmethode im Vergleich zur konventionellen manuellen Vorgehensweise und der Ultraschallspülung bei unterschiedlichen apikalen Präparationsgrößen des Wurzelkanals zu untersuchen. Dieser Vergleich bezog sich auf die Effektivität der Entfernung von Debris, der während der instrumentellen Präparation des Wurzelkanals entsteht. 


\section{Literaturübersicht}

\subsection{Ziele der Wurzelkanalbehandlung}

Ziel der endodontischen Maßnahme ist es, das irreversibel geschädigte Pulpagewebe möglichst vollständig zu entfernen, das Wurzelkanalsystem zu desinfizieren und die entstandenen Hohlräume bakteriendicht zu verschließen (Frentzen et al. 2004).

Es ist als Erfolg zu werten, wenn der endodontisch behandelte Zahn nach 4 Jahren keine klinischen Symptome und röntgenologisch keine periapikalen Veränderungen zeigt (ESE 2006).

Diese Ziele können durch die möglichst vollständige Entfernung des Pulpagewebes, Eliminierung der Mikroorganismen und eine wandständige Wurzelkanalfüllung erreicht werden (Löst et al. 1992, Trope und Bergenholtz 2002, Hülsmann et al. 2005). Diese Wurzelkanalfüllung soll den in den Dentintubuli verbliebenen Mikroorganismen das Substrat entziehen und gleichzeitig eine Reinfektion, die durch ein apikales und/oder ein koronales "Leakage“ entstehen kann, verhindern (Löst et al. 1992). Der bakteriendichte Verschluss des Zahnes nach Beendigung einer endodontischen Behandlung und zwischen den einzelnen Behandlungsterminen ist zwingend erforderlich, da es sonst bei Undichtigkeiten zu einem koronalen "Leakage“ und somit zu einer Reinfektion kommen könnte (Carrotte 2004, Hülsmann et al. 2005, Saunders und Saunders 1994). Eine bakteriendichte koronale Versorgung trägt wesentlich zum langfristigen Erfolg einer Wurzelkanalbehandlung bei ( $\mathrm{Ng}$ et al. 2008).

\subsection{Anatomie des Wurzelkanals}

Für die korrekte Präparation und nachfolgende Spülung ist eine genaue anatomische Kenntnis des Wurzelkanalsystems notwendig (Grossmann 1981, Guldener und Langeland 1987, Ingle und Taintor 1985, Schroeder 1987, Schilder 1984). 
Die Kanalwand zeichnet sich durch eine raue Oberfläche mit Nischen, Vorsprüngen und Gruben aus. Darüber hinaus treten Unregelmäßigkeiten durch Einengungen des Kanallumens bis zur vollständigen Obliteration, durch interne Resorptionen und durch Einmündungen von akzessorischen Kanälen auf.

Ein Wurzelkanal ist keine geradlinig verlaufende Röhre, sondern, wie die Untersuchungen von Fischer (1907), Hess (1917), Meyer und Scheele (1954, 1955) und Meyer (1960) belegen, handelt es sich um ein äußerst verzweigtes Kanalsystem mit zahlreichen Seitenkanälchen, Aufzweigungen und Ramifikationen (Abb. 2.1 und 2.2).
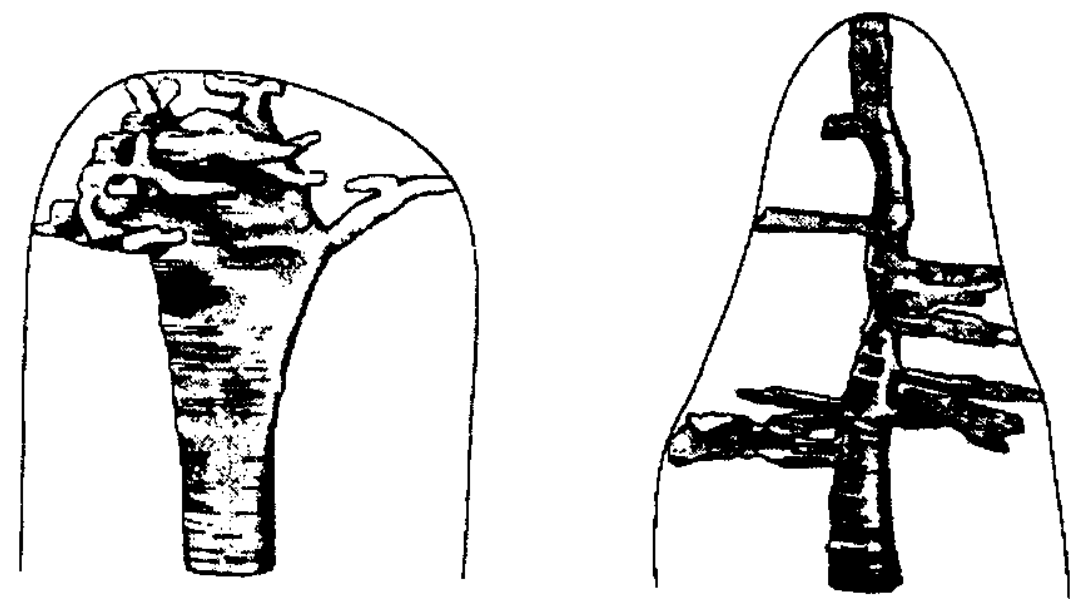

Abb. 2.1: Aufzweigungen des Wurzelkanalsystems eines Eckzahnes (rechts) sowie eines Prämolaren (links) (Meyer 1970, S.1064).
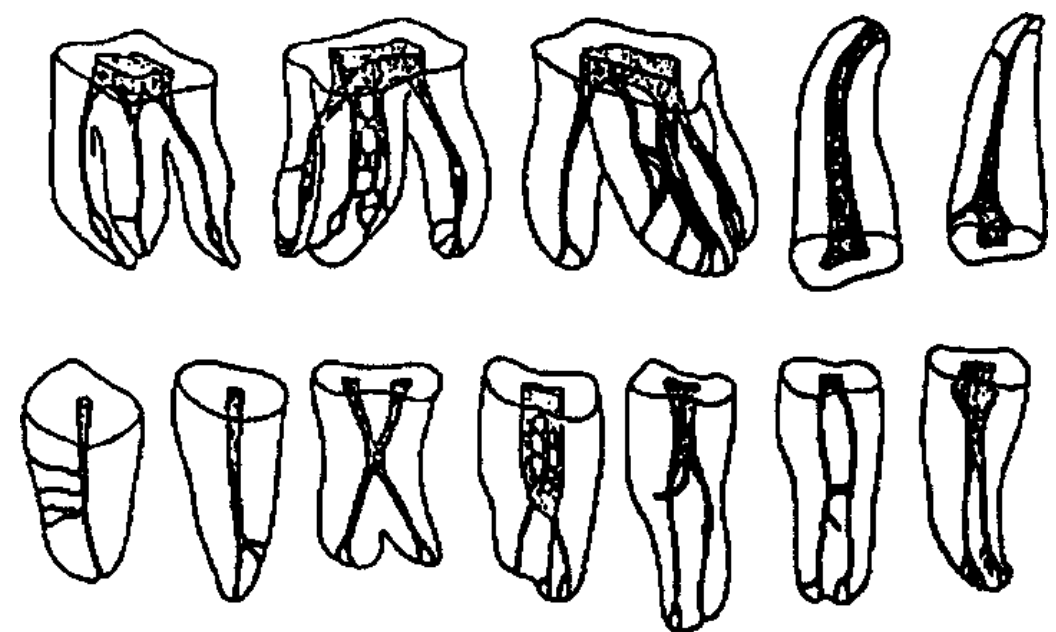

Abb. 2.2: Schematische Darstellung von Wurzelkanälen unterschiedlicher Zahntypen. Zahlreiche Aufzweigungen, Anastomosen und Seitenkanäle bilden ein höchst differenziertes Kanalsystem (Häupl et al. 1958, S. 170) 
Eine weitere anatomische Besonderheit stellt die häufig auftretende Aufspaltung des Hauptkanals in ein apikales Delta dar, wobei das Foramen apicale oft mit einer Flussmündung verglichen wird. Histologische Serienschnitte zeigen, dass diese apikalen Ramifikationen selten geradlinig, sondern meistens bizarr gekrümmt verlaufen (Ketterl 1984). Diese Apexkonfigurationen und Seitenkanälchen, wie sie in Abb. 2.2 dargestellt sind, lassen in vielen Fällen eine vollständige und somit hermetische Wurzelkanalfüllung nicht zu (Meyer 1960).

Aufgrund der Komplexität und Variationsbreite der Wurzelkanalanatomie wird die Verwendung des Begriffes „Wurzelkanalsystem“ von Guldener vorgeschlagen (Guldener 1989).

\subsection{Wurzelkanalinfektionen}

Eine endodontische Therapie wird in der Regel aufgrund einer bakteriellen Infektion der Pulpa notwendig. So dringen Bakterien beispielsweise über undichte Füllungen, kariöse Läsionen oder nicht abgedeckte Dentinbezirke in die Zahnhartsubstanz und schließlich in die Pulpa ein. Tronstadt (1991) beschreibt, dass die Zahnkrone eine der Haupteintrittspforten für Bakterien in die Pulpa und damit in das Wurzelkanalsystem sei.

Ist es zu einem Eindringen von Bakterientoxinen, Antigenen und Mikroorganismen in die Pulpa gekommen und werden die Noxen, die zu einer Pulpitis geführt haben, nicht ausgeschaltet, so kann dies zu einer Pulpanekrose führen. Das nekrotische Gewebe stellt einen ausgezeichneten Nährboden für die Bakterien dar (Koçkapan 2003). Diese Mikroorganismen infizieren die Pulpa und dringen schließlich in die Dentintubuli ein. In Untersuchungen von Pörzel und Petschelt (1986) konnten Bakterien bis zu einer Tiefe von 1,2 mm im Kanalwanddentin nachgewiesen werden. Das Pulpagewebe ist über das Foramen apicale und die Seitenkanäle mit dem umgebenden Gewebe verbunden. Daher führt eine unbehandelte Infektion der Pulpa immer zu einer Entzündung der periapikalen Gewebe (Parodontitis apicalis) (van Velzen et al. 1988, Hellwig et al. 1999). 


\subsection{Die Schmierschicht}

Die Schmierschicht entsteht bei der mechanischen Präparation an der Wurzelkanalwand auf der Dentinoberfläche. Dies geschieht durch die direkte Einwirkung der Instrumente (Goldman LB et al. 1981, Koçkapan 1995, Mader et al. 1984, McComb und Smith 1975, Petschelt und Oberschachtsiek 1985). Die Schmierschicht ist ca. 2-5 $\mu \mathrm{m}$ dick und besteht aus einem Gemisch von Dentin, Prädentin, denaturiertem Kollagen, Resten des Pulpagewebes, Odontoblastenfortsätzen und bei einem Zahn mit infizierter Pulpa auch Bakterien (Brännström 1984, Koçkapan 1987, Koçkapan 1995, Mader et al. 1984, McComb und Smith 1975, Torabinejad et al. 2002). Somit sind die Bestandteile der Schmierschicht sowohl anorganischer als auch organischer Natur (Koçkapan 1987, Pashley 1984, Yamada et al. 1983). Außerdem liegt eine nicht genau definierte Matrix vor (Koçkapan 1987). Erst bei genügend hoher Vergrößerung lassen sich viele verschiedenartige Partikel auf der Oberfläche der Schmierschicht erkennen (Koçkapan 1995).

Es können zwei unterschiedliche Typen der Schmierschicht differenziert werden: eine die Kanalwand bedeckende oberflächliche Schmierschicht und eine in die Dentintubuli hineingepresste Schmierschicht (Koçkapan 1987). McComb und Smith (1975) stellten fest, dass die oberflächliche Schmierschicht locker auf dem Dentin aufliegt. Koçkapan (1995) beobachtete unter dem REM, dass ein Teil der Schmierschicht in die Dentintubuli hineingepresst wird. Diese Schmierschicht kann bis zu $40 \mu \mathrm{m}$ tief in die Dentinkanäle eindringen (Mader et al. 1984).

Einerseits bewirkt die nicht entfernte Schmierschicht eine Verblockung der Dentinkanälchen und behindert dadurch das Einwirken von Spüllösungen und medikamentösen Einlagen (Byström und Sundqvist 1985, Foster et al. 1993). Weiterhin unterbindet die Schmierschicht eine dichte Verbindung des Sealers mit der Wurzelkanalwand (Taylor et al. 1997, Torabinejad et al. 2002). Es resultiert hieraus die Gefahr eines "microleakage", wodurch eine Reinfektion begünstigt werden kann (Shipper et al. 2005). Wurzelkanalfüllungen weisen nach Entfernung der Schmierschicht mehr kleine apikale Undichtigkeiten auf als die Wurzelkanalfüllungen der Zähne, bei denen die Schmierschicht intakt blieb (Cooke et al. 1976, Timpawat et al. 2001). Weiterhin wird befürchtet, dass sich in den offenen Dentinkanälchen 
Bakterien vermehren und leichter an die Wurzelaußenseite gelangen können (Drake et al. 1994, Galvan et al. 1994, Love 1996, Saleh et al. 2008, Shemesh et al. 2006). Cergneux et al. (1987) belegten, dass die Wandständigkeit und Dichtigkeit einer Wurzelkanalfüllung durch die Schmierschichtentfernung verbessert werden kann. Aufgrund der Verblockung der Dentintubuli durch die Schmierschicht wird angenommen, dass das Eindringen antibakteriell wirksamer Substanzen in die Dentintubuli verhindert wird (Koçkapan 1987, Petschelt und Oberschachtsiek 1985). Ørstavik und Haapasalo (1990) berichteten allerdings, dass die Schmierschicht die Wirkung antibakterieller Medikamente nur verzögert und nicht aufhebt. Weitere Studien ergaben, dass in der Schmierschicht eingeschlossene Bakterien immer noch überlebens- und vermehrungsfähig sind (Brännström und Nyborg 1973, Baker et al. 1975, Yamada et al. 1983). Brännström und Nyborg (1973) schlossen daraus, dass die Schmierschicht einen Nährboden für Bakterien darstellt.

Die Veröffentlichungen zu diesem Thema zwischen 1975 und 2005 wurden von Shahravan et al. (2007) in einer Metaanalyse ausgewertet. In dieser Metaanalyse kommen die Autoren zu dem Schluss, dass die Entfernung der Schmierschicht den flüssigkeitsdichten Verschluss des Wurzelkanalsystems verbessert. Die DGZMK empfiehlt in ihrer Stellungnahme hierzu, die Schmierschicht zu entfernen (Barthel et al. 2006).

\subsection{Debris}

Bei instrumenteller Aufbereitung des Wurzelkanalsystems wird das abgeschabte Dentin nicht vollständig aus dem Wurzelkanal abtransportiert. Es findet sich zum Teil in lockeren, schollenförmigen Ablagerungen an der Kanalwand wieder. Diese als Debris bezeichneten Auflagerungen können ebenfalls Reste des Pulpagewebes und Bakterien enthalten. Da die Späne der Kanalwand nur locker aufliegen, besteht die Gefahr, dass sie während der Präparation von den Instrumenten nach apikal gestoßen werden und die Apikalregion verbolzen oder gar über das Foramen physiologicum hinaus in das periradikuläre Gewebe gepresst werden und dort eine Entzündungsreaktion initiieren (Hülsmann 2001). Um diese Komplikationen zu vermeiden, muss der Debris aus dem Wurzelkanal entfernt werden (Koçkapan 2003, Stock und Nehammer 1994, Cohen und Burns 2002). 


\subsection{Wurzelkanalspülung}

Die mechanische Präparation allein ist nicht in der Lage, den Wurzelkanal von Bakterien und deren Abbauprodukten sowie von dem Debris und der Schmierschicht zu befreien. Aus diesem Grunde ist zusätzlich zur mechanischen Präparation der Einsatz chemischer Spüllösungen notwendig (Hülsmann 2006).

Wurzelkanalspülungen erleichtern zum einen das Gleiten der Instrumente entlang der Kanalwand und reduzieren die Gefahr einer Instrumentenfraktur. Zum anderen sind sie in der Lage, kleinere Partikel aus dem Kanal hinaus zu schwemmen. Es ist ratsam, nach jeder Instrumentengröße mit mehreren Millilitern Spüllösung den Kanal zu säubern, um die Verblockung des Kanals während der mechanischen Präparation zu verhindern (Hülsmann 1993).

Folgende Anforderungen werden an die Spülflüssigkeit gestellt (Abbott et al. 1991, Hellwig et al. 1999):

- gute antimikrobielle Eigenschaften

- Auflösung von organischem und anorganischem Material aus dem Wurzelkanal, auch in den Bereichen des komplexen endodontischen Systems, die der instrumentellen Bearbeitung nicht zugänglich sind. Hierdurch wird eventuell zurückbleibenden Bakterien ein Großteil des zu inrem Überleben notwendigen Substrats entzogen.

- erleichterte instrumentelle Erweiterung des Wurzelkanalsystems

- Entfernung des „smear layer“

- Gleitmittel für die Wurzelkanalinstrumente

- niedrige Oberflächenspannung.

Weiterhin sollten sie möglichst wenige unerwünschte Nebenwirkungen verursachen (Zehnder et al. 2003, Zehnder 2006). Gelegentlich wird auch eine Bleichwirkung auf die koronale und radikuläre Zahnhartsubstanz gefordert (Hülsmann 2006).

Die Reinigung der apikalen Anteile des Wurzelkanalsystems ist eine der schwierigsten Aufgaben in der Endodontie. Studien belegen, dass die Reinigungswirkung der Spüllösung entlang des Wurzelkanals bis hin zum Apex abnimmt (Abbott et al. 1991, Druttman und Stock 1989, Petschelt 1989, Petschelt und Dobler 1991). 
Für eine effiziente Spülung des Wurzelkanalsystems wird eine bestimmte apikale Präparationsgröße vorausgesetzt (ISO 35 - 40). Die Spüllösung soll mit einer dünnen Nadel drucklos in den Kanal appliziert werden (Hülsmann 1993, Ram 1977). Sie kann ihre Wirkung nur innerhalb von 1 bis $2 \mathrm{~mm}$ nach dem Austritt aus der Spülnadel entfalten (Hülsmann 1993, Weine 1988, Wiedemann und Klinger 1984). Ist aufgrund der Kanalanatomie ein Vorschieben der Spülnadel in die apikale Region nicht möglich, kann durch den Einsatz eines Ultraschallsystems die Reinigungswirkung der Spülflüssigkeit erhöht werden (Cunningham und Martin 1982, Druttman und Stock 1989, Hülsmann 1993, Petschelt et al. 1987).

\subsubsection{Natriumhypochlorit}

Natriumhypochlorit $(\mathrm{NaOCl})$ wurde im Jahre 1936 von Walker als Spüllösung für Wurzelkanäle vorgeschlagen. Natriumhypochlorit ist eine farblose bzw. gelbliche Flüssigkeit mit leichtem Chlorgeruch und einem pH-Wert zwischen 10,7 und 12,2. Die Wirkung des Natriumhypochlorits beruht auf der Chlorierung funktioneller Gruppen und der Zerstörung der Bakterienmembran (Dammaschke 1999). Es ist gegen bakterielle Biofilme und auch gegen $C$. albicans und $E$. faecalis wirksam (Camara et al. 2009, Heppeler und Hülsmann 2006). Weiterhin macht man sich in der Endodontie die starke Gewebe auflösende Wirkung zunutze, um vitales und nekrotisches Gewebe zu entfernen (Baumgartner und Mader 1987, Brandt et al. 2001, Koskinen et al. 1980). In hohen Konzentrationen (5,25\%) kann auch vitales Gewebe aufgelöst werden (Dammaschke 1999, Hülsmann 2006, Zehnder et al. 2002). Untersuchungen von Dammaschke (1999) und Zehnder (2006) ergaben, dass $\mathrm{NaOCl}$ in geringem Umfang zur Neutralisierung der bakteriellen Endotoxine (Lipopolysaccharide, LPS) führt. Dieser Effekt von $\mathrm{NaOCl}$ war in den Untersuchungen von Tanomaru et al. (2003) jedoch nicht zu beobachten. Martinho und Gomez (2008) konnten ebenfalls keine vollständige Neutralisation der LPS feststellen.

Viele Arbeitsgruppen konnten feststellen, dass Natriumhypochlorit die Schmierschicht nicht effektiv entfernen kann (Baumgartner und Mader 1987, Behrens und Sierra 1992, Berg et al. 1986, Ciucchi et al. 1989, Garberoglio und Becce 1994, McComb und Smith 1975). 
Die Wirkung von Natriumhypochlorit ist im Wesentlichen von der Anzahl freier Chloridionen abhängig. Deshalb ist nicht die Konzentration, sondern die Menge der verwendeten Spüllösung von Bedeutung (Hülsmann 2006, Zehnder et al. 2003). Die antibakterielle Wirkung von $0,5 \% \mathrm{NaOCl}$ unterscheidet sich nicht signifikant von der einer 5\%igen Lösung (Zehnder et al. 2003). Eine Steigerung der Temperatur erhöht jedoch die Gewebe auflösende Wirkung von $\mathrm{NaOCl}$ und die Wirkung gegen $\mathrm{E}$. faecalis (Sirtes et al. 2005). Durch die Erwärmung von 1\%iger NaOCl-Spüllösung auf $45^{\circ} \mathrm{C}$ kann eine Steigerung der Effektivität erreicht werden (Sirtes et al. 2005). Dadurch wird bei Verwendung einer niedrig konzentrierten NaOCl-Spüllösung von $1 \%$ eine geringere Toxizität erreicht.

\subsubsection{Chlorhexidin}

Chlorhexidin (CHX) ist ein bewährtes Medikament in der Parodontaltherapie, kann aber auch in $2 \%$ iger Konzentration als Wurzelkanalspüllösung in der Endodontie eingesetzt werden (Delaney et al. 1982, Ferraz et al. 2001, Leonardo et al. 1999, Ringel et al. 1982). CHX bietet neben einem breiten antibakteriellen Spektrum eine hohe Substantivität bei niedriger Toxizität (Hellwig et al. 2006, Jeansonne und White 1994, Ringel et al. 1982, White et al. 1997).

Allerdings besitzt $\mathrm{CHX}$ keine Gewebe auflösende Wirkung und ist gegenüber gramnegativen Bakterien, die häufig bei primären endodontischen Infektionen zu finden sind, weniger wirksam (Athanassiadis et al. 2007, Davies et al. 1954, Hennessey 1973, Emilson 1977). Außerdem ist Chlorhexidin nicht in der Lage, die bakterielle LPS zu inaktivieren (Naenni et al. 2004). Daher ist CHX, nach Natriumhypochlorit, als Spüllösung der zweiten Wahl anzusehen (Koçkapan 2003).

Chlorhexidin ist gegen E. faecalis und C. albicans wirksam (Dumani et al. 2007, Ballal et al. 2007) und wird deshalb bei Revisionsfällen als Spülung und in Kombination mit Kalziumhydroxid als medikamentöse Einlage empfohlen (Ercan et al. 2007). 


\subsubsection{EDTA}

Ethylendiamintetraessigsäure (EDTA) gehört zu der Stoffgruppe der Chelatoren. Chelatoren sind aus chemischer Sicht großmolekulare Komplexbildner, die in der Lage sind, Kalziumionen aus dem Dentin an sich zu binden. Man verspricht sich durch die Lösung der Kalziumionen eine Demineralisierung des Dentins sowie eine Erleichterung der Aufbereitung enger und/oder stark kalzifizierter Wurzelkanäle (Hülsmann 2001).

EDTA ist der in der Endodontie am meisten verbreitete Chelator (Calt und Serper 2002) und wurde als erster Chelator 1957 von Nygaard-Østby (1957) vorgestellt. Die Spülung des Kanalsystems mit EDTA-Lösung führt zu einer deutlichen Auflösung und Entfernung der Schmierschicht und zur Freilegung der Dentintubuli (Calt und Serper 2000, Ahn und Yu 2000, Czontskowsky et al. 1990, Hottel et al. 1999, O'Connell et al. 2000, Scelza et al. 2000). Die Reinigungswirkung von EDTA wird von einigen Autoren vor allem im koronalen und mittleren Drittel des Wurzelkanals bestätigt, wohingegen das apikale Drittel schlechter gereinigt wird (Lim et al. 2003, Hülsmann et al. 2002, O'Connell et al. 2000, Scelza et al. 2000). EDTA entfernt jedoch nur den anorganischen Teil der Schmierschicht und belässt den organischen Anteil (Baumgartner und lbay 1987, Takeda et al. 1999, Yamada et al. 1983). Aus diesem Grund wird der Einsatz von EDTA in Kombination mit $\mathrm{NaOCl}$ empfohlen (Guerisoli et al. 2002, Hata et al. 2001, Yamashita et al. 2003, Brandt et al. 2001). Es gibt für die Einwirkdauer von EDTA keine einheitliche Richtlinie. Nach zehn Minuten Anwendung können starke Erosionen des Dentins vor allem im koronalen und mittleren Kanaldrittel beobachtet werden. Torabinejad et al. (2003) beschreiben bereits nach einer Minute einen destruktiven Effekt von EDTA auf das Dentin. Hülsmann et al. (2003) empfehlen eine Einwirkdauer zwischen ein und fünf Minuten.

\subsection{Techniken der Wurzelkanalspülung}

\subsubsection{Handspülung}

Bei der Handspülung wird der Wurzelkanal mithilfe einer Einmalspritze gespült. Hierzu wird die Spüllösung mithilfe einer Injektionskanüle (meistens ISO 40) in den Wurzelkanal appliziert. Dabei soll die Kanüle bis zum apikalen Drittel des 
Wurzelkanals vorgeschoben werden, ohne dass die Spülkanüle dabei klemmt. Das ist erst möglich, wenn die Wurzelkanäle mindestens bis zur ISO-Größe 45 präpariert wurden. Hierdurch ist ein ausreichender Abfluss der verwendeten Spüllösung gewährleistet und somit eine suffiziente Spülung ermöglicht (Ram 1977).

Diese Art der Spülung ist im Wurzelkanal koronal und apikal unterschiedlich wirksam (Abou-Rass und Piccinino 1982, McComb und Smith 1975). Hierbei ist für eine ausreichende Spülung des Kanals, insbesondere der apikalen Region, die Eindringtiefe der Kanüle entscheidend (Chow 1983, Wiedemann und Klinger 1984).

Eine Erhöhung des Spüldrucks fördert den Abtransport von Material aus dem Kanal nicht, sondern steigert lediglich die Gefahr der Penetration von Material und Flüssigkeit über den Apex hinaus (Abou-Rass und Piccinino 1982). Für eine gründliche Spülung des Kanals ist ein hohes Spülvolumen von $10 \mathrm{ml}$ erforderlich (Yamada et al. 1983).

\subsubsection{RinsEndo}

Das RinsEndo-System (Dürr Dental, Bietigheim-Bissingen, Deutschland) ist ein Instrument zur hydrodynamischen Spülung von Wurzelkanälen. Dabei wird eine Wirkstofflösung (z. B. Natriumhypochlorit) oszillierend mithilfe einer speziellen Kanüle in den Wurzelkanal appliziert.

Das RinsEndo-System wird an der Stelle der Turbine auf die Turbinenkupplung aufgesetzt. Betätigt man den Fußschalter der Behandlungseinheit, wird das RinsEndo-Gerät mit Druckluft versorgt. Ein pneumatischer Frequenzgenerator im Handstück erzeugt ein Spül-Saug-Zyklus an der RinsEndo Kanüle.

Während der Spülphase werden ca. $65 \mu \mathrm{l}$ frischer Wirkstofflösung über die RinsEndo-Kanüle in den Wurzelkanal eingebracht. Bei der nachfolgenden Saugphase werden bis zu $65 \mu \mathrm{l}$ in die Kanüle zurückgesaugt und in einer Mischkammer mit der frischen Wirkstofflösung vermischt. Die Wirkstofflösung wird dabei automatisch der Spritze entnommen. Bei einer vordefinierten Taktfrequenz von ca. 1,6 Hz resultiert hieraus eine Spülgeschwindigkeit von mind. 6,2 $\mathrm{ml} / \mathrm{min}$ (Dürr Dental, Bietigheim-Bissingen, Deutschland, Handbuch zum RinsEndo System). 


\subsubsection{Ultraschall-Spülung}

Die Benutzung von Ultraschall in der Endodontie wurde schon 1957 von Richman (1957) vorgeschlagen, aber erst seit den 80er Jahren sind entsprechende Geräte verfügbar. Endodontische Ultraschallgeräte arbeiten im Frequenzbereich zwischen 25 und $40 \mathrm{kHz}$ (Stock 1992), wobei die Schwingungen durch piezoelektrische oder magnetostriktive Schallgeber erzeugt werden.

Es handelt sich hierbei um elektro-physikalische Effekte, wobei akustische Strömungsphänomene („Acoustic Streaming”) entstehen, d. h. Flüssigkeitspartikel werden um eine schwingende Feile herum in schnelle Bewegung versetzt. Die Bewegungsrichtung orientiert sich an den Schwingungsknoten und tälern der Feile und verläuft vom apikalen Feilenende nach koronal. Es kommt zu einem besseren und schnelleren Flüssigkeitsaustausch im Kanal und zu einer Erwärmung der Spülflüssigkeit (Hülsmann 2001, 2004). Die Reinigungs- und Desinfektionswirkung kann durch schwingungsinduzierte Strömungen erheblich gesteigert werden (Hülsmann 2004).

Die Ziele der ultraschallgestützten Spülung sind das Lösen und Ausspülen von nekrotischem Gewebe und Dentinspänen (Debris) und die Desinfektion des Wurzelkanalsystems. Hierbei soll die durch die ultraschallaktivierten Feilen in den Wurzelkanal geleitete Spülflüssigkeit auch in Räumen des Kanalsystems wirksam werden, die für die instrumentelle Bearbeitung nicht zugänglich sind (Martin und Cunningham 1984).

Durch die hochfrequent schwingenden Feilen wird das Spülmittel effektiv bis in die apikale Region transportiert (Hülsmann 2004). Haikel und Allemann (1988) stellten als Nachteil der Ultraschall-Systeme eine schlechte Reinigung des apikalen Drittels fest. Gelegentlich kann es auch zu einer Begradigung gekrümmter Kanäle kommen (Chenail und Teplitsky 1985, Nagy et al. 1997, Chenail und Teplitsky 1988, Petschelt 1989, Stock 1992).

Außer für die Wurzelkanalspülung wird Ultraschall auch für die Entfernung von frakturierten Instrumenten, Schrauben und Metallstiften aus dem Kanal verwendet. Stock und Nehammer (1985) empfahlen Ultraschall für die Beseitigung von kleinen 
Stufen an der Wurzelkanalwand. In der Zahnheilkunde wird Ultraschall außerdem für die Entfernung harter und weicher Zahnbeläge und beim adhäsiven Einsetzen vollkeramischer Inlays benutzt. 


\section{Material und Methode}

Die Versuchsdurchführung lehnt sich an den Versuchsaufbau von Lee et al. (2004a) an, welcher bereits in weiteren Studien vor allem zur Entfernbarkeit von der Debris aus dem Wurzelkanal Verwendung fand (van der Sluis et al. 2005a, 2005b).

Für die Versuche wurden 30 menschliche, einwurzelige Prämolaren mit geradem Wurzelkanalverlauf ausgewählt. Es wurden ausschließlich Zähne ohne Frakturen, ohne endodontische Vorbehandlung und mit vollständig ausgebildeten Wurzelspitzen verwendet. Diese Zähne wurden unmittelbar nach der Extraktion in thymolhaltiger Kochsalzlösung aufbewahrt. Nach Anlegen der Zugangskavität wurde die Gängigkeit der Kanäle bis zum Foramen apicale mit einem Reamer der ISO-Größe 10 (Vereinigte Dentalwerke, München, Deutschland) überprüft. Die klinischen Kronen der Zähne wurden abgetrennt, so dass die Gesamtlänge aller Wurzeln $17 \mathrm{~mm}$ betrug. Die Arbeitslänge wurde für alle Zähne auf $16 \mathrm{~mm}$ festgelegt. Anschließend erfolgte entsprechend dem apikalen Aufbereitungsdurchmesser eine randomisierte Einteilung der Zähne in drei Gruppen.

Die Zähne der Gruppe A wurden bis Größe 30, die Zähne der Gruppe B bis Größe 40 und die Zähne der Gruppe $C$ bis Größe 50 präpariert. 


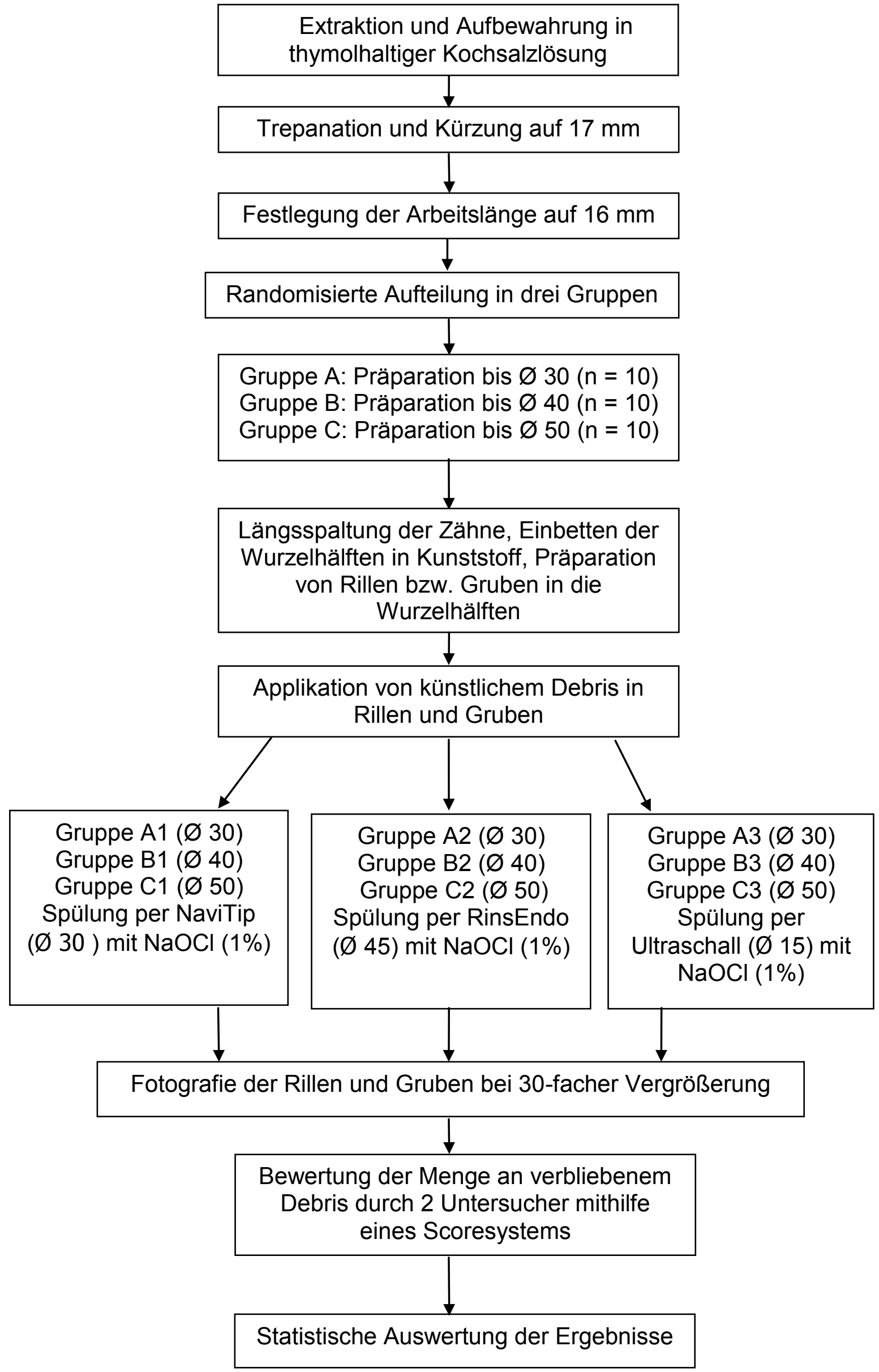

Abb. 3.1. Versuchsaufbau 
Danach erfolgte die standardisierte Präparation der Wurzelkanäle entsprechend den Gruppen A, B und C bis zum jeweiligen apikalen Durchmesser von Größe 30, 40 oder 50 mit FlexMaster-Nickel-Titan-Instrumenten (VDW, München, Deutschland). Bei der standardisierten Instrumentierung wurden die FlexMaster-Instrumente in der folgenden Reihenfolge eingesetzt: 06/30, 06/25, 06/20, 04/30, 04/25, 04/20. Nach jeder Feile wurde mit $2 \mathrm{ml}$ 1\%iger $\mathrm{NaOCl}$-Lösung gespült. Bei der ersten Instrumentierung mit 06/30 wurden die Kanäle $6 \mathrm{~mm}$ tief präpariert (AL-10 mm), mit jedem weiteren Instrument wurden die Kanäle jeweils $2 \mathrm{~mm}$ tiefer präpariert, bis die endgültige Arbeitslänge von $16 \mathrm{~mm}$ erreicht wurde (Tab. 1). Die jeweilige apikale Präparation wurde mit den Instrumenten 02/20,02/25,02/30, 02/35,02/40, 02/45 und 02/50 durchgeführt. Nach jeder Instrumentierung wurden die Wurzelkanäle mit einer dünnen Spülkanüle mit einem Außendurchmesser von 0,3 mm (NaviTip, Ultradent, South Jordan, UT, USA) und mit 2 ml 1\%iger NaOCl Lösung gespült.

\begin{tabular}{|c|c|}
\hline Instrument & Arbeitslänge \\
\hline $06 / 30$ & $\mathrm{AL}-10 \mathrm{~mm}$ \\
\hline $06 / 25$ & $\mathrm{AL}-8 \mathrm{~mm}$ \\
\hline $06 / 20$ & $\mathrm{AL}-6 \mathrm{~mm}$ \\
\hline $04 / 30$ & $\mathrm{AL}-4 \mathrm{~mm}$ \\
\hline $04 / 25$ & $\mathrm{AL}-2 \mathrm{~mm}$ \\
\hline $04 / 20$ & $\mathrm{AL}$ \\
\hline $02 / 20$ & $\mathrm{AL}$ \\
\hline $02 / 25$ & $\mathrm{AL}$ \\
\hline $02 / 30$ & $\mathrm{AL}$ \\
\hline $02 / 35$ & $\mathrm{AL}$ \\
\hline $02 / 40$ & $\mathrm{AL}$ \\
\hline $02 / 45$ & $\mathrm{AL}$ \\
\hline $02 / 50$ & $\mathrm{AL}$ \\
\hline
\end{tabular}

Tab. 3.1 Standardisierte Reihenfolge der Arbeitsschritte mit den FlexMasterInstrumenten (Vereinigte Dentalwerke, München, Deutschland) 
Nachdem alle Wurzelkanäle entsprechend ihrer Gruppenzuteilung präpariert waren, wurden mit einer Diamantscheibe (Horico, Berlin, Deutschland) zwei Rillen in Längsrichtung über die gesamte Länge des Zahnes gefräst. Dabei wurde beachtet, dass die Kanallumina nicht eröffnet wurden. Anschließend wurden die Zähne mithilfe eines Le Crons (Aesculap, Tuttlingen, Deutschland) vorsichtig aufgespalten, wieder zusammengesetzt und unter einem Auflichtmikroskop (Motic Ergonomic Trinokular Zoom Stereo Mikroskop, Xiamen, China) mit 30facher Vergrößerung auf ein spaltfreies Zusammensetzen überprüft. Zähne, die nicht spaltfrei zusammensetzbar waren, wurden aussortiert.

Jede Hälfte wurde von außen mit horizontalen Retentionskerben versehen (Abb. 3.2), damit die spätere Haftung in Kunststoff gesichert war. Danach wurden die Hälften wieder zusammengesetzt und erneut unter dem Mikroskop auf Spaltfreiheit überprüft. Mithilfe von lichthärtendem Komposit (Heraeus, Hanau, Deutschland) wurden die Hälften in dieser spaltfreien Position fixiert. Dadurch war gewährleistet, dass beim anschließenden Einbetten der Zähne in Paladur (Heraeus, Hanau, Deutschland) ein Verrutschen der Zahnhälften ausgeschlossen war. Zunächst wurden die fixierten Zähne nur bis zur einen Hälfte in Paladur eingebettet.

Nach Aushärtung wurden mit einem Rosenbohrer der Größe 018 (Hager und Meisinger, Neuss, Deutschland) zwei Ausbuchtungen in den Kunststoff präpariert und vollständig mit Vaseline (Favodent Karl Huber $\mathrm{GmbH}$, Karlsruhe, Deutschland) isoliert (Abb. 3.3). Danach konnte die andere Zahnhälfte eingebettet werden. Durch die Isolierung konnte nach der Aushärtung der zweiten Kunststoffhälfte diese einfach von der ersten abgenommen werden.

Durch die in den Kunststoff der ersten Hälfte eingelassenen Ausbuchtungen sind in der zweiten Hälfte zwei zu den Ausbuchtungen passgenaue Erhebungen entstanden (Abb. 3.3). Dadurch war ein genaues und verschiebungsfreies Zusammensetzten der beiden Probenhälften möglich. Die Fixierung der Probenhälften aneinander erfolgte durch eine Rohrschelle. In den Spaltbereich der beiden Kunststoffblöcke jedes Versuchskörpers wurden Sichtfenster präpariert, um mit dem Mikroskop die Spaltfreiheit der Probenkörper kontrollieren zu können (Abb. 3.4). 


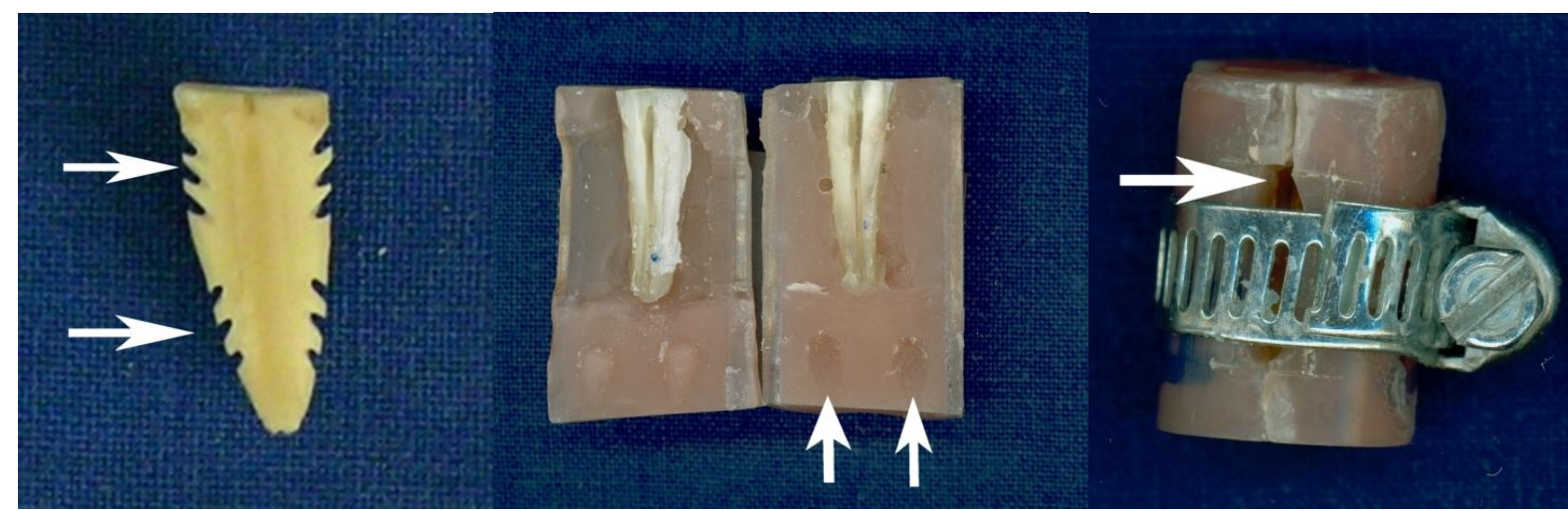

Abb. 3.2: Retentionskerben

Abb. 3.3: Ausbuchtungen

Abb. 3.4: Sichtfenster

In Anlehnung an den Versuchsaufbau von Lee et al. (2004a) erfolgte in einer der beiden Zahnhälften im Kanallumen die Präparation einer Grube. In die jeweils andere Zahnhälfte wurden drei Bohrlöcher präpariert. Diese Präparationen dienten der Aufnahme einer Mischung aus Dentinspänen und 1\%iger $\mathrm{NaOCl}$-Lösung (künstlicher Debris).

Die Gruben wurden mithilfe eines modifizierten Rosenbohrers unter dem Mikroskop im Abstand von 2 bis $6 \mathrm{~mm}$ vom Apex angelegt und waren $4 \mathrm{~mm}$ lang, 0,2 $\mathrm{mm}$ breit und $0,5 \mathrm{~mm}$ tief (Abb. 3.5).
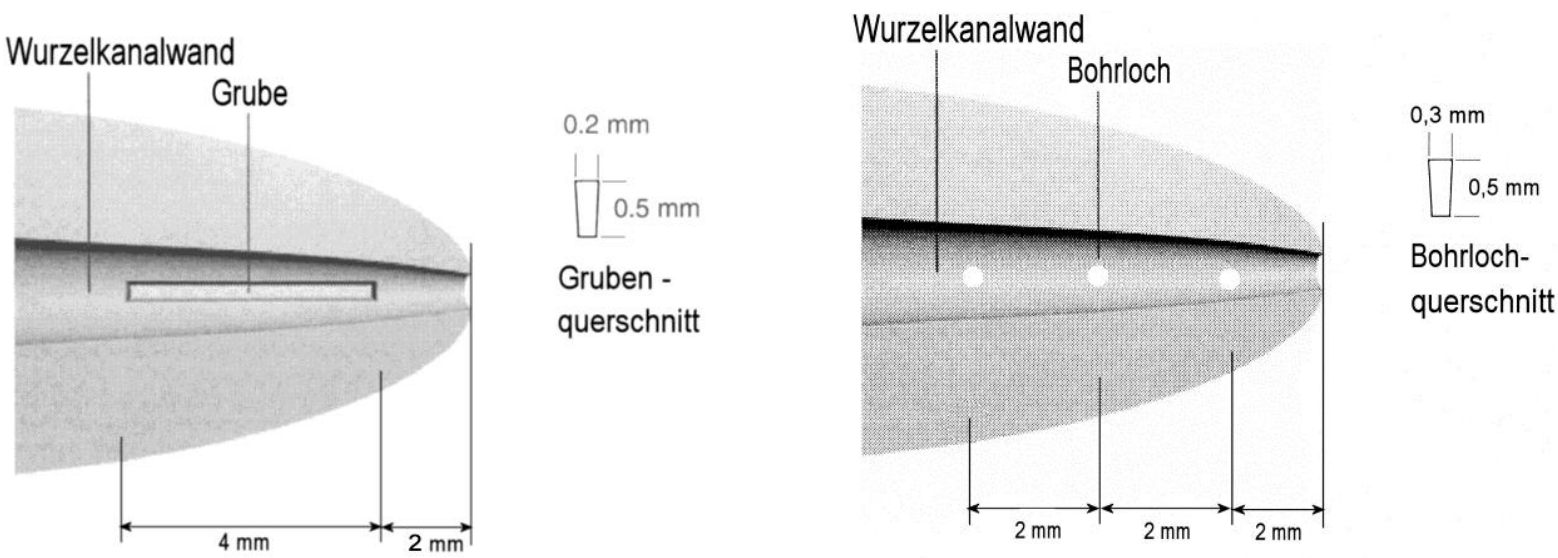

Abb. 3.5 Grube (van der Sluis et al. 2007, S. 54) Abb. 3.6 Bohrlöcher

In die andere Zahnhälfte wurden drei Bohrlöcher ebenfalls für die Aufnahme des künstlichen Debris präpariert. Diese wurden im Abstand von 2, 4 und $6 \mathrm{~mm}$ vom Apex mit einer Tiefe von 0,5 mm und einem Durchmesser von 0,3 mm mit oben beschriebener Methode in das Kanallumen präpariert (Abb. 3.6).

Um dies exakt zu ermöglichen, wurde das Handstück mit dem modifizierten 
Rosenbohrer an dem Objektträger eines Mikroskops, der exakt in horizontaler und vertikaler Richtung zu bewegen war, fixiert (Abb. 3.7). Diese Präparationen wurden zur Simulation von natürlich vorkommenden Ausbuchtungen und Extensionen des Wurzelkanals angelegt.

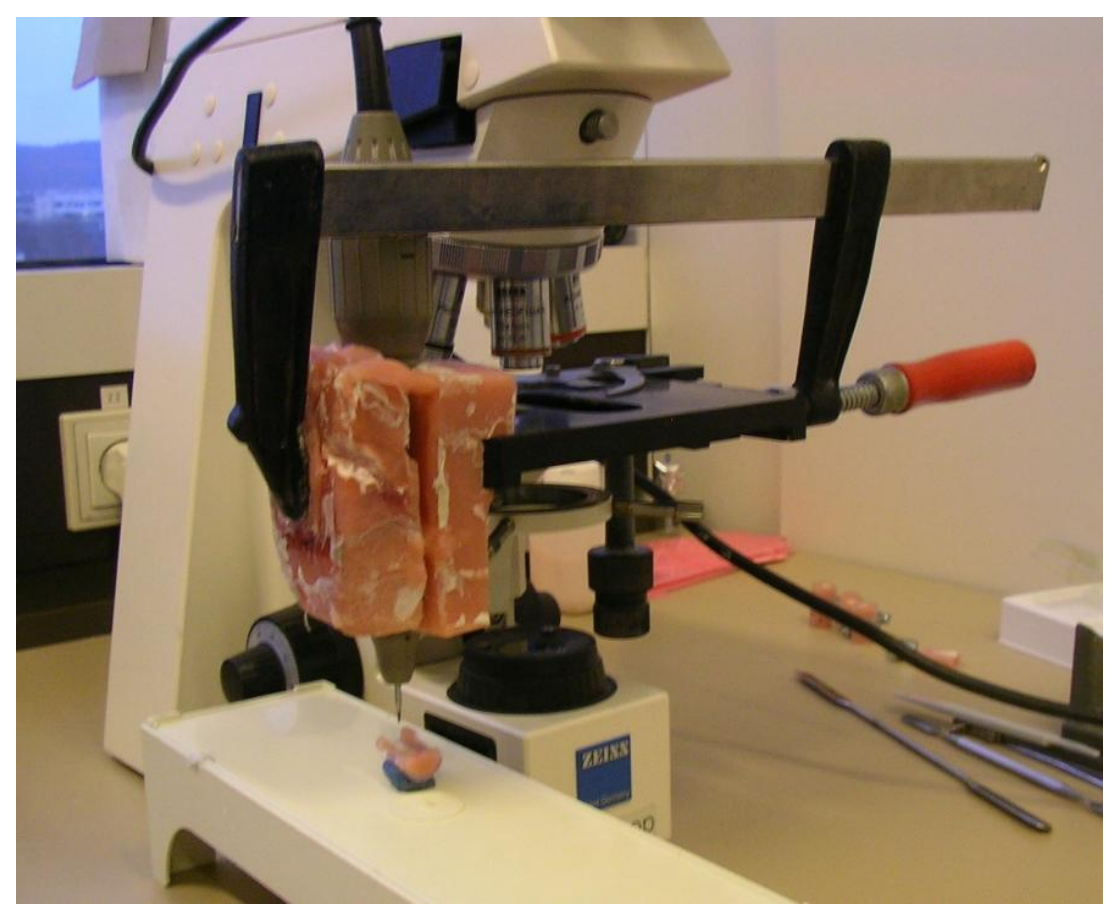

Abb. 3.7 Vorrichtung zur Präparation der Gruben und Bohrlöcher

Anschließend wurden die präparierten Kavitäten mithilfe eines Reamers der ISOGröße 08 (Vereinigte Dentalwerke, München, Deutschland) unter Sichtkontrolle mithilfe des Auflichtmikroskops mit 30facher Vergrößerung vollständig gesäubert.

Es folgte das Fotografieren der leeren Kavitäten beider Wurzelhälften mit einer Digitalkamera (Moticam 1300, Motic, Xiamen, China) mit 30facher Vergrößerung. Hierfür wurden die eingebetteten Wurzelhälften in einem Schlüssel aus einer Silikonmasse von Silaplast (Dentax $\mathrm{GmbH}$ und CoKG, Eftlingen, Deutschland) so ausgerichtet, dass alle Bereiche der Kavitäten unter dem Mikroskop gut zu erkennen waren. Mit dem Schlüssel aus Silaplast war es möglich, jede Probe immer von demselben Ausrichtungswinkel zu fotografieren (Abb. 3.8). 


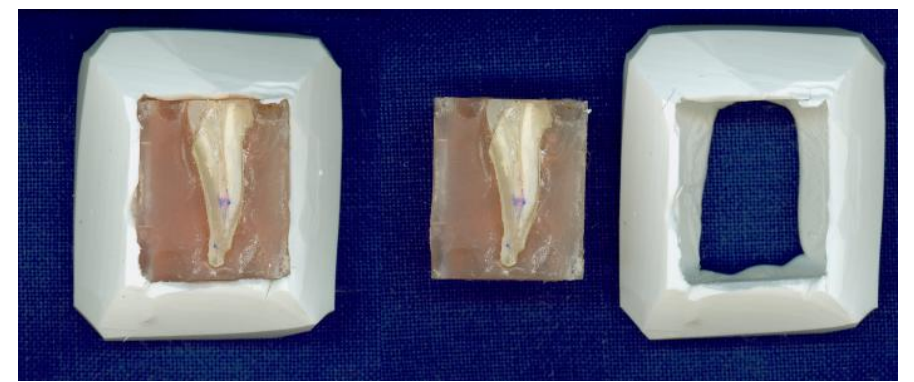

Abb. 3.8 Eingebettete Wurzelhälfte und Silaplastschlüssel

Anschließend erfolgte die Herstellung des künstlichen Debris. Dafür wurden Dentinspäne mithilfe eines Rotringdiamanten (Horico, Berlin, Deutschland) aus extrahierten Zähnen gewonnen. Diese wurde im Verhältnis von 100 mg Dentinspäne mit 0,175 ml 1\%iger NaOCl-Lösung gemischt, so dass der künstliche Debris eine cremige Konsistenz aufwies.

Zur Durchführung der ersten Versuchsreihe wurden die Gruben und Bohrlöcher der Zahnhälften unter dem Auflichtmikroskop bei 30facher Vergrößerung locker mit dem künstlichen Debris befüllt. Danach wurden unter dem Mikroskop die Gruben und Bohrlöcher auf eine vollständige Befüllung überprüft und mit 30facher Vergrößerung fotografiert. Anschließend wurden die Zahnhälften zusammengesetzt und mithilfe einer Rohrschelle fixiert. Die Spaltfreiheit der Proben wurde durch die präparierten Sichtfenster unter dem Auflichtmikroskop bei 30facher Vergrößerung kontrolliert.

Im Anschluss wurden die Proben (A1, B1, C1) mit einer Handspritze und einer NaviTip mit einem Außendurchmesser von 0,3 mm mit $30 \mathrm{ml}$ 1\%iger $\mathrm{NaOCl}$ gespült (Abb. 3.9). Zur Bestimmung der Eindringtiefe der Kanüle wurde sie bis zur Klemmung der Kanülenspitze in den Kanal vorsichtig vorgeschoben. Anschließend wurde sie um $1 \mathrm{~mm}$ zurückgezogen. Demnach betrug die Spültiefe für jeden Zahn $15 \mathrm{~mm}$. 


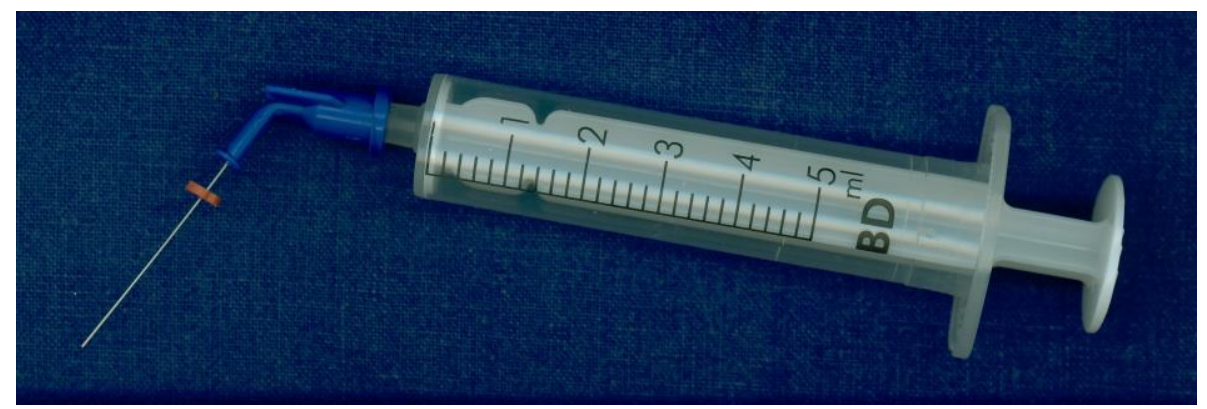

Abb. 3.9 Handspritze mit NaviTip (Ultradent, South Jordan, UT, USA)

Nach der Spülung wurden die Zahnhälften zur Feststellung der Spülwirkung unter dem Auflichtmikroskop mit 30facher Vergrößerung fotografiert.

Nach der Durchführung der ersten Versuchsreihe wurden die Gruben und Bohrlöcher der Proben mithilfe eines Reamers der ISO-Größe 08 und Kochsalzspülung vollkommen von verbliebenen Debris-Resten befreit.

Für die Durchführung der zweiten Versuchsreihe wurden die Gruben und Bohrlöcher der Zahnhälften erneut unter dem Auflichtmikroskop (Motic Ergonomic Trinokular Zoom Stereo Mikroskop, Xiamen, China) bei 30facher Vergrößerung locker mit der künstlichen Debris befüllt und anschließend fotografiert. Danach wurden die Zahnhälften zusammengesetzt und mithilfe einer Rohrschelle fixiert. Die Spaltfreiheit der Proben wurde durch die präparierten Sichtfenster unter dem Auflichtmikroskop bei 30facher Vergrößerung kontrolliert. In der zweiten Versuchreihe erfolgte die Spülung von $30 \mathrm{ml}$ 1\%iger NaOCl-Lösung mit RinsEndo (Dürr Dental, BietigheimBissingen, Deutschland) (Abb. 3.10).

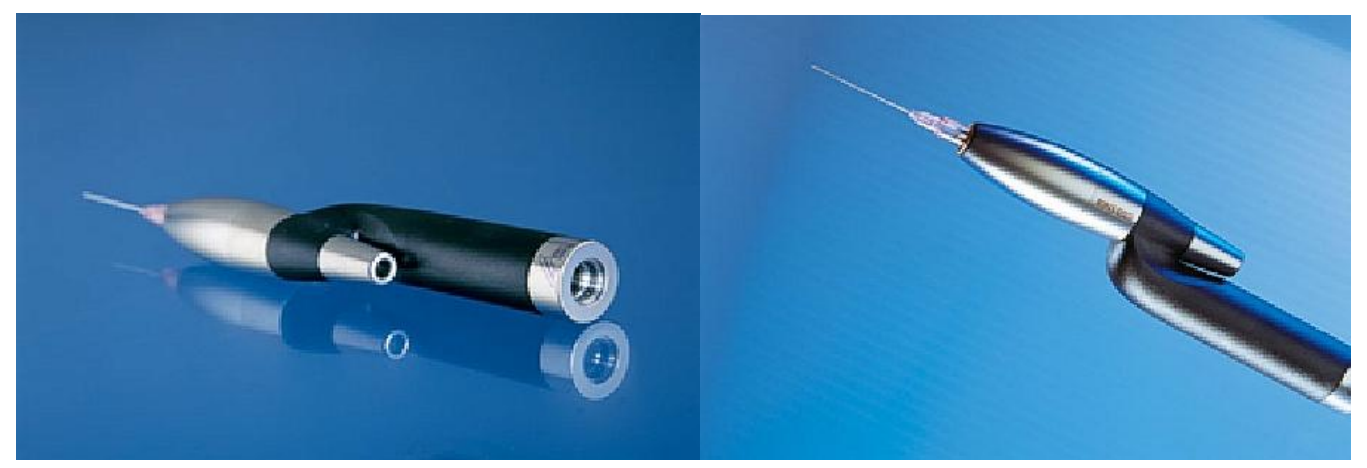

Abb. 3.10 RinsEndo-Handstück (Dürr Dental, Bietigheim-Bissingen) 
Gespült wurde mit einer Kanüle der ISO-Größe 45 bei einem konstanten Druck von 3,5 bar. Dieser Druck wurde mithilfe eines dem RinsEndo-Gerät vorgeschalteten Druckregulierers (Rieger und Co. KG, Bad Urach, Deutschland) eingestellt. Zur Bestimmung der Eindringtiefe der Kanüle wurde sie bis zur Klemmung der Kanülenspitze in den Kanal vorsichtig vorgeschoben. Anschließend wurde sie um 1 $\mathrm{mm}$ zurückgezogen. Demnach betrug die Spültiefe für jeden Zahn $15 \mathrm{~mm}$. Danach wurde die Rohrschelle entfernt und die Zahnhälften im Silaplastschlüssel reponiert. Anschließend wurden die Zahnhälften zur Feststellung der Spülwirkung unter dem Auflichtmikroskop mit 30facher Vergrößerung fotografiert.

Vor der Durchführung der dritten Versuchsreihe wurde ebenfalls der künstliche Debris vollständig aus den Gruben und Rillen der Proben mithilfe eines Reamers der ISO-Größe 08 und Kochsalzspülung entfernt. Auch die Vorgehensweise dieser dritten Versuchsreihe unterschied sich nur durch die Art der Spülung von der ersten und zweiten Versuchsreihe. Diesmal wurde per Ultraschall (EMS Piezon Master 400, Nyon, Schweiz) mit einem Ansatz der ISO-Größe 15 und mit 30 ml 1\%iger NaOClLösung und einer Eindringtiefe von $15 \mathrm{~mm}$ gespült. Das Ultraschallgerät wurde auf 1/4 der Leistung und auf eine maximale Flüssigkeitsmenge eingestellt.

Zur Bewertung der Auflichtmikroskop-Fotos aller drei Versuchsreihen war es notwendig, die Bilder zu verschlüsseln, damit die Untersucher die Gruppenzugehörigkeit der Fotos nicht erkennen konnten. Die Bilder wurden von zwei Untersuchern nach dem Scoresystem von van der Sluis et al. (2007) ausgewertet.

Dabei wurden folgende Scores (Abb. 3.11-3.18) unterschieden:

Score 0: die Kavität ist leer

Score 1: weniger als die Hälfte der Kavität ist mit künstlichem Debris gefüllt

Score 2: mehr als die Hälfte der Kavität ist mit künstlichem Debris gefüllt

Score 3: die Kavität ist vollständig mit künstlichem Debris gefüllt 
Kalibrierungsbilder für die Vergabe von Score-Werten:

Zahnhälfte A (Gruben) bei 30facher Vergrößerung:

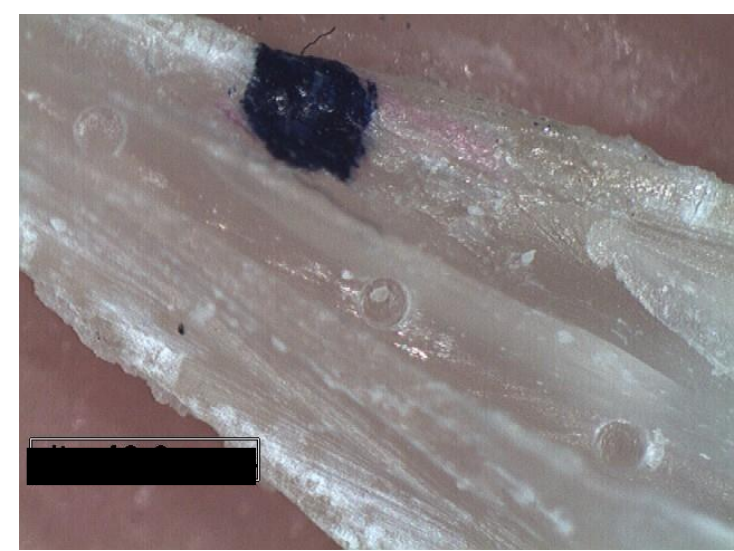

Abb. 3.11 Score 0

Die Kavität ist leer.

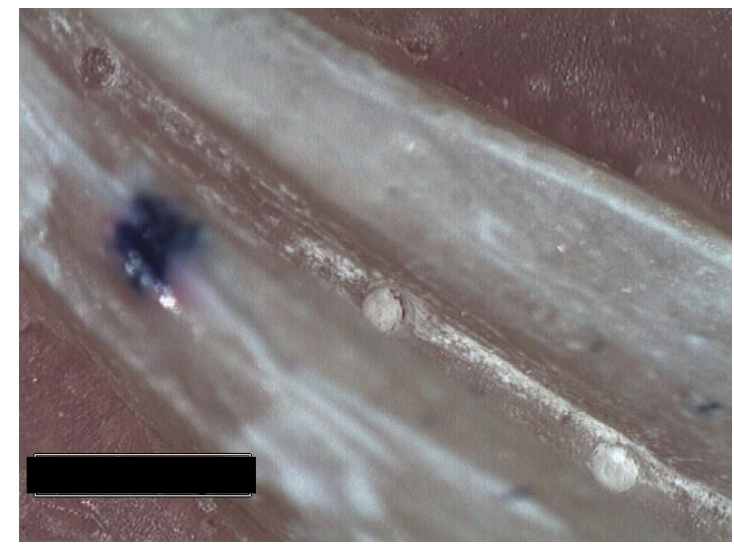

Abb. 3.13 Score 2

Mehr als die Hälfte der Kavität ist mit künstlichem Debris gefüllt.

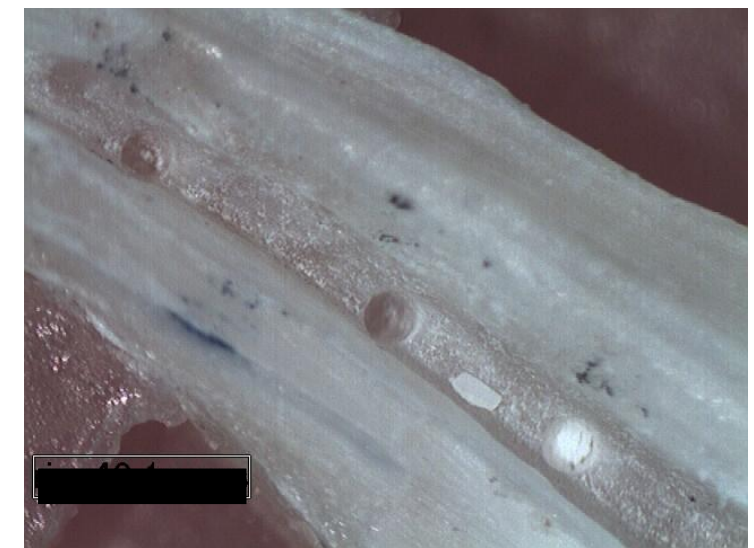

Abb. 3.12: Score 1

Weniger als die Hälfte der Kavität ist mit künstlichem Debris gefüllt.

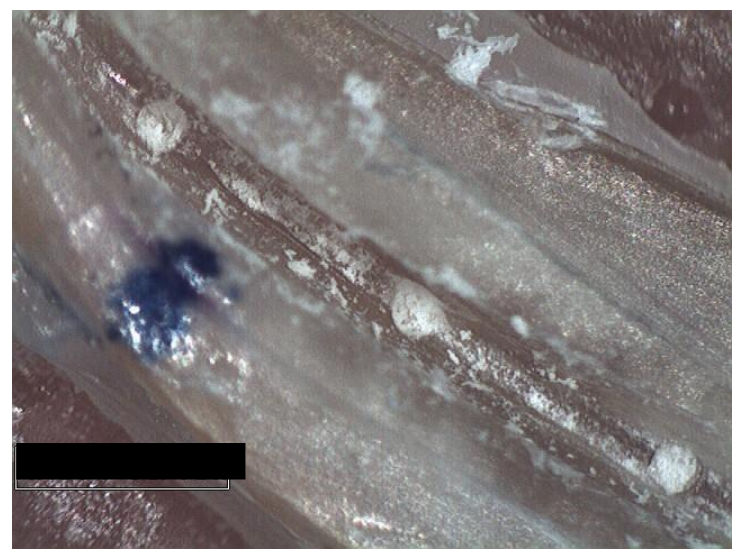

Abb. 3.14 Score 3

Die Kavität ist vollständig mit künstlichem Debris gefüllt. 


\section{Zahnhälfte B (Rillen) bei 30facher Vergrößerung:}

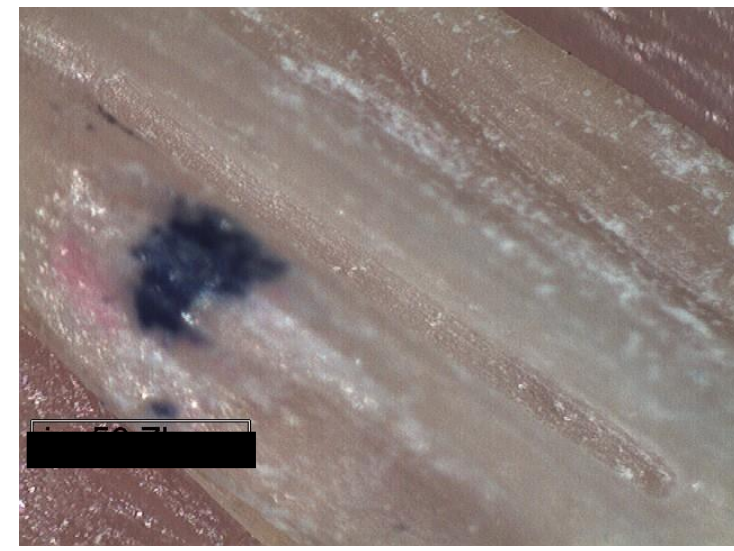

Abb. 3.15: Score 0 Die Kavität ist leer.

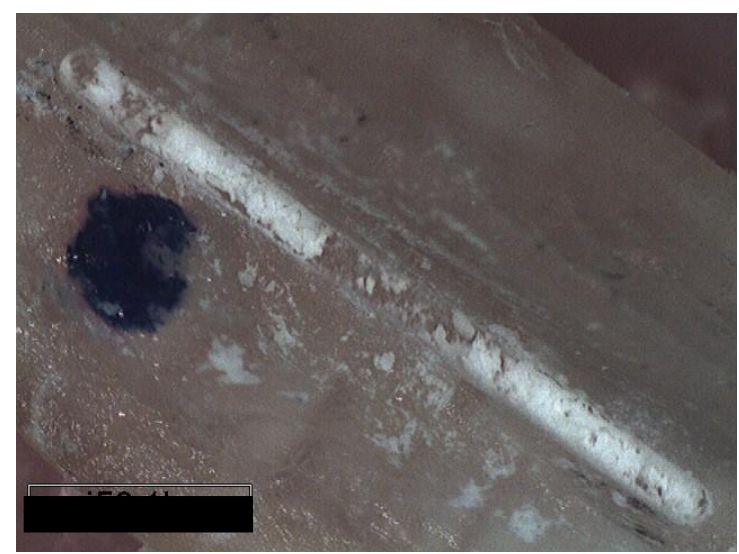

Abb. 3.17: Score 2

Mehr als die Hälfte der Kavität ist mit künstlichem Debris gefüllt.

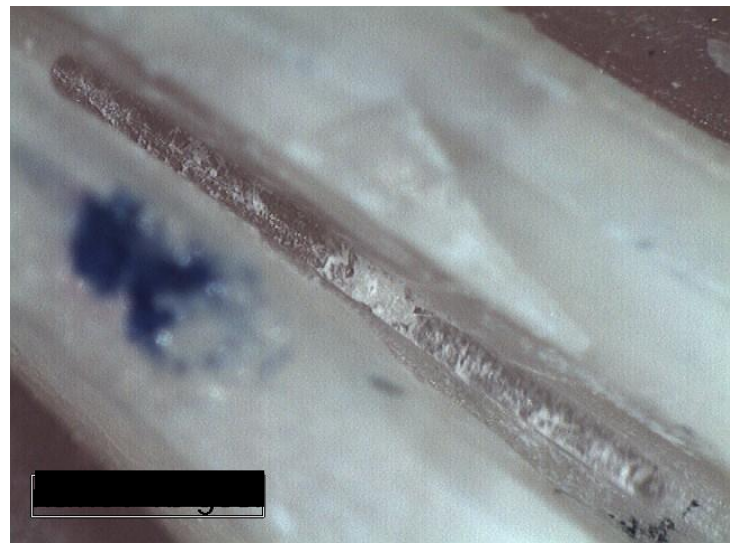

Abb. 3.16: Score 1 Weniger als die Hälfte der Kavität ist mit künstlichem Debris gefüllt.

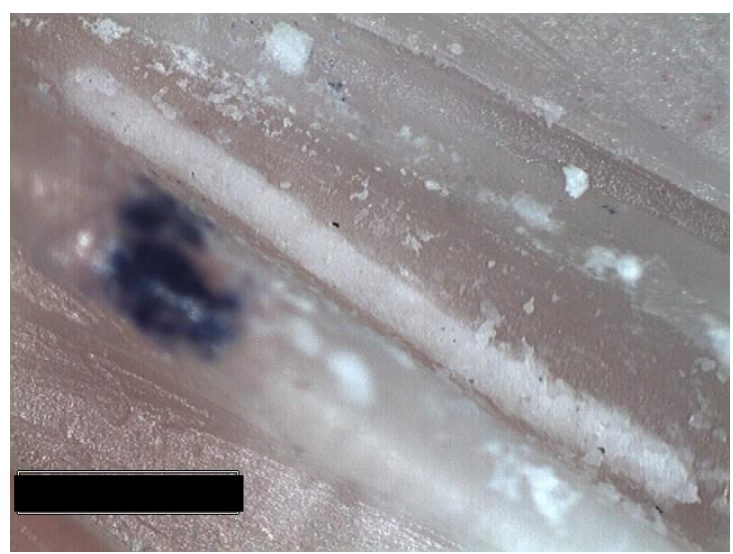

Abb. 3.18: Score 3

Die Kavität ist vollständig mit künstlichem Debris gefüllt.

Die Kalibrierung der Untersucher auf das Scoresystem fand vor der Hauptuntersuchung statt. Es wurden zunächst 150 nach dem Zufallsprinzip ausgesuchte Bilder bewertet und anschließend besprochen.

Im Folgenden wurden 50 Bilder aus den zuvor ausgesuchten 150 Bildern nochmals nach dem Zufallsprinzip bewertet. Anschließend wurden die abweichenden Ergebnisse besprochen. Fünf Tage später bewerteten die Untersucher erneut 50 
Zahnhälften und diskutierten wiederum abweichende Ergebnisse.

Aus diesen Ergebnissen wurden die interindividuelle Übereinstimmung und die intraindividuelle Reproduzierbarkeit berechnet (Hülsmann et al. 1996).

Für die interindividuelle Übereinstimmung wurde der Quotient aus den von beiden Untersuchern übereinstimmend bewerteten Proben und der Gesamtprobenzahl bestimmt.

Für die intraindividuelle Reproduzierbarkeit wurde der Quotient aus dem von einem Untersucher in einem zweiten Durchgang erneut mit dem gleichen Score bewerteten Proben und der Gesamtprobenzahl ermittelt.

Diese Resultate geben eine Aussage über das Maß der Standardisierung in der Bewertung der Proben. 


\section{Ergebnisse}

\subsection{Untersucherübereinstimmung}

Bei der Bewertung der Proben durch die beiden Untersucher wurde eine Differenz von einem Score weder bei der intraindividuellen Reproduzierbarkeit noch bei der interindividuellen Übereinstimmung überschritten.

Im ersten Durchgang lag die interindividuelle Übereinstimmung bei $96 \%$, im abschließenden Durchgang bei 98\% (Tab. 4.1.1)

\begin{tabular}{|l|l|l|}
\hline \multicolumn{3}{|c|}{ Vollständige Übereinstimmung } \\
\hline & $\mathrm{n}$ & $\%$ \\
\hline 1. Untersuchung & $48 / 50$ & 96 \\
\hline 2. Untersuchung & $49 / 50$ & 98 \\
\hline
\end{tabular}

Tab. 4.1.1 Interindividuelle Übereinstimmung

Die intraindividuelle Reproduzierbarkeit zwischen dem 1. und 2. Durchgang betrug bei beiden Untersuchern 98\% (Tab. 4.1.2 und 4.1.3).

\begin{tabular}{|l|l|}
\hline \multicolumn{2}{|c|}{ Vollständige Übereinstimmung zwischen 1. und 2. Durchgang } \\
\hline$n$ & $\%$ \\
\hline $49 / 50$ & 98 \\
\hline
\end{tabular}

Tab. 4.1.2 Intraindividuelle Reproduzierbarkeit Untersucher 1

\begin{tabular}{|l|l|}
\hline \multicolumn{2}{|c|}{ Vollständige Übereinstimmung zwischen 1. und 2. Durchgang } \\
\hline$n$ & $\%$ \\
\hline $49 / 50$ & 98 \\
\hline
\end{tabular}

Tab. 4.1.3 Intraindividuelle Reproduzierbarkeit Untersucher 2 


\subsection{Ergebnisse des Hauptversuches}

Dem faktoriellen Modell liegen verbundene und unverbundene Daten zugrunde. Alle Daten, die von einem Zahn stammen, sind verbunden. Zur Auswertung wurde eine spezielle nichtparametrische Kovarianzanalyse durchgeführt (Brunner et al. 2002).

Aufgrund der ordinalskalierten Zielgröße (4-Punkte-Scoresystem) kann die Auswertung nicht mit einem parametrischen Verfahren durchgeführt werden, sondern nur mit einem nichtparametrischen (verteilungsfreien) Verfahren. Das Verfahren basiert auf Rängen der Daten, wobei die Ränge über alle Daten vergeben werden. Man kann sich dabei an der erzeugenden Ordnungsstruktur orientieren: Da wo die Ränge am größten sind, da sind die unterliegenden Scores am größten. Die auf das 0-1 Intervall normierten Rangmittelwerte werden als Relative Effekte bezeichnet.

Untersucht wurden folgende Effekte:

\begin{tabular}{|c|c|c|}
\hline Effekt & $p$-Wert & Interpretation \\
\hline Gruppe & $<.0001$ & Signifikant \\
\hline Reader & 0.9854 & Nicht signifikant \\
\hline Gruppe* Reader & 0.8104 & Nicht signifikant \\
\hline Zahnhälfte & $<.0001$ & Signifikant \\
\hline Zahnhälfte*Gruppe & 0.3248 & Nicht signifikant \\
\hline Zahnhälfte* Reader & 0.9834 & Nicht signifikant \\
\hline Zahnhälfte*Gruppe*Reader & 0.7818 & Nicht signifikant \\
\hline Größe & 0.6940 & Nicht signifikant \\
\hline Gruppe*Größe & 0.0246 & Signifikant \\
\hline Reader*Größe & 0.9571 & Nicht signifikant \\
\hline Reader*Größe & 0.9571 & Nicht signifikant \\
\hline Gruppe $^{\star}$ Reader$^{*}$ Größe & 0.9249 & Nicht signifikant \\
\hline Zahnhälfte*Größe & 0.2417 & Nicht signifikant \\
\hline Zahnhälfte*Gruppe* Größe & 0.7372 & Nicht signifikant \\
\hline Zahnhälfte ${ }^{*}$ Reader $^{*}$ Größe & 0.6851 & Nicht signifikant \\
\hline Zahnh. ${ }^{*}$ Gruppe ${ }^{*}$ Reader ${ }^{*}$ Größe & 0.9998 & Nicht signifikant \\
\hline Voll & 0.1898 & Nicht signifikant \\
\hline Leer & 0.5052 & Nicht signifikant \\
\hline
\end{tabular}

Tab. 4.2.1 Spezielle nichtparametrische Kovarianzanalyse zur Überprüfung der Effekte 
Bei den Zahnhälften war ein signifikanter Effekt zu beobachten $(p<0.0001)$. Hier waren die Ergebnisse der Zahnhälfte b (Gruben) besser als die der Zahnhälfte a (Bohrlöcher), wie es der Abb. 4.2.1 zu entnehmen ist.

Handspülung

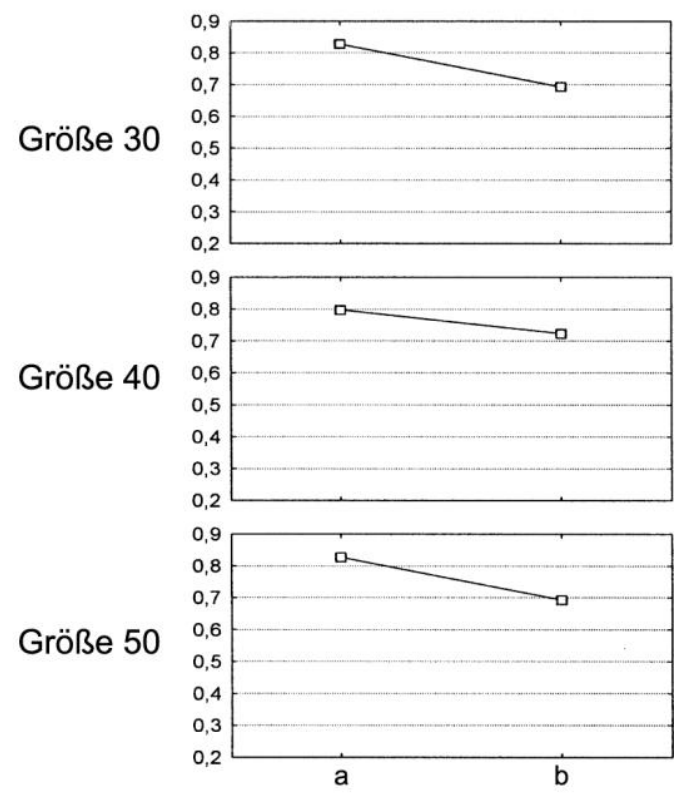

$a=$ Bohrlöcher $\quad b=$ Gruben
RinsEndo
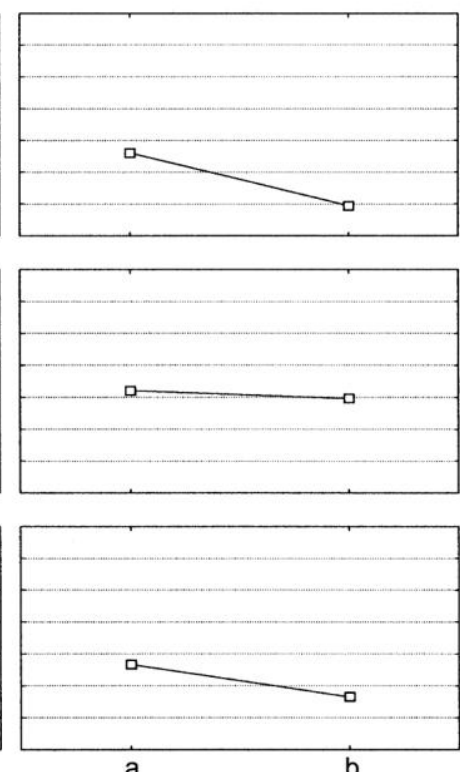

a
Ultraschall

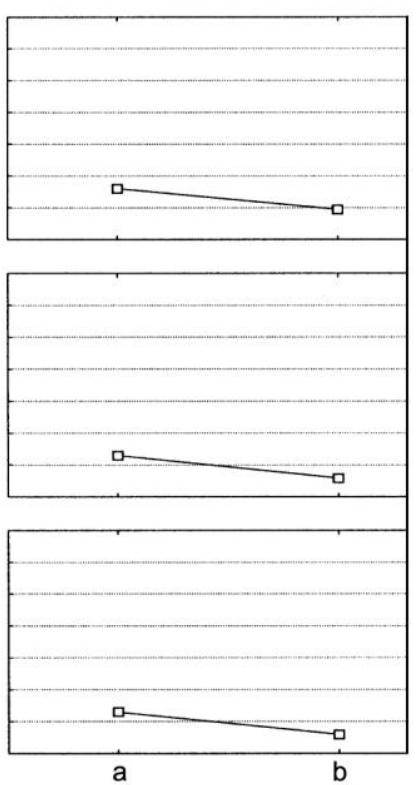

Zahnhälfte

Abb. 4.2.1 Grafische Darstellung der Spüleffektivität für jede Präparationsgröße und Spülmethode der Zahnhälften a (Bohrlöcher) und b (Gruben) 
Diese spezielle nichtparametrische Kovarianzanalyse zeigte weiterhin signifikante Effekte von Gruppe $(p<0,0001)$ und Interaktion Gruppe*Größe $(p<0,0246)$ auf das Ergebnis (Abb. 4.2.2).
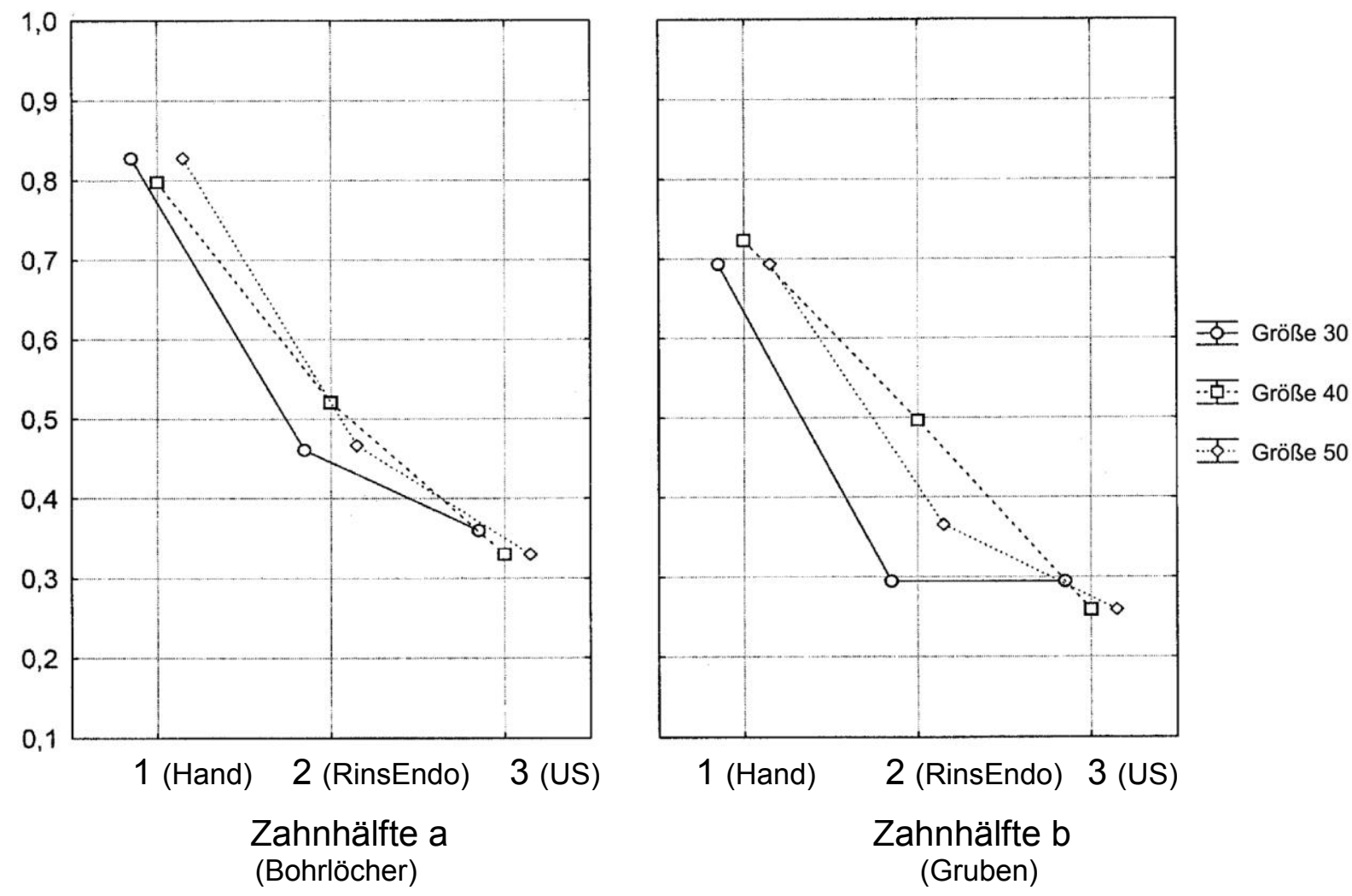

Abb. 4.2.2: Grafische Übersicht der Spüleffektivität für Zahnhälfte a (Bohrlöcher) und Zahnhälfte b (Gruben) in Abhängigkeit der Präparationsgröße und der Spülmethode 
Aufgrund dieser signifikanten Wechselwirkung zwischen Gruppe und Größe wurde die gleiche Analyse für jede Größe getrennt durchgeführt (Tab. 4.2.2).

\begin{tabular}{|l|l|l|l|}
\hline \multirow{2}{*}{ Effekt } & Größe 30 & Größe 40 & Größe 50 \\
\cline { 2 - 4 } & Interpretation & Interpretation & Interpretation \\
\hline Gruppe & Signifikant & Signifikant & Signifikant \\
& $p<0.0001$ & $p<0.0001$ & $p<0.0001$ \\
\hline Reader & Nicht signifikant & Nicht signifikant & Nicht signifikant \\
& $p=0.8184$ & $p=0.9699$ & $p=0.8878$ \\
\hline Zahnhälfte & Nicht signifikant & Nicht signifikant & Nicht signifikant \\
& $p=0.7996$ & $p=0.8494$ & $p=0.7382$ \\
\hline Zahnhälfte*Gruppe & Signifikant & Signifikant & Signifikant \\
& $p<0.0001$ & $p=0.0379$ & $p=0.0369$ \\
\hline Zahnhälfte* Reader & Nicht Signifikant & Nicht Signifikant & Nicht Signifikant \\
& $p=0.3200$ & $p=0.9936$ & $p=0.5624$ \\
\hline Zahnhälfte*Gruppe ${ }^{*}$ Reader & Nicht Signifikant & Nicht Signifikant & Nicht Signifikant \\
& $p=0.5963$ & $p=0.8990$ & $p=0.5382$ \\
\hline Voll & $p=0.8961$ & $p=0.9830$ & $p=0.8981$ \\
\hline Leer & Nicht Signifikant & Nicht Signifikant & Nicht Signifikant \\
& $p=0.052$ & $p=0.1029$ & $p=0.8734$ \\
\hline & Nicht Signifikant & Nicht Signifikant & Nicht Signifikant \\
& $p=0.2253$ & $p=0.4893$ & $p=0.3394$ \\
\hline
\end{tabular}

Tab. 4.2.2 Spezielle nichtparametrische Kovarianzanalyse für Größe-Gruppe 
Um zu untersuchen, zwischen welchen Gruppen ein signifikanter Unterschied besteht, wurden Paarvergleiche adjustiert für multiples Testen nach Tukey zwischen den einzelnen Gruppen durchgeführt.

Dabei zeigten sich folgende Ergebnisse:

Im Paarvergleich zwischen den Spülmethoden in der Größe-30-Gruppe zeigte sich keine Signifikanz zwischen Ultraschall und RinsEndo $(p=0.9900)$. Die Reinigungswirkung der NaviTip war sowohl der von Ultraschall $(p<0,0001)$ als auch der von RinsEndo ( $p<0,0001)$ unterlegen (Tab. 4.2.3 u. Abb. 4.2.3).

\section{Größe 30}

\begin{tabular}{|l|l|l|l|}
\hline \multicolumn{2}{|c|}{ Effekt } & p-Wert (adj.) & Interpretation \\
\hline Gruppe 1 (Hand) & Gruppe 2 (RinsEndo) & $<0,0001$ & Signifikant \\
\hline Gruppe 1 (Hand) & Gruppe 3 (Ultraschall) & $<0,0001$ & Signifikant \\
\hline Gruppe 2 (RinsEndo) & Gruppe 3 (Ultraschall) & 0,9900 & Nicht signifikant \\
\hline
\end{tabular}

Tab. 4.2.3 Paarvergleich der Spülmethoden in der Gruppe mit Größe 30.

Im Paarvergleich zwischen den Spülmethoden in der Größe-40-Gruppe zeigt sich die Reinigungswirkung von Ultraschall sowohl der von RinsEndo $(p<0.0001)$ als auch der von NaviTip $(p<0.0001)$ überlegen. Hierbei war die Reinigungswirkung von RinsEndo der von der NaviTip überlegen ( $p<0.0001$ ) (Tab. 4.2.4 u. Abb. 4.2.4).

\section{Größe 40}

\begin{tabular}{|l|l|l|l|}
\hline \multicolumn{2}{|c|}{ Effekt } & $p$-Wert (adj.) & Interpretation \\
\hline Gruppe 1 (Hand) & Gruppe 2 (RinsEndo) & $<0,0001$ & Signifikant \\
\hline Gruppe 1 (Hand) & Gruppe 3 (Ultraschall) & $<0,0001$ & Signifikant \\
\hline Gruppe 2 (RinsEndo) & Gruppe 3 (Ultraschall) & $<0,0001$ & Signifikant \\
\hline
\end{tabular}

Tab. 4.2.4 Paarvergleich der Spülmethoden in der Gruppe mit Größe 40.

Im Paarvergleich zwischen den Spülmethoden in der Größe-50-Gruppe waren die Ergebnisse wie Ergebnisse der Größe-40-Gruppe. Die Reinigungswirkung von Ultraschall war sowohl der von RinsEndo $(p=0.0174)$ als auch der von NaviTip $(p<0.0001)$ überlegen. Die Reinigungswirkung von NaviTip zeigte sich der von RinsEndo unterlegen ( $p<0.0001)$ (Tab. 4.2.5 u. Abb. 4.2.5). 


\section{Größe 50}

\begin{tabular}{|l|l|l|l|}
\hline \multicolumn{2}{|c|}{ Effekt } & $p$-Wert (adj.) & Interpretation \\
\hline Gruppe 1 (Hand) & Gruppe 2 (RinsEndo) & $<0,0001$ & Signifikant \\
\hline Gruppe 1 (Hand) & Gruppe 3 (Ultraschall) & $<0,0001$ & Signifikant \\
\hline Gruppe 2 (RinsEndo) & Gruppe 3 (Ultraschall) & 0,0174 & Signifikant \\
\hline
\end{tabular}

Tab. 4.2.5 Paarvergleich der Spülmethoden in der Gruppe mit Größe 50.

Die Ergebnisse der Paarvergleiche lassen sich grafisch wie folgt darstellen:

\section{Mittelwertplot für den relativen Effekt}
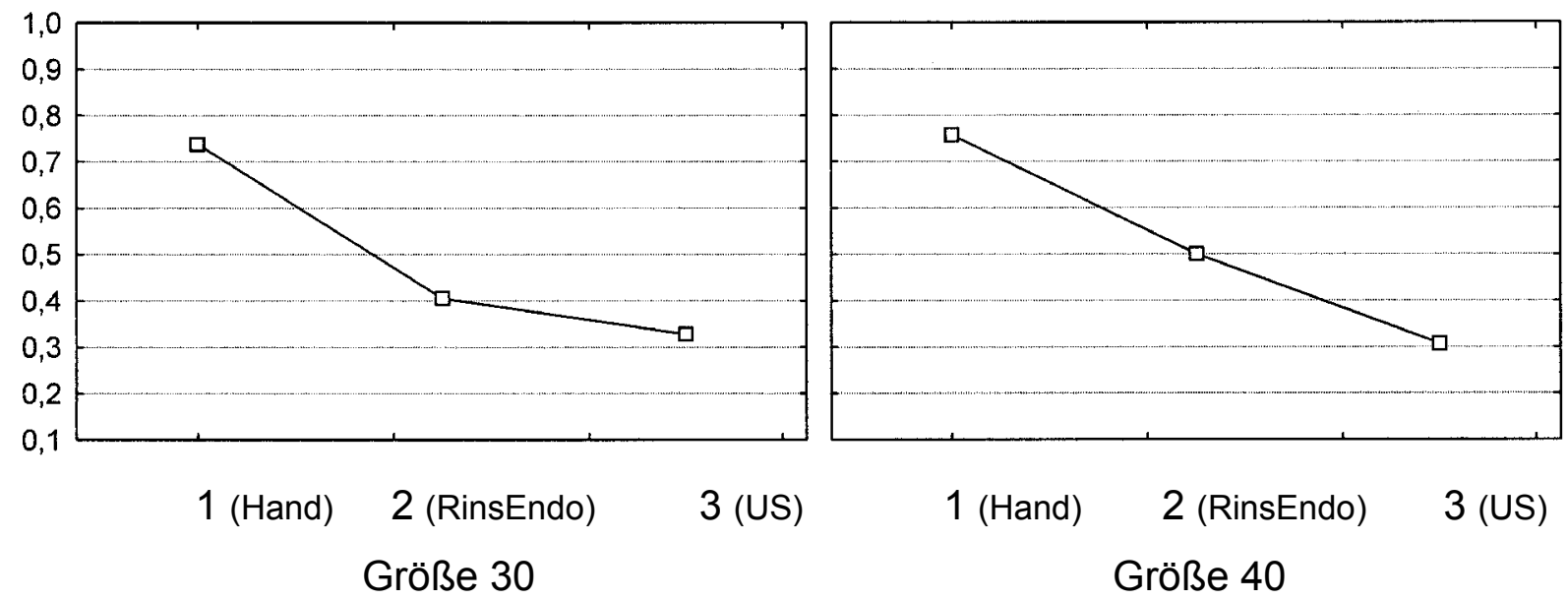

Abb. 4.2.3 Mittelwertplot relativer Effekt (30)

Abb. 4.2.4 Mittelwertplot relativer Effekt (40)

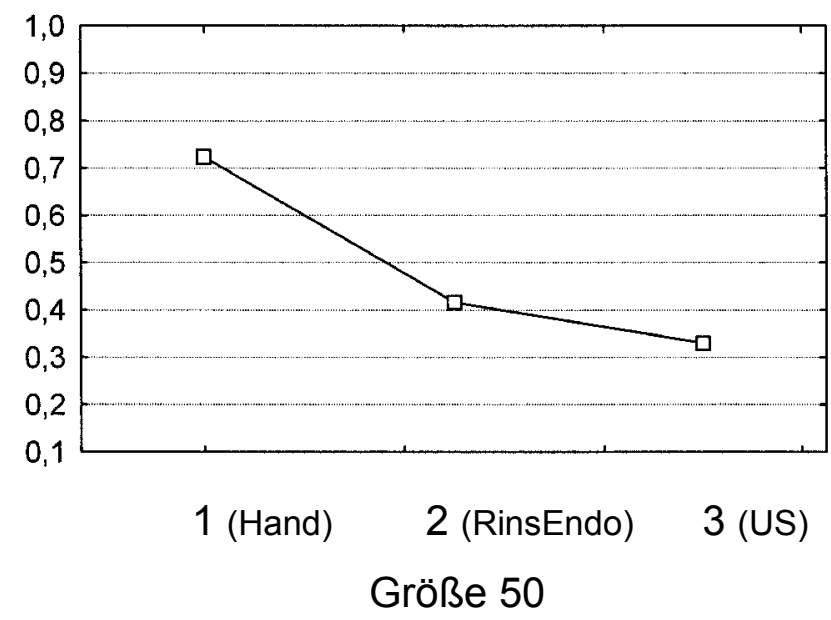

Abb. 4.2.5 Mittelwertplot relativer Effekt (50) 


\section{Diskussion}

\subsection{Diskussion der Methode}

Das Ziel der vorliegenden Studie war die vergleichende Untersuchung dreier verschiedener Wurzelkanalspülmethoden hinsichtlich deren Effektivität bei unterschiedlichen apikalen Präparationsgrößen.

Der Aufbau der Studie lehnt sich an den Versuchsaufbau von Lee et al. (2004a) an. Diese Methode wurde bereits in verschiedenen Studien zur Untersuchung der Entfernbarkeit von Debris aus dem Wurzelkanal herangezogen (van der Sluis et al. 2005a, 2005b, 2006) und zeigte sich geeignet, um die Entfernbarkeit verschiedener Materialen aus dem Wurzelkanal zu untersuchen.

Bei dieser Methode werden künstlich präparierte Gruben und/oder Bohrlöcher an der Wurzelkanalwand mit dem zu untersuchenden Material befüllt. Nach der Spülung des Wurzelkanals wird der Füllungsgrad der Gruben und Bohrlöcher beurteilt. Die künstlich präparierten Gruben und Bohrlöcher simulieren die Ausdehnungen ovaler Wurzelkanalbereiche, wobei die Gruben größere Ausdehnungen und die Bohrlöcher die kleineren Ausdehnungen darstellen. Solche Ausläufer sind in den apikalen $5 \mathrm{~mm}$ der Wurzelkanäle sehr häufig anzutreffen (Wu et al. 2000). Eine dementsprechende mechanische Präparation dieser Bereiche ist ohne massive Schwächung des Wurzelkanals oder gar Gefahr der Perforation der Wurzelkanalwand nicht möglich (Wu et al. 2000). Zudem gilt dieser Bereich als besonders schwierig zu reinigen (Hülsmann et al. 2003, Lambrianidis et al. 2006, Margelos et al.1997, Nandini et al. 2006, Scelza et al. 2000, Torabinejad et al. 2003).

In mehreren Studien wurde gezeigt, dass in diesem Bereich große Mengen an Debris verbleiben (Cunningham et al. 1982, Goodman et al. 1985, Wu et al. 2001, Wu und Wesselink 2001). Der verbleibende Debris kann bei Instrumentierung des Wurzelkanals nach apikal gestoßen werden und die apikale Region verbolzen oder sogar über das Foramen physiologicum in das periradikuläre Gewebe gepresst werden und dort eine Entzündungsreaktion verursachen (Hülsmann 2001). Der verbliebene Debris vermindert die Wirkung von Kalziumhydroxid und anderen 
Medikamenten im Wurzelkanal, weil diese Medikamente ihre Wirkung nur in direktem Kontakt mit Bakterien entfalten können (Siqueira und Lopez 1999). Außerdem können die durch Debris verlegten Wurzelkanalbereiche nicht vollständig mit Guttapercha und Sealer ausgefüllt werden. Dies führt zur Undichtigkeit der Wurzelkanalfüllung (Wu et al. 2001). Daher ist es von großer Wichtigkeit, die Reinigung auch in diesem, durch mechanische Präparation nicht zu erfassenden Bereich zu überprüfen. Um die Effektivität der Spülung in diesem Bereich zu überprüfen, wurden die Gruben bei dieser Studie 2-6 mm und die Bohrlöcher jeweils 2, 4 und $6 \mathrm{~mm}$ vom Apex entfernt präpariert. Der Vorteil dieser künstlich angelegten Gruben und Bohrlöcher besteht in deren konstanter Größe und einheitlicher Platzierung in der Wurzelkanalwand, wodurch standardisierte Versuchsbedingungen geschaffen werden.

In vorangegangen Studien wurden die präparierten Wurzelkanäle lediglich nach der Spülung beurteilt (Abbott et al. 1991, Lumley et al. 1993, Wu und Wesselink 1995), ohne dass vor der Spülung die Menge an vorhandenem Debris überprüft wurde. Somit war nach der Spülung keine konkrete Aussage über die Effizienz der Spülung möglich. In der vorliegenden Untersuchung wurde ebenfalls die Entfernbarkeit von künstlichem Debris mithilfe verschiedener Spülverfahren untersucht. Allerdings wurde in diesem Versuchsschema bei jeder Grube und jedem Bohrloch der Füllungsgrad mit künstlichem Debris vor der Spülung fotografisch dokumentiert. Somit konnte der Füllungsgrad jeder einzelnen Grube und jedes einzelnen Bohrloches nach der Spülung mit dem Füllungsgrad vor der Spülung verglichen werden. Dadurch war eine sehr genaue Beurteilung der Spüleffektivität möglich.

Zur Beurteilung der Menge an vorhandenem Debris in Gruben und Bohrlöchern wurde ein Scoresystem mit vier Graden verwendet, wobei Score 0 kein Debris und Score 3 eine vollständig mit Debris gefüllte Kavität bedeutet (Abb. 11-18). Dieses Scoresystem wurde von van der Sluis et al. (2007) beschrieben. Der Vorteil dieses Scoresystems ist eine genauere Aussage über die Menge an Debris in den Gruben und Bohrlöchern gegenüber einer ja/nein-Entscheidung. Der Nachteil dieses Scoresystems ist der Einfluss der subjektiven Wahrnehmung der Untersucher auf das Ergebnis. Dieser Einflussfaktor wurde in dieser Studie jedoch durch die Kalibrierung der Untersucher minimiert. Während der ersten Kalibrierung, die vor der 
Hauptuntersuchung vorgenommen wurde, erreichten die Untersucher eine interindividuelle Übereinstimmung von $96 \%$ bei Untersucher 1 und $98 \%$ bei Untersucher 2. Die intraindividuelle Reproduzierbarkeit zwischen dem 1. und 2. Durchgang betrug bei beiden Untersuchern 98\%. In der statistischen Auswertung zeigten sich keine signifikanten Interaktionen zwischen Untersucher („reader“) und anderen untersuchten Effekten. Dies schließt eine Beeinträchtigung der Ergebnisse durch die Untersucher aus.

Um verschiedene Techniken der Wurzelkanalspülung miteinander vergleichen zu können, müssen die Versuchsbedingungen möglichst standardisiert werden. Eine Möglichkeit der Standardisierung wäre die Verwendung simulierter Wurzelkanäle in Plastik- oder Kunstharzblöckchen. Simulierte Wurzelkanäle wurden schon in vielen experimentellen Studien verwendet (van der Sluis et al. 2005a, Tepel et al. 1993, Ahmad 1989), Lim K und Webber 1985). Als Alternative steht dem gegenüber die Verwendung frisch extrahierter Zähne. Untersuchungen an extrahierten Zähnen haben im Gegensatz zu Kunststoffmodellen die größere anatomische Variationsbreite. Dies entspricht eher den realen Verhältnissen. Darüber hinaus lassen sich an Kunststoffmodellen keine Dentintubuli und kein vitales Gewebe nachweisen, die aber wichtige Untersuchungskriterien darstellen und für eine möglichst praxisnahe Untersuchung notwendig sind. Haapasalo et al. (2000) und Portenier et al. (2001) zeigten, dass diese Eigenschaften des Wurzeldentins Einfluss auf die Wirksamkeit der Spülung haben.

In dieser Studie diente die Verwendung einwurzeliger Prämolaren zur Standardisierung der Versuchsbedingungen. Prämolaren haben, mit Ausnahme der ersten oberen Prämolaren, fast immer nur eine einfach geformte Wurzel mit nur einem Wurzelkanal (Rohen 1988). Diese Eigenschaften ermöglichten eine leichtere Aufbereitung und Aufspaltung des Wurzelkanals.

Es ist erwiesen, dass die Menge an verwendetem Natriumhypochlorit Einfluss auf die Spüleffektivität hat (Hülsmann 2006, Zehnder et al. 2003). Um die Versuchsbedingungen für alle Spülmethoden zu standardisieren, wurde bei allen Versuchen eine einheitliche Menge an Natriumhypochloritlösung verwendet. Um bei den Untersuchungen eine möglichst praxisnahe Situation zu simulieren, wurden die 
Wurzelkanäle mit $30 \mathrm{ml}$ 1\%iger $\mathrm{NaOCl}$-Lösung gespült. Dies repräsentiert die Spülmenge eines Wurzelkanals, bei dem zehn Instrumente benutzt wurden, nach jeder Instrumentierung mit $2 \mathrm{ml} \mathrm{NaOCl}$ gespült (Walters et al. 2002) und eine Abschlussspülung von $10 \mathrm{ml}$ vorgenommen wurde (Santos et al. 1999).

Die Kürzung der Wurzelkanallänge auf $17 \mathrm{~mm}$ diente ebenfalls zur Standardisierung der Versuchsbedingungen. Weiterhin wurden für alle drei Hauptversuche immer die gleichen Zähne in einer Gruppe benutzt, um eine weitere Standardisierung der verwendeten Proben zu erzielen. Der Hauptversuch mit Ultraschall erfolgte zum Schluss, damit die Versuchsbedingungen nicht durch eine mögliche mechanische Veränderung der Wurzelkanalwand durch die Ultraschallspülung beeinflusst wurden.

\subsection{Diskussion der Ergebnisse}

Da der Untersucher (,reader") eine wichtige Komponente des Bewertungsverfahrens ist, können Unterschiede in der Bewertung zwischen Untersuchern die Ergebnisse beeinflussen. Diese Differenzen können sich in der Interpretation der Ergebnisse niederschlagen. In vielen vorangegangen Studien, die sich mit der Effektivität endodontischer Maßnahmen beschäftigten, wurden nur zwei Kriterien benutzt: Erfolg/Misserfolg bzw. Ja/Nein. Nach Goldman M et al. (1972) ist dies als fragliche Methode zur Untersuchung anzusehen, da die Entscheidung des Untersuchers sehr subjektiv ist und von mehreren Faktoren beeinflusst wird. Daher wurden in dieser Untersuchung die intraindividuelle Reproduzierbarkeit und die interindividuelle Übereinstimung von Untersuchern berücksichtigt.

Bei der Untersuchung aller Faktoren bestand in dieser Studie kein signifikanter Effekt der beiden „reader" (Untersucher) auf die Ergebnisse. Dies bedeutet, dass die Anzahl an unterschiedlich bewerteten Einzelproben durch die Untersucher so gering war, dass dies keinen signifikanten Einfluss auf die Ergebnisse hatte (Tab. 5). Dies ermöglichte eine genauere Auswertung der erzielten Ergebnisse und deren Interpretation. Ein signifikanter Einzeleffekt der Untersucher hätte bedeutet, dass die Untersucher die einzelnen Proben teilweise unterschiedlich bewertet hätten und es dadurch zu Ungenauigkeiten im Gesamtergebnis gekommen wäre. 
Die Auswertung zeigt weiterhin, dass keine Spülmethode in der Lage war, den künstlichen Debris vollständig aus dem apikalen Kanaldrittel zu entfernen (Abb. 19). Die Studien von van der Sluis et al. (2009) und Jiang et al. (2010) können dies für die Ultraschall-Spülung und die Studien von Zmener et al. (2009) und Al-Hadlaq et al. (2006) für die Handspülung bestätigen.

Bei dem Paarvergleich zwischen Ultraschall, RinsEndo und Handspülung in allen drei Gruppen (A: Größe 30, B: Größe 40, C: Größe 50) schnitt die ultraschallaktivierte Spülung hinsichtlich der Entfernung von Debris signifikant besser als RinsEndo und Handspülung ab. Dass die Ultraschallspülung effektiver ist als die manuelle Methode, zeigten auch Lee et al. (2004a). Die Ergebnisse von Cameron (1995) zeigten, dass die Reinigungseffizienz sich von koronal nach apikal verschlechtert. Dies widerspricht den Ergebnissen der vorliegenden Studie und der Untersuchung von Hülsmann et al. (1997). Walmsley (1994) berichtete, dass Ultraschallsysteme im apikalen Drittel nicht effizient arbeiten, weil dort laterale Behinderungen auftreten können, die das Schwingungsverhalten der Ultraschallfeilen behindern. Für die ultraschallgestützte Spülung des Wurzelkanals wird daher ein passives Arbeiten ohne Wandkontakt der Feile empfohlen (Jensen et al. 1999, Sabins et al. 2003, Spoleti et al. 2003). Während der Wurzelkanalspülung soll die eingespannte Feile ohne Wandkontakt in der Spülflüssigkeit schwingen (passive ultrasonic irrigation), da dies zu einer optimalen Ausnutzung der Mikroströmung führen soll (Ahmad et al. 1987). Wandkontakt während der Spülung würde die Schwingungen so dämpfen, dass eine effektive Spülwirkung nicht zu erwarten ist. Alle Versuchsdurchführungen mit Ultraschall in dieser Studie wurden unter Berücksichtigung der Technik der passiven Ultraschallaktivierung durchgeführt. Dies könnte die besseren Ergebnisse der Ultraschallspülung in dieser Studie erklären.

Eine andere Erklärung für die besseren Resultate der Ultraschallspülung könnte die höhere Flussrate der Spülflüssigkeit sein. Bereits Nanzer et al. (1989) zeigten, dass die höhere Flussrate des Spülmediums einen positiven Einfluss auf die Spüleffektivität in Wurzelkanälen hat. Die Flussrate des Ultraschallgerätes in dieser Studie war auf $10 \mathrm{ml} / \mathrm{min}$ eingestellt. RinsEndo hat eine voreingestellte Flussrate von $6,2 \mathrm{ml} / \mathrm{min}$. Es wurde versucht, die Flussrate der Spülflüssigkeit bei Handspülung auf 
$6.6 \mathrm{ml} / \mathrm{min} \mathrm{zu}$ halten, wobei die Kontrolle und Standardisierung der Flussrate bei der Handspülung schwierig ist (Boutsioukis et al. 2007). Die höhere Flussrate der Ultraschallspülung könnte zur besseren Reinigung der Gruben und Bohrlöcher geführt haben.

Es liegt noch keine andere vergleichbare Studie vor, in der die Reinigungseffektivität von RinsEndo bei Entfernung der Debris mit manueller Spülung oder Ultraschallspülung miteinander verglichen wurden. Die vergangenen Studien über RinsEndo untersuchten die Penetration des Spülmediums in das Dentin (Hauser et al. 2007) und die Entfernung des Pulpagewebes (Braun et al. 2005). McGill et al. (2008) untersuchten die Spüleffektivität von RinsEndo hinsichtlich der Entfernung des bakteriellen Biofilms im Vergleich zu manuell-statischer und manuell-dynamischer Methode. Hier zeigte sich, dass RinsEndo eine signifikant effektivere Spülmethode als die statische manuelle Spülung war.

In der vorliegenden Studie zeigte sich nur in der Gruppe A (Größe 30) kein statistisch signifikanter Unterschied zwischen RinsEndo und Ultraschallspülung (Tab. 8-9). Warum RinsEndo in der Gruppe mit der kleineren apikalen Präparationsgröße besser abgeschlossen hat, ist unklar.

Eine Erklärung für die bessere Spüleffektivität der Ultraschallspülung liegt in der höheren Geschwindigkeit und den akustischen Strömungen der Spülflüssigkeit, welche durch die Benutzung von Ultraschall zustande kommen. Diese führen möglicherweise zum Transport von mehr Spülflüssigkeit in die Ausläufer des Wurzelkanals.

In einer ähnlichen Untersuchung zeigten Lee et al. (2004a), dass die mit Debris gefüllten Gruben besser gereinigt waren als die Bohrlöcher. Zu diesem Ergebnis kam auch die vorliegende Untersuchung: in allen drei Gruppen waren die Gruben signifikant besser gereinigt als die Bohrlöcher. Daraus kann man schließen, dass die Spülmethode keinen Einfluss auf diesen Effekt hatte. Möglicherweise lässt sich dieser Effekt darauf zurückführen, dass die Gruben der Spüllösung eine größere Angriffsfläche bieten $\left(A=0,8 \mathrm{~mm}^{2}\right)$, als die Bohrlöcher $\left(A=0,07 \mathrm{~mm}^{2}\right)$. 
Es liegen nur wenige Studien vor, die sich mit der Spüleffektivität in Wurzelkanälen befassen, die mit verschiedenen Konizitäten (Lee et al. 2004b, van der Sluis et al. 2005b, Huang et al. 2008) oder mit verschiedenen apikalen Größen präpariert wurden (Hsieh et al. 2007, Huang et al. 2008). Van der Sluis et al. (2005b) untersuchten in ihrer Studie die Effektivität der Ultraschallspülung in Wurzelkanälen, die mit verschiedenen Konizitäten präpariert waren. Die Untersuchung bezog sich auf die Entfernbarkeit von Debris in der apikalen Hälfte der Wurzelkanäle. Die apikale Präparation für alle Wurzelkanäle betrug ISO 20 und die Konizität jeweils 6\%, 8\% und 10\%. Die Präparation erfolgte mit System GT-Nickel-Titan-Instrumenten (Dentsply Maillefer, Ballaigues, Schweiz). In dieser Studie waren die Wurzelkanäle mit größerer Konizität besser gereinigt als die Wurzelkanäle mit kleinerer Konizität. Der Unterschied war allerdings statistisch nicht signifikant. In der vorliegenden Studie wurden die Wurzelkanäle mit FlexMaster-Nickel-Titan-Instrumenten aufbereitet (Fa. VDW, München, Deutschland) und, im Gegensatz zu der Studie von van der Sluis (2005b), mit unterschiedlichen apikalen Präparationsgrößen bei gleicher Konizität.

Einige Autoren sind der Meinung, dass eine effektive Wurzelkanalspülung eine bestimmte apikale Präparationsgröße (mind. ISO 35-40) voraussetzt. In dieser Studie wurden unterschiedliche Präparationsgrößen untersucht, die alle mit einer Konizität von $6 \%$ auf ihre jeweiligen ISO-Größen erweitert wurden. Wie bereits oben beschrieben wurden in anderen Studien die Wurzelkanäle mit einer größeren Konizität präpariert (van der Sluis et al. 2005b). Dies könnte der Grund für eine bessere Spüleffizienz im Vergleich zu dieser Studie sein.

Die Ergebnisse der vorliegenden Studie zeigen, dass die Effektivität der drei angewandten Spülmethoden bei der Entfernung von künstlichem Debris nicht von der Größe der apikalen Aufbereitung abhängig ist. Dagegen fanden Lee et al. (2004b) in einer Studie an künstlichen Wurzelkanälen heraus, dass der Durchmesser und die Konizität der präparierten Plastikkanäle einen Einfluss auf die Effektivität der Spülung bei der Entfernung von Debris haben. Dies deutet darauf hin, dass sich die natürlichen Wurzelkanäle nicht so leicht von Debris befreien lassen wie die künstlichen Wurzelkanäle aus Plastik. Dafür könnten zwei Gründe verantwortlich sein: Erstens ist die Anatomie der natürlichen Wurzelkanäle viel komplizierter (Dentinkanälchen, Apex, Variationen des Kanalquerschnitts und mögliche zusätzliche 
Seitenkanäle) und zweitens sind die Wurzelkanalwände rauer und poröser aufgrund der Anwesenheit von Dentintubuli. Zu denselben Ergebnissen kamen auch van der Sluis et al. (2005b).

Weiterhin wurde gezeigt, dass die Eindringtiefe der Spülkanüle einen Einfluss auf die Entfernung von Debris im Wurzelkanal hat (Chow 1983, Abou-Rass und Piccinino 1982). Die Untersuchungen haben ergeben, dass die effektivste Eindringtiefe der Spülnadel in Bezug auf die Spüleffektivität $1 \mathrm{~mm}$ kürzer als die Arbeitslänge ist (Zehnder 2006, Boutsioukis et al. 2009).

Gemäß der Gebrauchsanweisung von RinsEndo soll die Spülkanüle zur besseren Reinigungseffektivität des apikalen Kanaldrittels in das koronale Kanaldrittel appliziert werden. Die vorliegende Studie zeigt, dass die Effektivität von RinsEndo unabhängig vom Durchmesser der apikalen Aufbereitung und damit auch unabhängig von der Eindringtiefe der Spülkanüle ist.

Der direkte Vergleich dieser Ergebnisse mit den Ergebnissen anderer Studien kann jedoch nur bedingt und vorsichtig vorgenommen werden. Man darf nicht außer Acht lassen, dass die zahlreichen vorliegenden Studien mithilfe unterschiedlicher Versuchsanordnungen durchgeführt wurden. Im Hinblick auf die Kanalanatomie finden sich bereits Unterschiede, da in einigen Studien nur weite und gerade, in anderen aber nur enge und gekrümmte Kanäle verwendet wurden. Außerdem sind die Art, die Konzentration und die Menge des Spülmediums sowie die Präparationsmethode in den diversen Untersuchungen verschieden. Ebenso ist die Definition der Reinigungswirkung einer Spülmethode nicht einheitlich: in einigen Studien wurde die Entfernung der Schmierschicht und in anderen die Entfernung von Debris beurteilt. Das Fehlen einer einheitlichen Bewertungsmethode oder eines Scoresystems erschwert zusätzlich den Vergleich.

\subsection{Schlussfolgerungen}

Anhand der Ergebnisse der vorliegenden Studie ist festzustellen, dass die Forderung nach einer Wurzelkanalspülmethode mit dem Ziel der vollständigen Entfernung von Debris aus dem apikalen Drittel der Wurzelkanäle nicht erfüllt werden konnte. Die 
Spülung mit Ultraschall schnitt hinsichtlich der Entfernung von Debris aus dem apikalen Wurzelkanaldrittel signifikant besser ab als die Handspülung und RinsEndo und zwar, mit Ausnahme der Versuchsgruppe A (Größe 30), unabhängig von dem Durchmesser der apikalen Präparation. 


\section{Zusammenfassung}

Die Wurzelkanalspülung ist für eine erfolgreiche Wurzelkanalbehandlung von großer Bedeutung. Es gibt verschiedene Möglichkeiten, die Wurzelkanalspülung zu applizieren und zu aktivieren. In dieser Studie wurde die Entfernbarkeit von Debris in künstlich angelegten Wurzelkanalunregelmäßigkeiten mithilfe der folgenden Wurzelkanalspülmethoden untersucht: Handspülung, Ultraschall-Spülung und Spülung mit RinsEndo. Ziel dieser Studie war es, die effektivste Spülmethode zu ermitteln.

Dafür wurden die Zahnkronen von 30 extrahierten humanen einkanaligen Prämolaren abgetrennt. Anschließend fand eine randomisierte Aufteilung in 3 Gruppen statt $(n=10)$. Danach wurden die Wurzelkanäle mit FlexMaster-NickelTitan-Instrumenten (VDW, München) entsprechend ihrer Gruppenzuteilung präpariert: Gruppe A: 02/30, Gruppe B: 02/40 und Gruppe C: 02/50. Die Zähne wurden dann längs gespalten. Um nicht instrumentierte Wurzelkanalbereiche zu simulieren, wurde in der einen Zahnhälfte eine Rille 2-6 mm vom Apex entfernt angelegt. In die jeweils andere Zahnhälfte wurden drei Gruben im Abstand von 2, 4 und $6 \mathrm{~mm}$ vom Apex präpariert. Die Gruben und Rillen wurden mit künstlichem Debris befüllt und die Zahnhälften anschließend reponiert. Alle drei Versuchsgruppen wurden den drei folgenden Spülmethoden mit $30 \mathrm{ml} \mathrm{NaOCl}$ (1\%) unterzogen: Gruppe 1: Handspülung, Gruppe 2: RinsEndo und Gruppe 3: Ultraschallspülung. Um den befültten Zustand zu kontrollieren und die Spülwirkung sicher feststellen zu können, wurden vor und nach jeder Spülung digitale Fotos mit 30facher Vergrößerung angefertigt. Die Menge des verbliebenen Debris wurde mithilfe eines 4-Punkte Scoresystems bewertet. Die Daten wurden mit einer nichtparametrischen Kovarianzanalyse ausgewertet und ein Paarvergleich adjustiert für multiples Testen nach Tukey $(p=0,5)$ durchgeführt.

Die Ultraschallspülung zeigte eine signifikant bessere Debrisentfernung aus den künstlich angelegten Gruben und Rillen als die Handspülung bzw. die Spülung mit RinsEndo unabhängig von der apikalen Präparationsgröße der Wurzelkanäle. Nur in Gruppe A (02/30) unterschied sich die Spülwirkung von Ultraschall und RinsEndo nicht signifikant $(p=0,99)$. RinsEndo zeigte in allen Versuchsgruppen eine signifikant 
bessere Spülwirkung als die Handspülung ( $p=0,001)$.

Die Ultraschallspülung war signifikant effektiver bei der Entfernung des Debris aus künstlich angelegten Gruben und Rillen in geraden Wurzelkanälen als die Handspülung und die Spülung mit RinsEndo. 


\section{Literaturverzeichnis}

Abbott PV, Heijkoop PS, Cardaci SC, Hume WR, Heithersay GS (1991):

An SEM study of the effects of different Irrigation sequences and ultrasonics.

Int Endod J 24, 308-316

Abou-Rass M, Piccinino M V (1982):

The effectiveness of four clinical irrigation methods on the removal of root canal debris.

Oral Surg $\underline{54}, 323-328$

Ahmad M (1989):

The validity of using simulated root canals as models for ultrasonic instrumentation.

J Endod $\underline{15}$, 544-547

Ahmad M, Pitt Ford T, Crum LA (1987):

Ultrasonic debridement of root canals: acoustic streaming and its possible role.

J Endod $\underline{13}$, 490-499

Ahn A, Yu T (2000):

Effects of irrigation solution on smear layer using light speed instrumentation.

J Dent Res $\underline{79}, 527$

Al-Hadlaq S, Al-Turaiki S, Al-Sulami U, Saad A (2006):

Efficacy of a new brush-covered irrigation needle in removing root canal debris: a scanning electron microscopic study.

J Endod 32, 1181-1184

Athanassiadis B, Abbott PV, Walsh LJ (2007):

The use of calcium hydroxide, antibiotics and biocides as antimicrobial medicaments in endodontics.

Aust Dent J $\underline{52}, 64-82$ 
Baker NA, Eleazer PD, Overbach RE, Seltzer S (1975):

Scanning electron microscopic study of the efficacy of various irrigating solutions.

J Endod 1, 127-135

Ballal V, Kundabala M, Acharyas S, Ballal M (2007):

Antimicrobial action of calcium hydroxide, chlorhexidine and their combination on endodontic pathogens.

Aust Dent J $\underline{52}, 21-118$

Barthel CR, Georgi M, Schäfer E, Petschelt A, Flachsenberg S, Neuber T, Koçkapan C, Weiger R, Hülsmann M (2006):

Wurzelkanalspülung: Stellungnahme der DGZMK.

Zahnärztl Mitt $\underline{96}, 51-52$

Baumgartner JC, Ibay A (1987):

The chemical reactions of irrigants used for root canal debridement.

J Endod 13, 47-51

Baumgartner JC, Mader CL (1987):

A scanning electron microscopic evaluation of four root canal irrigation regimens.

J Endod 13, 147-157

Behrens VG, Sierra F (1992):

Kristallbildung im Wurzelkanal nach Behandlung mit Spüllösungen.

ZWR 101, 85-88

Berg MS, Jacobsen EL, BeGole EA, Remeikis NA (1986):

A comparison of five irrigating solutions: a scanning electron microscopic study.

J Endod 12, 192-197

Boutsioukis C, Lambriandis T, Kastriniakis E, Bekiaroglou P (2007):

Measurement of pressure and flow rates during irrigation of a root canal ex vivo with three endodontic needles.

Int Endod J 느, 504-513 
Boutsioukis C, Lambrianidis T, Kastrinakis E (2009):

Irrigant flow within a prepared root canal using various flow rates: a computational fluid dynamic study.

Int Endod J 42, 144-155

Brandt M, Stiefel A, Schaller H (2001):

Wirkungen von Spüllösungen für die endodontische Behandlung.

ZWR $110,74-77$

Brännström M (1984):

Smear layer: pathological and treatment considerations.

Oper Dent $\underline{3}, 35-42$

\section{Brännström M, Nyborg H (1973):}

Cavity treatment with a microbicidal fluoride solution: growth of bacteria and effect on the pulp.

J Prosthet Dent $\underline{30}, 303-310$

Braun A, Kappes D, Krause F, Jepsen S (2005):

Efficiency of a novel rinsing device for the removal of pulp tissue in vitro.

Int Endod J $\underline{38}, 923$ (abstract)

\section{Brunner E, Domhof S, Langer F :}

Nonparametric analysis longitudinal data in factorial experiments.

Wiley, New York 2002

\section{Byström A, Sundqvist G (1985):}

The antibacterial action of sodium hypochlorite and EDTA in 60 cases of endodontic therapy.

Int Endod J 18, 35-40

Calt S, Serper A (2000):

Smear layer removal by EGTA.

J Endod 26, 459-461 
Calt S, Serper A (2002):

Time-dependent effects of EDTA on dentin structures.

J Endod 2ㅇ, 17-19

Camara A, de Albuquerque M, Aguiar C, de Barros Correia A (2009):

In vitro antimicrobial activity of $0,5 \%, 1 \%$, and $2,5 \%$ sodium hypochlorite in root canals instrumented with the ProTaper Universal system.

Oral Surg Oral Med Oral Pathol Oral Radiol Endod $\underline{108}$, 55-61

\section{Cameron JA (1995):}

Factors affecting the clinical efficiency of ultrasonic endodontics: a scanning electron microscopy study.

Int Endod J 28, $47-53$

Carrotte P (2004):

Endodontics: Part 9 Calcium hydroxide, root resorption, endo-perio lesions.

Br Dent J 197, 735-743

Cergneux M, Ciucchi B, Dietschi JM, Holz J (1987):

The influence of the smear layer on the sealing ability of canal obturation.

Int Endod J 20, 228-232

Chenail BL, Teplitsky PE (1985):

Endosonics in curved root canals.

J Endod 11, 369-374

Chenail BL, Teplitsky PE (1988):

Endosonics in curved root canals part II.

J Endod 14, 214-217

Chow TW (1983):

Mechanical effectiveness of root canal irrigation.

J Endod $\underline{9}, 475-479$ 


\section{Ciucchi B, Khettabi M, Holz J (1989):}

The effectiveness of different endodontic irrigation procedures on the removal of the smear layer: a scanning electron microscopic study.

Int Endod J 22, 21-28

\section{Cohen S, Burns RC:}

Orofacial dental pain emergencies.

In: Pathways of the pulp, eighth edition; hrsg. v. Cohen S, Burns RC.

Mosby, St. Louis 2002, 31-77

Cooke H, Grower MF, del Rio C (1976):

Effects of instrumentation with a chelating agent on the periapical seal of obturated root canals.

J Endod 2, $312-314$

\section{Cunningham WT, Martin H (1982):}

A scanning electron microscope evaluation of canal debridement with the endosonic, ultrasonic synergistic system.

Oral Surg Oral Med Oral Pathol $\underline{53}, 527$ - 531

\section{Cunningham WT, Martin H, Forrest WR (1982):}

Evaluation of root canal debridement by the endosonic ultrasonic synergistic system. Oral Surg Oral Med Oral Path $\underline{53}, 401-404$

\section{Czonstkowsky M, Wilson E, Holstein F (1990):}

The smear layer in endodontics.

Dent Clin North Am $\underline{34}, 13-25$

\section{Dammaschke T (1999):}

Natriumhypochlorit - eine Übersicht.

Endodontie 1, 9-19 


\section{Davies GE, Francis J, Martin AR, Rose FL, Swain G (1954):}

1:6-Di-4'-Chlorophenyldiguanidohexane (hibitane): laboratory investigation of a new antibacterial agent of high potency.

Br J Pharmacol Chemother $\underline{9}, 192-196$

\section{Delaney GM, Patterson SS, Miller CH, Newton CW (1982):}

The effect of chlorhexidine gluconate irrigation on the root canal flora of freshly extracted necrotic teeth.

Oral Surg Oral Med Oral Pathol $\underline{53}$, 518-523

Drake DR, Wiemann AH, Rivera EM, Walton RE (1994):

Bacterial retention in canal walls in vitro: effect of smear layer.

J Endod 20, 78-82

\section{Druttman ACS, Stock CJR (1989):}

An in-vitro-comparison of ultrasonic and conventional methods of irrigant replacement.

Int Endod J 22, 174-178

\section{Dumani A, Yoldas O, Isci A, Köksal F, Kayar B, Polat E (2007):}

Disinfection of artificially contaminated resilon cones with chlorhexidine and sodium hypochlorite at different time exposures.

Oral Surg Oral Med Oral Pathol Oral Radiol Endod 103, 82-85

\section{Emilson CG (1977):}

Susceptibility of various microorganisms to chlorhexidine.

Scand J Dent Res $\underline{85}$, 255-265

\section{Ercan E, Dalli M, Duülgergil C, Yaman F (2007):}

Effect of intracanal medication with calcium hydroxide and $1 \%$ chlorhexidine in endodontic retreatment cases with periapical lesions: an in vivo study.

J Formos Med Assoc 106, 217-224 


\section{ESE (2006):}

Quality guidelines for endodontic treatment: consensus report of the European Society of Endodontology.

Int Endod J 39, 921-930

Ferraz CCR, de Almeida Gomez PF, Zaia AA, Teixeira FB, de Sousa-Filho (2001):

In vitro assessment of the antimicrobial action and the mechanical ability of chlorhexidine gel as an endodontic irrigant.

J Endod 27, 452-455

Fischer G (1907):

Über die feinere Anatomie der Wurzelkanäle menschlicher Zähne.

Dtsch Monatsschr Zahnheilkd 25, 544-552

Foster KH, Kulild JC, Weller RN (1993):

Effect of smear layer removal on the diffusion of calcium hydroxide through radicular dentin.

J Endod 19,136-140

Frentzen M, Schmitt UH, Braun A (2004):

Dimensionsstabilität von Guttaperchastiften bei unterschiedlichen Desinfektionsmaßnahmen.

ZWR $\underline{113}, 73-80$

Galvan DA, Ciarlone AE, Pashley DH, Kulild JC, Primack PD, Simpson MD (1994):

Effect of smear layer removal on the diffusion permeability of human roots.

J Endod 20, 83-86

Garberoglio R, Becce C (1994):

Smear layer removal by root canal irrigants. A comparative scanning electron microscopic study.

Surg Oral Med Oral Pathol $\underline{78}, 359-367$ 
Goldman LB, Goldman M, Kronman JH, Sun Lin P (1981):

The efficacy of several irrigating solutions for endodontics: A scanning electron microscopic study.

Oral Surg Med Oral Pathol $\underline{52}, 197-204$

Goldman M, Pearson A, Darzenta N (1972):

Endodontics success - who reading the radiograph?

Oral Surg Oral Med Oral Pathol $\underline{33}, 432-437$

Goodman A, Beck M, Melfi R, Meyers W (1985):

An in vitro comparison of the efficacy of the step-back technique versus a stepback/ultrasonic technique in human mandibular molars.

J Endod 11, 249-256

\section{Grossman L:}

Endodontic practice.

10th edition; Lea und Febiger, Philadelphia 1981

Grossman L, Meimann B (1941):

Solution of pulp tissue by chemical agents.

J Am Dent Assoc 28, 223-225

\section{Guerisoli D, Marchesan M, Walmsley A, Lumley P, Pecora J (2002):}

Evaluation of smear layer removal by EDTAC and sodium hypochlorite with ultrasonic agitation.

Int Endod J 35, 418-421

\section{Guldener PHA (1989):}

Endodontie: Wurzelkanalaufbereitung und -füllung.

Schweiz Monatsschr Zahnmed 99, 1019-1028

\section{Guldener PHA, Langeland K:}

Endodontologie.

2. Auflage; G. Thieme, Stuttgart 1987 
Haapasalo HK, Siren EK, Waltimo TK, Orstavik D, Haapasalo M (2000):

Inactivation of local root canal medicaments by dentine: an in vitro study.

J Endod 28, 126-131

Haikel Y, Allemann C (1988):

Effectiveness of four methods for preparing root canals: a scanning electron microscopic evaluation.

J Endod 14, 340-345

Hata G, Hyami S, Weine F, Toda T (2001):

Effectiveness of oxidative potential water as a root canal irrigant.

Int Endod J 34, 308-317

Häupl K, Meyer W, Schuchardt K:

Anatomie der Zähne

In: Die Zahn-, Mund und Kieferheilkunde, Band I; hrsg. Meyer W;

Urban und Schwarzenberg, München 1958, 169-251

Hauser V, Braun A, Frentzen M (2007):

Penetration depth of a dye marker into dentine using a novel hydrodynamic system (Rins Endo).

Int Endod J 40, 644-652

\section{Hellwig E, Klimek J, Attin T:}

Einführung in die Zahnerhaltung.

2. Auflage; Urban und Fischer, München 1999

Hellwig E, Klimek J, Attin T:

Einführung in die Zahnerhaltung.

3. Auflage; Urban und Fischer Verlag, München 2006

Hennessey TS (1973):

Some antibacterial properties of chlorhexidine.

J Periodontal Res (Suppl) 12, 61-67 
Heppeler J, Hülsmann M (2006):

Enterococcus faecalis - ein Problemkeim.

Endodontie 15,137-144

\section{Hess W (1917):}

Zur Anatomie der Wurzelkanäle des menschlichen Gebisses mit Berücksichtigung der feineren Verzweigungen am Foramen apikale.

Schweiz Vierteljahresschr Zahnheilkd 27, 51-52

Hottel T, el-Refai N, Jones J (1999):

A comparison of three chelating agents on the root canals of extracted human teeth.

J Endod 25, 716-717

Hsieh Y, Gau C, Kung Wu S, Shen E, Hsu P, Fu E (2007):

Dynamic recording of irrigation fluid distribution in root canals using thermal image analysis.

Int Endod J $\underline{40}, 7-11$

\section{Huang T, Gulabivala K, Ng Y (2008):}

A bio-molecular film ex-vivo model to evaluate the influence of canal dimensions and irrigation variables on the efficacy of irrigation.

Int Endod J $\underline{41}, 60-71$

\section{Hülsmann M:}

Endodontie.

Thieme, Stuttgart 1993

\section{Hülsmann M:}

Die Aufbereitung des Wurzelkanals.

In: Endodontie. Praxis der Zahnheilkunde, Band 3, 79-123; hrsg. v. Heidemann Urban und Fischer, München, 2001

Hülsmann M. (2004):

Die Anwendung elektro-physikalisch-chemischer Methoden in der Endodontie. ZWR $113,85-96$ 
Hülsmann M (2006):

Die Desinfektion des endodontischen Systems.

Endodontie 15, 147-168

Hülsmann M, Franz B. Lorch V (1996):

Reproduzierbarkeit des Periapical Probability Index (PRI).

Zahnärztl Welt 105. 366-372

Hülsmann M, Rümmelin C, Schäfers F (1997):

Root canal cleanliness after preparation with different endodontic handpieces and hand instruments: a comparative SEM investigation.

J Endod 23, 301-306

Hülsmann M, Heckendorff M, Schäfers F (2002):

Comparative in-vitro evaluation of three chelator pastes.

Int Endod J 35, 668-679

Hülsmann M, Heckendorff M, Lennon A (2003):

Chelating agents in root canal treatment: mode of action and indications for their use. Int Endod J 36, 810-830

\section{Hülsmann M, Peters OA, Dummer PMH (2005):}

Mechanical preparation of root canals: shaping goals, techniques and means.

Endodontic Topics 10, 30-76

Ingle J, Taintor J:

Endodontics.

3rd edition; Lea und Febiger, Philadelphia 1985

Jeansonne MJ, White RR (1994):

A comparison of $2 \%$ chlorhexidine gluconate and $5,25 \%$ sodium hypochlorite as antimicrobial endodontic irrigants.

J Endod 20, 276-278 
Jensen SA, Walker TL, Hutter JW, Nicoll BK(1999):

Comparison of the cleaning efficacy of passive sonic activation and passive ultrasonic activation after hand instrumentation in molar root canals.

J Endod 25, 735-738

Jiang L, Verhaagen B, Versluis M, van der Sluis L (2010):

Evaluation of a sonic device designed to activate irrigant in root canal.

J Endod $\underline{36}, 143-146$

Ketterl W:

Endodontie. Kompendium für Studium und Praxis.

Hüthig, Heidelberg 1984

Koçkapan C (1987):

Elektronenmikroskopische Untersuchungen über die Struktur der Schmierschicht.

Dtsch Zahnärztl Z $\underline{42}, 1028-1034$

Koçkapan C (1995):

Die Bedeutung der Schmierschicht bei der Wurzelkanalbehandlung - eine Übersicht.

Endodontie 4, 33-48

\section{Koçkapan C:}

Curriculum Endodontie.

Quintessenz, Berlin 2003

Koskinen KP, Meurman JH, Stenvall H (1980):

Appearance of chemically treated root canal walls in the scanning electron microscope.

Scand J Dent Res $\underline{88}, 397-405$

Lambrianidis T, Kosti E, Boutsioukis C, Mazinis M (2006):

Removal efficacy of various calciumhydroxide/chlorhexidine medicaments from the root canal.

Int Endod J $\underline{39}, 55-61$ 


\section{Lamers AC, van Mullem PJ, Simon M (1980):}

Tissue reactions to sodium hypochlorite and iodine potassium iodine under clinical conditions in monkey teeth.

J Endod $\underline{6}, 788-792$

\section{Lee SJ, Wu MK, Wesselink PR (2004a):}

The effectiveness of syringe irrigation and ultrasonics to remove debris from simulated irregularities within prepared root canal walls.

Int Endod J 37, 672-678

\section{Lee SJ, Wu MK, Wesselink PR (2004b):}

The efficacy of ultrasonic irrigation to remove artificially placed dentine debris from different-sized simulated plastic root canal.

Int Endod J 37, 607-612

Leonardo MR, Tanomaru M Jr, Silva LAB, Nelson P Jr, Bonifacio KC (1999): In vivo antimicrobial activity of $2 \%$ chlorhexidine used as a root canal irrigating solution.

J Endod 25, 167-171

\section{Lim K, Webber J (1985):}

The validity of simulated root canals for the investigation of the prepared root canal shape.

Int Endod J 18, 240-246

\section{Lim T, Wee T, Choi M, Koh W, Sae-Lim V (2003):}

Light and scanning electron microscopic evaluation of Glyde ${ }^{\text {TM }}$ File Prep in smear layer removal.

Int Endod J $\underline{36}, 336-343$

\section{Löst C, Wesselink PR, Winkler R (1992):}

Grundlagen und Prinzipien der modernen Endodontie.

Endodontie 1, 7-18 


\section{Love RM (1996):}

Adherence of Streptococcus gordonii to smeared and nonsmeared dentine.

Int Endod J 29, 108-112

\section{Lumley PJ, Walmsley AD, Walton RE, Rippin JW (1993):}

Cleaning oval canal using ultrasonic or sonic instrumentation.

J Endod $\underline{19}$, 453-457

Mader CL, Baumgartner JC, Peters DD (1984):

Scanning microscopic investigation of the smeared layer on root canal walls.

J Endod $\underline{10}, 477-483$

Margelos J, Eliades G, Verdelis C, Palaghias G (1997):

Interaction of calcium hydroxide with zinc oxide-eugenol type sealers: a potential clinical problem.

J Endod 23, 43-48

\section{Martin H, Cunningham W (1983):}

The effect of endosonic and hand manipulation on the amount of root canal material extruded.

Oral Surg Oral Med Oral Pathol $\underline{53}, 611-613$

\section{Martin H, Cunningham W (1984):}

Endosonic endodontics: the ultrasonic synergistic system.

Int Dent J 34, 198-203

\section{Martin H, Cunningham W (1985):}

Endosonics the ultrasonic synergistic system of endodontics.

Endod Dent Traumatol 1, 201-206

\section{Martin H, Cunningham W, Morris J, Cotton W (1980):}

Ultrasonic versus hand filing of dentine: a quantitative study.

Oral Surg Oral Med Oral Pathol 무, 566-568 
Martinho FC, Gomez BP (2008):

Quantification of endotoxins and cultivable bacteria in root canal infection before and after chemomechanical preparation with $2,5 \%$ sodium hypochlorite.

J Endod $\underline{34}, 268-272$

McComb D, Smith DC (1975):

A preliminary scanning electron microscopic study of root canals after endodontic procedures.

$\mathrm{J}$ Endod 1,238-242

McGill S, Gulabivala K, Mordan N, Ng YL (2008):

The efficacy of dynamic irrigations using a commercially available system (RinsEndo) determined by removal of a collagen "bio-molecular film" from an ex vivo model.

Int Endod J 41, 602-608

\section{Meyer W (1960):}

Die anatomischen Grundlagen der Wurzelkanalbehandlung.

Dtsch Zahnärztl Z 15 , 777-786

\section{Meyer W (1970):}

Die Anatomie der Wurzelkanäle dargestellt an mikroskopischen Rekonstruktionsmodellen.

Dtsch Zahnärztl Z $\underline{25}, 1064-1077$

\section{Meyer W, Scheele E (1954):}

Die Anatomie der Wurzelkanäle: eine vorläufige Mitteilung.

Dtsch Zahnärztl Z $\underline{9}, 497-500$

\section{Meyer W, Scheele E (1955):}

Die Anatomie der Wurzelkanäle der oberen Frontzähne.

Dtsch Zahnärztl Z 10 , 1041-1045

\section{Naenni N, Thoma K, Zehnder M (2004):}

Soft tissue dissolution capacity of currently used and potential endodontic irrigants.

J Endod $\underline{30}, 785-787$ 
Nagy CD, Bartha K, Bernalh M, Verdes E, Szabo J (1997):

The effect of root canal morphology on canal shape following instrumentation using different techniques.

Int Endod J $\underline{30}, 124-132$

Nandini S, Velmurugan N, Kandaswamy D (2006):

Removal efficiency of calcium hydroxide intracanal medicament with two calcium chelators: volumetric analysis using spiral CT. An in vitro study.

J Endod 32, 1097-1101

Nanzer J, Langlois S, Coeuret F (1989):

Electrochemical engineering approach to the irrigation of tooth canals under the influence of a vibrating file.

J Biomed Eng 11, 157-163

Ng YL, Mann V, Rahbaran S, Lewsey J, Gulabivala K (2008):

Outcome of primary root canal treatment: systematic review of the literature-

Part 2. Influence of clinical factors.

Int End J 41, 31-36

Nygaard-Østby B (1957):

Chelation in root canal therapy.

Odontologisk Tidskrift $\underline{65}, 3-11$

O'Connell M, Morgan L, Beeler W; Baumgartner J (2000):

A comparative study of smear layer removal using different salts of EDTA.

J Endod 26, 739-743

Ørstavik D, Haapasalo M (1990):

Disinfection by endodontic irrigants and dressings of experimentally infected dentinal tubules.

Endod Dent Traumatol $\underline{6}, 142-149$ 


\section{Pashley DH (1984):}

Smear layer: Pathological considerations.

Oper Dent $\underline{9}, 13-29$

\section{Petschelt A (1989):}

Endodontie: Maschinell - manuell? Die Aufbereitung und Spülung des Wurzelkanals.

Dtsch Zahnärztl Z $\underline{44}, 407-413$

\section{Petschelt A, Oberschachtsiek H (1985):}

Über die Schmierschicht (smear layer) nach der Wurzelkanalaufbereitung (REMUntersuchung).

Dtsch Zahnärztl Z $\underline{40}, 845-849$

\section{Petschelt A, Dobler J (1991):}

Großvolumige versus aktivierte Wurzelkanalspülung.

Dtsch Zahnärztl Z $\underline{46}, 285$ - 287

\section{Petschelt A, Stumpf B, Raab W (1987):}

Dichtigkeit von Wurzelfüllungen mit und ohne Schmierschicht (smear layer).

Dtsch Zahnärztl Z $\underline{42}, 743-746$

\section{Poertzel E, Petschelt A (1986):}

Bakterien in der Wurzelkanalwand bei Pulpagangrän.

Dtsch Zahnärztl Z $\underline{41}, 772-777$

Portenier I, Haapasalo H, Rye A, Waltimo TK, Ørstavik D, Haapasalo M (2001): Inactivation of root canal medicaments by dentine, hydroxylapatite and bovine serum albumin.

Int Endod J 누, 184-188

Ram Z (1977):

Effectiveness of root canal irrigation.

Oral Surg Oral Med Oral Pathol $\underline{44}$, 306-312 


\section{Richman M (1957):}

The use of ultrasonics in root canal therapy and root resection.

J Dent Med 12, 12-18

\section{Ringel AM, Patterson SS, Newton CW, Miller CH, Mulhern JM (1982):}

In vivo evaluation chlorhexidine gluconate solution and sodium hypochlorite solution as root canal irrigants.

J Endod $\underline{8}, 200-204$

\section{Rohen W:}

Anatomie für Zahnmediziner: ein Kurzlehrbuch der funktionellen und topographischen Anatomie des Menschen.

Schattauer, Stuttgart 1988

\section{Sabins RA, Johnson JD, Hellstein JW (2003):}

A comparison of the cleaning efficacy of short-term sonic and ultrasonic passive irrigation after hand instrumentation in molar root canals.

J Endod 29, 674-678

Saleh IM, Ruyter IE, Haapasalo M, Ørstavik D (2008):

Bacterial penetration along different root canal filling materials in the presence or absence of smear layer.

Int Endod J 41, 32-40

Santos MD, Walker WA 3rd, Carnes DL Jr. (1999):

Evaluation of apical seal in straight canals after obturation using the lightspeed sectional method.

J Endod 25, 609-612

\section{Saunders WP, Saunders EM (1994):}

Coronal leakage as a cause of failure in root-canal therapy: a review.

Endod Dent Traumatol 10, 105-108 
Scelza M, Antoniazzi J, Scelza P (2000):

Efficacy of final irrigation - a scanning electron microscopic evaluation.

J Endod 26, 355-358

\section{Schilder H:}

Canal debridement and disinfection.

In Cohen S, Burns R C: Pathways of the Pulp. 3rd edition

Mosby, St. Louis 1984

\section{Schroeder H:}

Orale Strukturbiologie.

3. Auflage; G. Thieme, Stuttgart 1987

Sharavan A, Hagdoost AA, Adl A, Rahimi H, Shadifar F (2007):

Effect of smear layer on sealing ability of canal obturation: a systematic review and meta-analysis.

J Endod $\underline{33}, 96-105$

\section{Shemesh H, Wu MK, Wesselink PR (2006):}

Leakage along apical root fillings with and without smear layer using two different leakage models: a two-month longitudinal ex vivo study.

Int Endod J 39, 968-976

\section{Shipper G, Teixeira FB, Arnold RR, Trope M (2005):}

Periapical inflammation after coronal microbial inoculation of dog roots filled with guttapercha or Resilon.

J Endod $\underline{31}$, 91-96

\section{Siqueira JF Jr., Lopez HP (1999):}

Mechanisms of antimicrobial activity of calcium hydroxide: a critical review.

Int Endod J 32, 361-369 
Sirtes G, Waltimo T, Schätzle M, Zehnder M (2005):

The effects of temperature on sodium hypochlorite short-term stability, pulp dissolution capacity and antimicrobial efficacy.

J Endod $\underline{31}, 669-671$

Spoleti P, Siragusa M, Spoleti MJ (2003):

Bacteriological evaluation of passive ultrasonic activation.

J Endod 29, 12-14

Stock C (1992):

Derzeitiger Stand der Ultraschallanwendung in der Endodontie.

Endodontie 1, 35-44

Stock C, Nehammer CF (1985):

Negotiation of obstructed canals; bleaching of teeth.

Br Dent J 158, 457-462

Stock C, Nehammer CF:

Endodontie praxisnah. 1. Auflage;

Hanser, München 1994

Takeda F, Harashima T, Kimura Y, Matsumoto K (1999):

A comparative study of the removal of smear layer by three endodontic irrigants and two types of laser.

Int Endod J $\underline{32}, 32-39$

Tanomaru JM, Leonardo MR, Tanomaru Filho M, Bonetti Filho I, Silva LA (2003):

Effect of different irrigation solutions and calcium hydroxide on bacterial LPS.

Int Endod J $\underline{36}, 733-739$

Taylor JK, Jeansonne BG, Lemon RR (1997):

Coronal leakage: effect of smear layer, obturation technique and sealer.

J Endod 23, 508-512 
Tepel G, Schäfer C, Hoppe W (1993):

Kunststoffe als Modellmaterial in der Endodontie.

Dtsch Zahnärztl Z $\underline{48}, 736-38$

Timpawat S, Vongsavan N, Messer HH (2001):

Effect of removal of the smear layer on apical microleakage.

J Endod 27, 351-353

Torabinejad M, Handysides R, Khademi AA, Bakland LK (2002):

Clinical implications of the smear layer in endodontics: a review.

Oral Surg Oral Med Oral Pathol 94, 658-666

Torabinejad M, Khademi A, Babagoli J, Cho Y, Johnson W, Bozhilov K, Kim J, Shabahang S (2003):

A new solution for the removal of the smear layer.

J Endod 29, 170-175

\section{Tronstad L:}

Clinical endodontics.

Thieme, New York 1991

\section{Trope M, Bergenholtz G (2002):}

Microbiological basis for endodontic treatment: can a maximal outcome be achieved in one visit?

Endodontic Topics 1, 40-53.

van der Sluis LW, Wu MK, Wesselink PR (2005a):

A comparison between a smooth wire and a K-file in removing artificially placed dentine debris from root canals in resin blocks during ultrasonic irrigation.

Int Endod J $\underline{38}, 593-596$

van der Sluis LW, Wu MK, Wesselink PR (2005b):

The efficiency of ultrasonic irrigation to remove artificially placed dentine debris from human root canals prepared using instruments of varying taper.

Int Endod J $\underline{38}, 764-768$ 
van der Sluis LW, Gambarini G, Wu MK, Wesselink PR (2006):

The influence of volume, type of irrigant and flushing method on removing artificially placed dentin debris from the apical root canal during passive ultrasonic irrigation. Int Endod J $\underline{39}, 472-476$

van der Sluis LW, Wu MK, Wesselink PR (2007):

The evaluation of removal of calcium hydroxide paste from an artificial standardized groove in the apical root canal using different irrigation methodologies.

Int Endod J 40, 52-57

van der Sluis LW, Wu MK, Wesselink PR (2009):

Comparison of 2 flushing methods used during passive ultrasonic irrigation of the root canal.

Quintessence Int $\underline{40}$, 875-879

van Velzen S, Genet J, Kersten H, Moorer W, Wesselink P:

Endodontie

Dtsch Ärzte-Verlag, Köln 1988

Walmsley AD (1994):

Ultraschall in der Zahnheilkunde. Eine Übersicht.

Phillip J 11, 487-490

Walters MJ, Baumgartner JC, Marshall JG (2002):

Efficacy of irrigation with rotary instrumentation.

J Endod 28, 837-839

Weine FS:

Endodontic therapy.

C.V. Mosby, St. Louis 1988

White RR, Hays GL, Janer LR (1997):

Residual antimicrobial activity after canal irrigation with chlorhexidine.

J Endod 23, 229-231 


\section{Wiedemann W, Klinger $\mathrm{H}$ :}

Über die Eindringtiefe von Spülflüssigkeiten in Wurzelkanäle. Zitiert nach Inhaltsangabe des Vortrages (gehalten am 26.10.1984)

in: 12. Jahrestagung der Deutschen Gesellschaft für Zahnerhaltung, Kiel, 26.-27.

Oktober 1984, Programm und Autoreferate; o. Hrsg., o. Verl., o. O, 1984 S. 23

\section{Wu MK, Wesselink PR (1995):}

Efficacy of three techniques in cleaning the apical portion of curved root canals.

Oral Surg Oral Med Oral Pathol Oral Radiol Endod $\underline{79}$, 492-496

\section{Wu MK, Wesselink PR (2001):}

A primary observation on the preparation and obturation in oval canals. Int Endod J 34, 137-141

\section{Wu MK, Roris A, Barkis D, Wesselink PR (2000):}

Prevalence and extent of long oval canals in the apical third.

Oral Surg Oral Med Oral Pathol Oral Radiol Endod 89, 739-743

Wu MK, de Schwartz FB, van der Sluis LW, Wesselink PR (2001):

The quality of root fillings remaining in mandibular incisors after root-end cavity preparation.

Int Endod J $\underline{36}, 218-224$

\section{Yamada RS, Armas A, Goldman M, Lin PS (1983):}

A scanning electron microscopic comparison of a high volume final flush with several irrigating solutions: Part 3.

J Endod $\underline{9}, 137-142$

\section{Yamashita J, Tanomaru Filho M, Leonardo M, Rossi M, Silva I (2003):}

Scanning electron microscopic study of the cleaning ability of chlorhexidine as a rootcanal irrigant.

Int Endod J 36, 391-394 
Zehnder M (2006):

Root canal irrigants.

J Endod 32, 389-398

Zehnder M, Kosicki D, Luder H, Sener B, Waltimo T (2002):

Tissue-dissolving capacity and antibacterial effect of buffered and unbuffered hypochlorite solution.

Oral Surg Oral Med Oral Pathol Oral Radiol Endod 94, 756-762

Zehnder M, Lehnert B, Schönenberger K, Waltimo T (2003):

Spüllösungen und medikamentöse Einlagen in der Endodontie.

Schweiz Monatsschr Zahnmed 113, 756-763

Zmener O, Pameijer C, Serrano S, Palo R, Iglesias E (2009):

Efficacy of the NaviTip FX irrigation needle in removing post instrumentation canal smear layer and debris in curved root canals.

J Endod 35, 1270-1273 


\section{Anhang: Biometrische Auswertung}

Dem Versuch liegt ein faktorielles Modell zugrunde. Folgende Faktoren sind vorhanden:

- Gruppe (Gruppe A, B, C)

- Reader (Reader 1, Reader 2)

- Zahnhälfte $(a, b)$

- $\operatorname{Größe~}(30,40,50)$

Die 4 Faktoren sind gekreuzt; die Daten wurden in jeder 4-fach Kombination erhoben.

Weiterhin wurden folgende Kovariablen gemessen:

- Voll

- Leer

Als Zielgröße wurde ein Score in den Stufen 0, 1, 2, 3 gemessen. 


\section{Deskriptive Angaben}

Die folgende Tabelle zeigt die Häufigkeitsverteilungen der Messungen in jeder Faktorkombination:

\begin{tabular}{|c|c|c|c|c|c|c|c|c|}
\hline Größe & Gruppe & $\begin{array}{l}\text { Zahn- } \\
\text { hälfte }\end{array}$ & Reader & $\begin{array}{c}\text { Score } \\
0\end{array}$ & $\begin{array}{c}\text { Score } \\
1\end{array}$ & $\begin{array}{c}\text { Score } \\
2\end{array}$ & $\begin{array}{c}\text { Score } \\
3\end{array}$ & Row \\
\hline 30 & 1 & $a$ & 1 & 0 & 1 & 8 & 1 & 10 \\
\hline 30 & 1 & $a$ & 2 & 0 & 1 & 6 & 3 & 10 \\
\hline Total & & & & 0 & 2 & 14 & 4 & 20 \\
\hline 30 & 1 & $\mathrm{~b}$ & 1 & 0 & 5 & 5 & 0 & 10 \\
\hline 30 & 1 & $b$ & 2 & 0 & 5 & 5 & 0 & 10 \\
\hline Total & & & & 0 & 10 & 10 & 0 & 20 \\
\hline 30 & 2 & $a$ & 1 & 4 & 4 & 2 & 0 & 10 \\
\hline 30 & 2 & $a$ & 2 & 4 & 4 & 2 & 0 & 10 \\
\hline Total & & & & 8 & 8 & 4 & 0 & 20 \\
\hline 30 & 2 & $\mathrm{~b}$ & 1 & 7 & 3 & 0 & 0 & 10 \\
\hline 30 & 2 & $b$ & 2 & 9 & 1 & 0 & 0 & 10 \\
\hline Total & & & & 16 & 4 & 0 & 0 & 20 \\
\hline 30 & 3 & $a$ & 1 & 6 & 3 & 1 & 0 & 10 \\
\hline 30 & 3 & $a$ & 2 & 6 & 3 & 1 & 0 & 10 \\
\hline Total & & & & 12 & 6 & 2 & 0 & 20 \\
\hline 30 & 3 & $\mathrm{~b}$ & 1 & 7 & 3 & 0 & 0 & 10 \\
\hline 30 & 3 & $\mathrm{~b}$ & 2 & 7 & 3 & 0 & 0 & 10 \\
\hline Total & & & & 14 & 6 & 0 & 0 & 20 \\
\hline 40 & 1 & $a$ & 1 & 0 & 2 & 7 & 1 & 10 \\
\hline 40 & 1 & $a$ & 2 & 0 & 1 & 8 & 1 & 10 \\
\hline Total & & & & 0 & 3 & 15 & 2 & 20 \\
\hline 40 & 1 & $\mathrm{~b}$ & 1 & 0 & 4 & 6 & 0 & 10 \\
\hline 40 & 1 & $b$ & 2 & 0 & 3 & 7 & 0 & 10 \\
\hline Total & & & & 0 & 7 & 13 & 0 & 20 \\
\hline 40 & 2 & $a$ & 1 & 4 & 2 & 4 & 0 & 10 \\
\hline 40 & 2 & $a$ & 2 & 4 & 2 & 4 & 0 & 10 \\
\hline Total & & & & 8 & 4 & 8 & 0 & 20 \\
\hline 40 & 2 & $b$ & 1 & 3 & 5 & 2 & 0 & 10 \\
\hline 40 & 2 & $\mathrm{~b}$ & 2 & 4 & 4 & 2 & 0 & 10 \\
\hline Total & & & & 7 & 9 & 4 & 0 & 20 \\
\hline 40 & 3 & $a$ & 1 & 6 & 4 & 0 & 0 & 10 \\
\hline 40 & 3 & $a$ & 2 & 6 & 4 & 0 & 0 & 10 \\
\hline
\end{tabular}




\begin{tabular}{|c|c|c|c|c|c|c|c|c|}
\hline Total & & & & 12 & 8 & 0 & 0 & 20 \\
\hline 40 & 3 & $b$ & 1 & 8 & 2 & 0 & 0 & 10 \\
\hline 40 & 3 & $\mathrm{~b}$ & 2 & 8 & 2 & 0 & 0 & 10 \\
\hline Total & & & & 16 & 4 & 0 & 0 & 20 \\
\hline 50 & 1 & $a$ & 1 & 0 & 1 & 8 & 1 & 10 \\
\hline 50 & 1 & $a$ & 2 & 0 & 3 & 5 & 2 & 10 \\
\hline Total & & & & 0 & 4 & 13 & 3 & 20 \\
\hline 50 & 1 & $\mathrm{~b}$ & 1 & 0 & 5 & 5 & 0 & 10 \\
\hline 50 & 1 & $\mathrm{~b}$ & 2 & 0 & 5 & 5 & 0 & 10 \\
\hline Total & & & & 0 & 10 & 10 & 0 & 20 \\
\hline 50 & 2 & $a$ & 1 & 3 & 6 & 1 & 0 & 10 \\
\hline 50 & 2 & $a$ & 2 & 3 & 6 & 1 & 0 & 10 \\
\hline Total & & & & 6 & 12 & 2 & 0 & 20 \\
\hline 50 & 2 & $b$ & 1 & 5 & 5 & 0 & 0 & 10 \\
\hline 50 & 2 & $b$ & 2 & 5 & 5 & 0 & 0 & 10 \\
\hline Total & & & & 10 & 10 & 0 & 0 & 20 \\
\hline 50 & 3 & $a$ & 1 & 6 & 4 & 0 & 0 & 10 \\
\hline 50 & 3 & $a$ & 2 & 6 & 4 & 0 & 0 & 10 \\
\hline Total & & & & 12 & 8 & 0 & 0 & 20 \\
\hline 50 & 3 & $b$ & 1 & 8 & 2 & 0 & 0 & 10 \\
\hline 50 & 3 & $b$ & 2 & 6 & 4 & 0 & 0 & 10 \\
\hline Total & & & & 14 & 6 & 0 & 0 & 20 \\
\hline $\begin{array}{l}\text { Column } \\
\text { Total }\end{array}$ & & & & 135 & 121 & 95 & 9 & 360 \\
\hline
\end{tabular}




\section{Auswertung}

Dem faktoriellen Modell liegen verbundene und unverbundene Daten zugrunde. Alle Daten, die von einem Zahn stammen, sind verbunden. Wir führen zur Auswertung eine spezielle nichtparametrische Kovarianzanalyse durch, so wie diese im Lehrbuch über nichtparametrische Statistik von Brunner et al. (2002) beschrieben ist.

Aufgrund der ordinalskalierten Zielgröße (4-Punkte-Score) kann die Auswertung nicht mit einem parametrischen Verfahren durchgeführt werden, sondern nur mit einem nichtparametrischen (verteilungsfreien) Verfahren.

Das Verfahren basiert auf Rängen der Daten, wobei die Ränge über alle Daten vergeben werden. Man kann sich dabei an der erzeugenden Ordnungsstruktur orientieren: da wo die Ränge (bzw. deren Mittelwerte) am größten sind, da sind die unterliegenden Scores am größten. Die auf das 0-1 Intervall normierten Rangmittelwerte werden als Relative Effekte bezeichnet. 
Die folgenden Grafiken zeigen die Rangmittelwerte für verschiedene Faktorkombinationen:

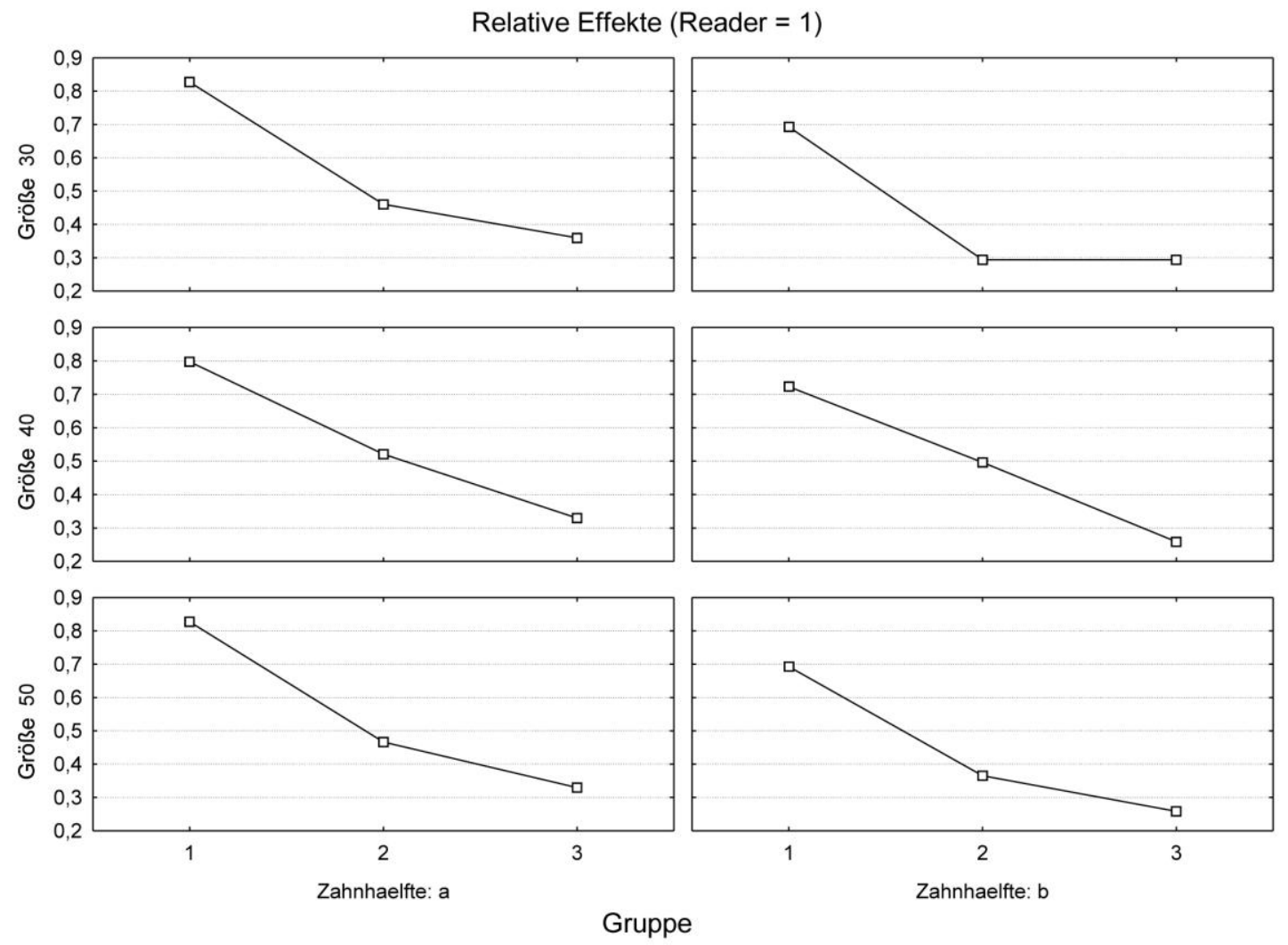

Relative Effekte (Reader = 2)
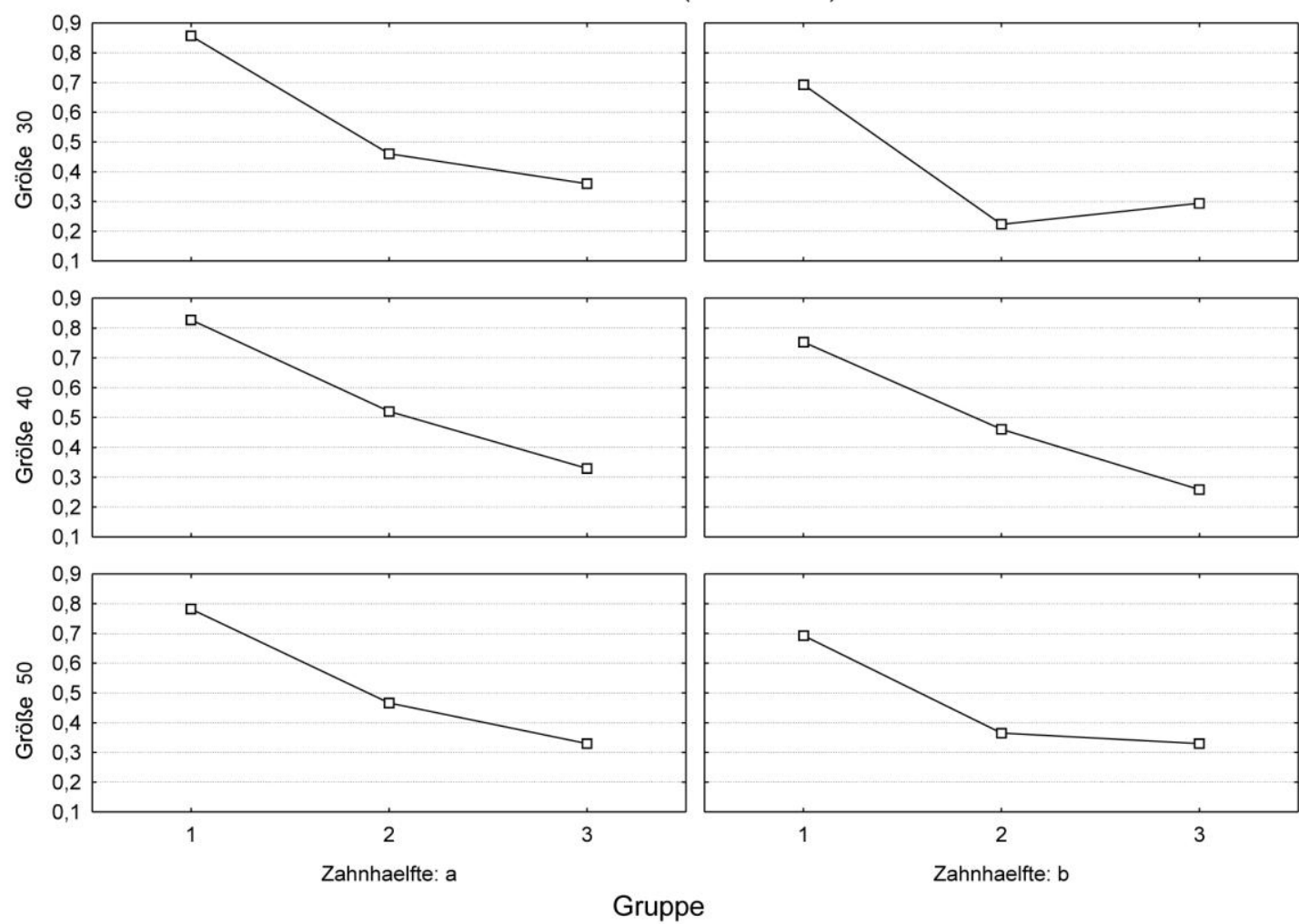

Gruppe 
Relative Effekte (Reader $=1$ )
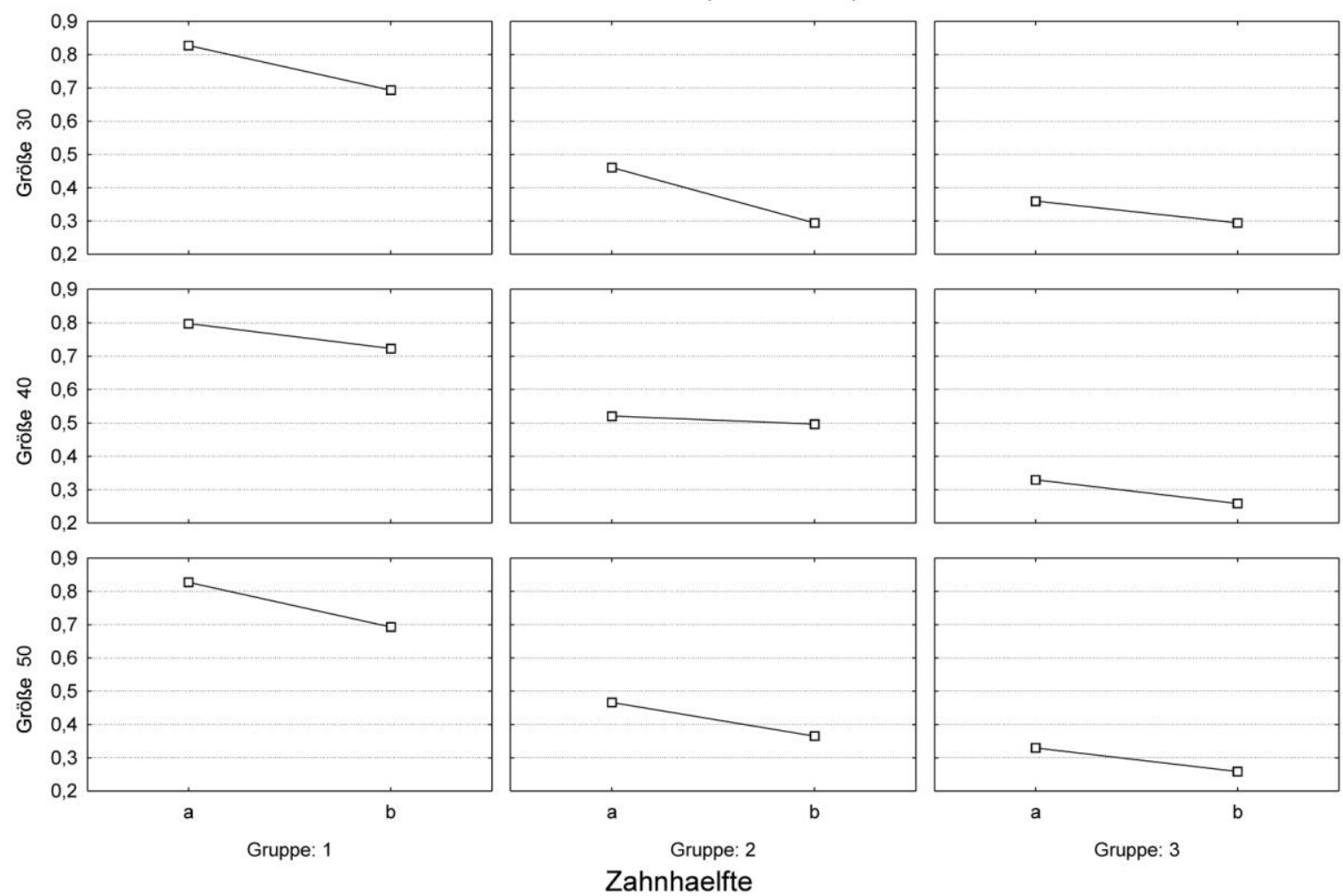

Zahnhaelfte

Relative Effekte (Reader $=2$ )
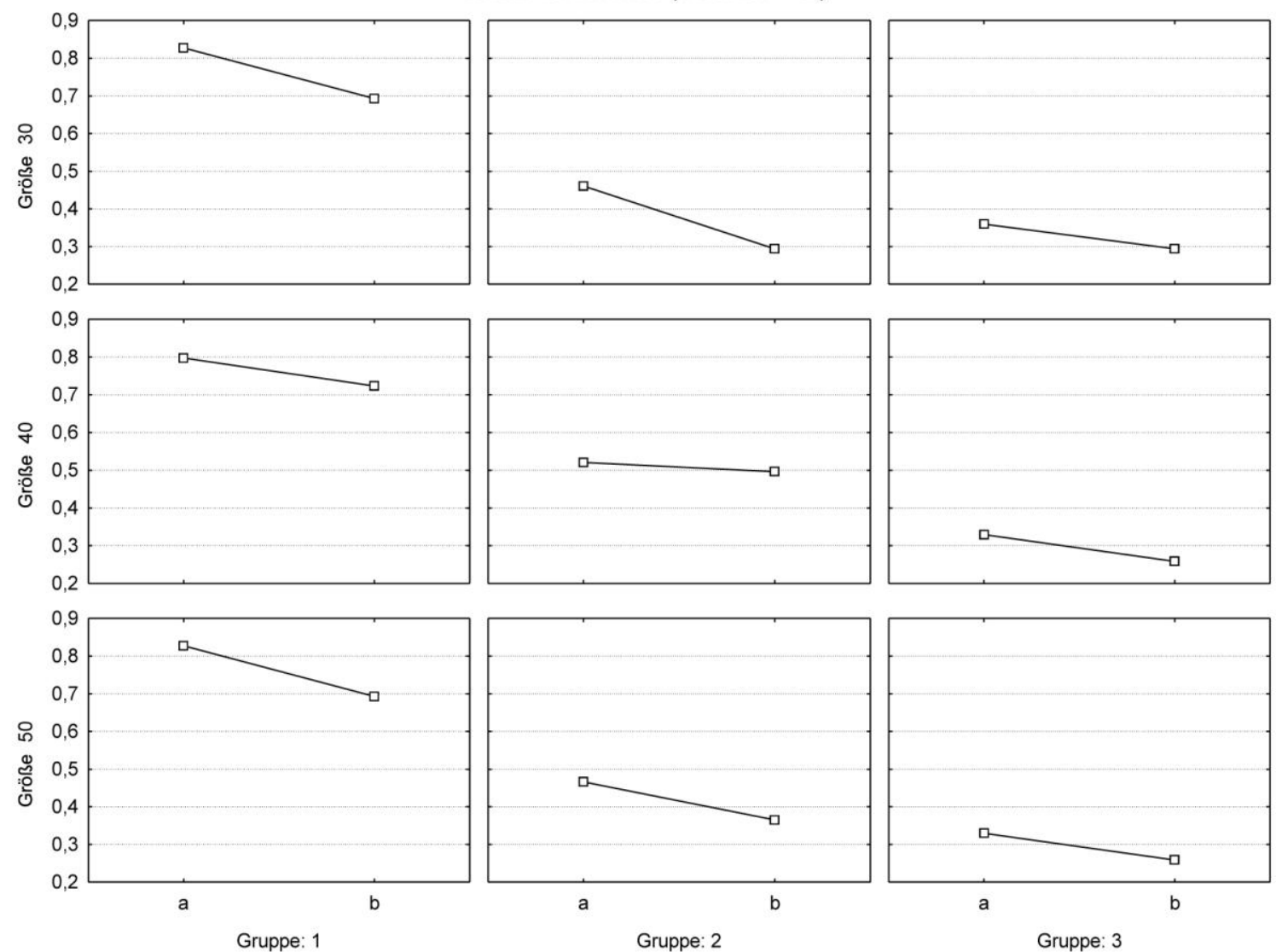

Zahnhaelfte

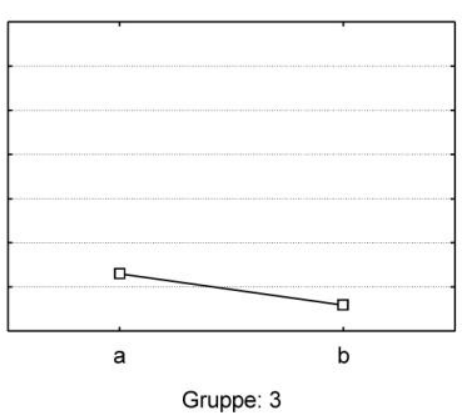


Relative Effekte Größe * Gruppe

Factors: Levels

Reader: 1
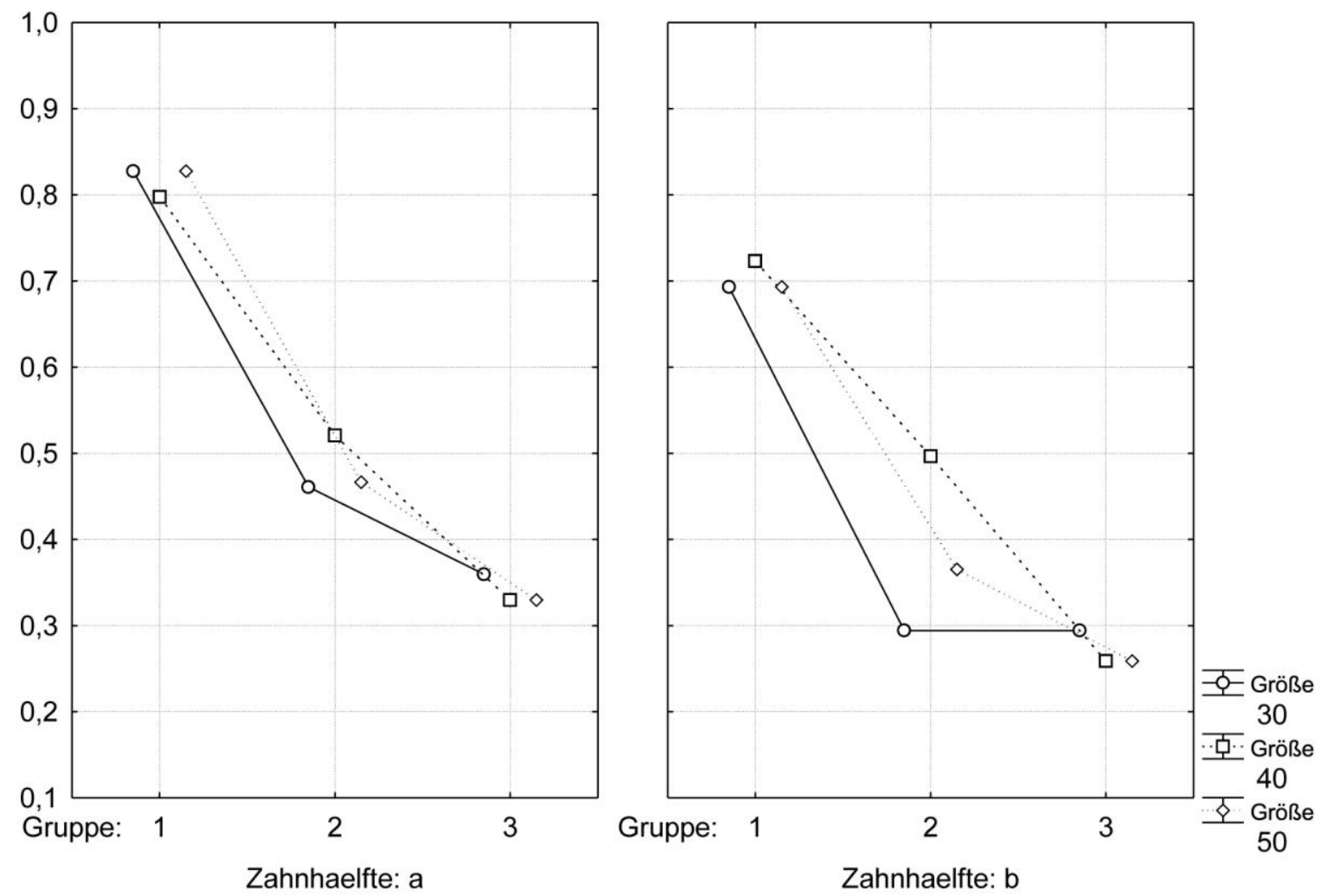

Relative Effekte Größe * Gruppe

Factors: Levels Reader: 2
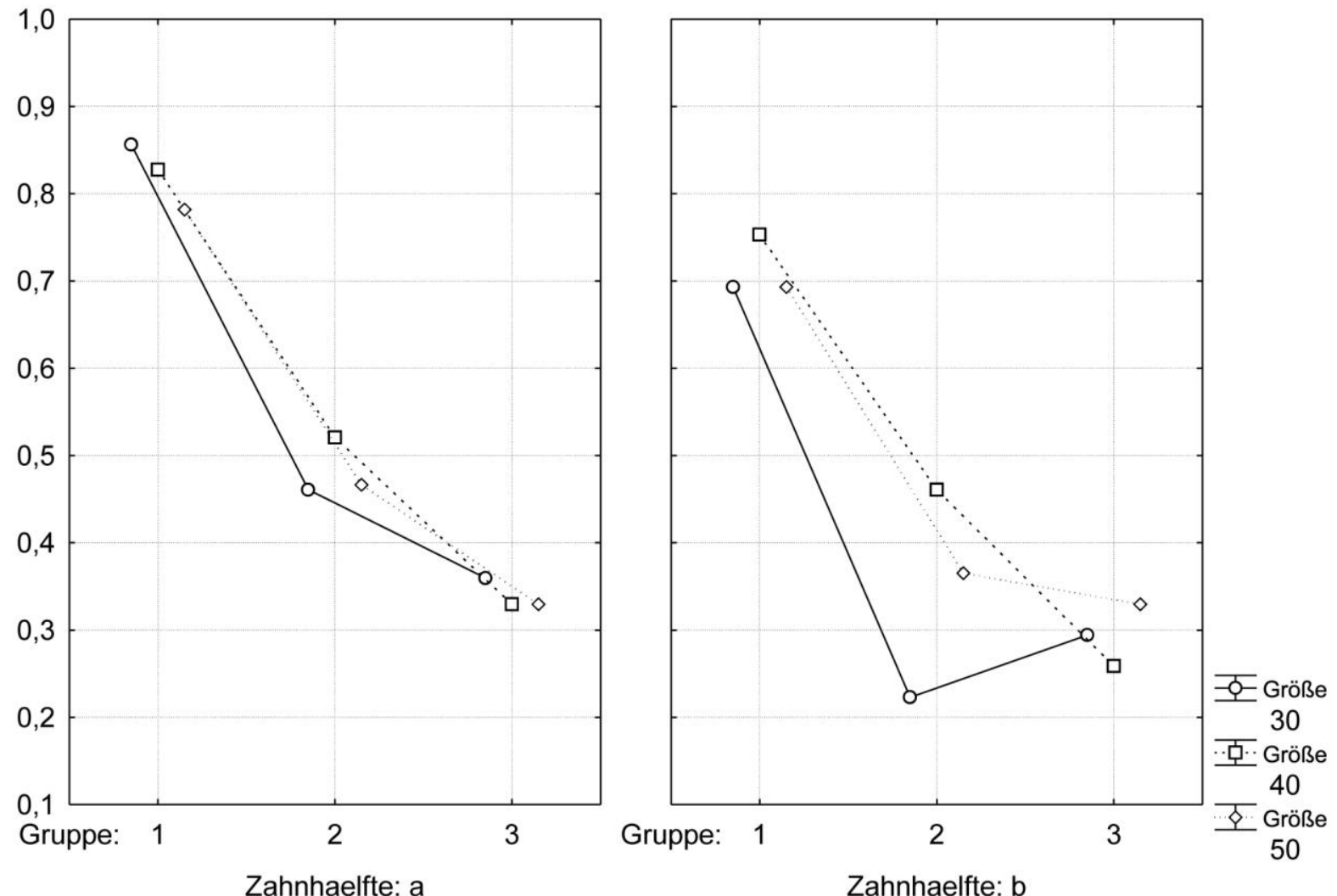
Im Modell werden die Hypothesen in den Verteilungen getestet. Wir können hier folgende Hypothesen testen:

- Effekt = Gruppe: Unterscheiden sich die drei Gruppen?

- Effekt $=$ Reader: Unterscheiden sich die beiden Reader ?

- Effekt $=$ Gruppe ${ }^{*}$ Reader: Gibt es eine statistische Interaktion zwischen Reader und Gruppe? (d.h. begutachtet jeder Reader in den drei Gruppen gleich gut)

- Effekt = Zahnhälfte: Unterscheiden sich die beiden Zahnhälften?

- Effekt = Zahnhälfte * Gruppe: Gibt es eine Wechselwirkung (= statistische Interaktion) zwischen den Zahnhälften und Gruppen (d.h. zeigen die beiden Zahnhälften in den Gruppen ähnliches Verhalten)?

- $\quad$ Effekt $=$ Zahnhälfte ${ }^{*}$ Reader: Gibt es eine Interaktion zwischen Reader und Zahnhälfte (d.h. beeinträchtigt die Zahnhälfte die Befundung des Readers)?

- Effekt $=$ Zahnhälfte * Gruppe * Reader: Gibt es eine Interaktion zwischen Zahnhälfte, Gruppe und Reader?

- Effekt $=$ Größe: Unterscheiden sich die drei Größe-Gruppen?

- Effekt $=$ Größe *Gruppe: Gibt es eine Interaktion zwischen Größe und Gruppe?

- Effekt $=$ Reader * Größe

- Effekt $=$ Gruppe ${ }^{*}$ Reader ${ }^{*}$ Größe

- Effekt $=$ Zahnhälfte * Größe

- Effekt $=$ Zahnhälfte * Gruppe *Größe

- Effekt $=$ Zahnhälfte * Reader * Größe

- Effekt $=$ Zahnhälfte * Reader * Gruppe * Größe

- Effekt = voll: Beeinflusst die Kovariable „voll“ die anderen Messungen?

- Effekt = leer: beeinflusst die Kovariable „leer“ die anderen Messungen? 
Wir erhalten folgende $p-W e r t e:$

\begin{tabular}{|l|l|l|}
\hline Effekt & $p$-Wert & Interpretation \\
\hline Gruppe & $<.0001$ & Signifikant \\
\hline Reader & 0.9854 & Nicht signifikant \\
\hline Gruppe*Reader & 0.8104 & Nicht signifikant \\
\hline Zahnhälfte & $<.0001$ & Signifikant \\
\hline Zahnhälfte*Gruppe & 0.3248 & Nicht signifikant \\
\hline Zahnhälfte*Reader & 0.9834 & Nicht signifikant \\
\hline Zahnhälfte*Gruppe*Reader & 0.7818 & Nicht signifikant \\
\hline Größe & 0.6940 & Nicht signifikant \\
\hline Gruppe*Größe & $\mathbf{0 . 0 2 4 6}$ & Signifikant \\
\hline Reader*Größe & 0.9571 & Nicht signifikant \\
\hline Reader*Größe & 0.9571 & Nicht signifikant \\
\hline Gruppe*Reader Größe & 0.9249 & Nicht signifikant \\
\hline Zahnhälfte*Größe & 0.2417 & Nicht signifikant \\
\hline Zahnhälfte*Gruppe*Größe & 0.7372 & Nicht signifikant \\
\hline Zahnhälfte*Reader*Größe & 0.6851 & Nicht signifikant \\
\hline Zahnhälfte*Gruppe*Reader Größe & 0.9998 & Nicht signifikant \\
\hline voll & 0.1898 & Nicht signifikant \\
\hline leer & 0.5052 & Nicht signifikant \\
\hline
\end{tabular}


Aufgrund der signifikanten Wechselwirkung zwischen Gruppe und Größe führten wir die gleiche Analyse für jede Größe-Gruppe getrennt durch:

\section{Größe 30}

\begin{tabular}{|l|l|l|}
\hline Effekt & $p-$ Wert & Interpretation \\
\hline Gruppe & $<.0001$ & Signifikant \\
\hline Reader & 0.8184 & Nicht Signifikant \\
\hline Gruppe ${ }^{*}$ Reader & 0.7996 & Nicht Signifikant \\
\hline Zahnhälfte & $<\mathbf{0 . 0 0 0 1}$ & Signifikant \\
\hline Zahnhälfte ${ }^{*}$ Gruppe & 0.3200 & Nicht Signifikant \\
\hline Zahnhälffte Reader $^{*}$ & 0.5963 & Nicht Signifikant \\
\hline Zahnhälfte*Gruppe ${ }^{*}$ Reader & 0.8961 & Nicht Signifikant \\
\hline voll & 0.052 & Nicht Signifikant \\
\hline leer & 0.2253 & Nicht Signifikant \\
\hline
\end{tabular}

Um zu untersuchen, zwischen welchen Gruppen ein signifikanter Unterschied besteht, wurden Paarvergleiche zwischen den einzelnen Gruppen durchgeführt. Es ergaben sich bei Größe 30 folgende Resultate:

\begin{tabular}{|l|l|l|l|}
\hline Effekt & & $\mathrm{p}$-Wert & Interpretation \\
\hline Gruppe 1 & Gruppe2 & $<.0001$ & Signifikant \\
\hline Gruppe 1 & Gruppe 3 & $<.0001$ & Signifikant \\
\hline Gruppe 2 & Gruppe 3 & 0.9900 & Nicht Signifikant \\
\hline
\end{tabular}

Größe 40

\begin{tabular}{|l|l|l|}
\hline Effekt & $p-$ Wert & Interpretation \\
\hline Gruppe & $<.0001$ & Signifikant \\
\hline Reader & 0.9699 & Nicht Signifikant \\
\hline Gruppe ${ }^{*}$ Reader & 0.8494 & Nicht Signifikant \\
\hline Zahnhälfte & $\mathbf{0 . 0 3 7 9}$ & Signifikant \\
\hline Zahnhälfte ${ }^{*}$ Gruppe & 0.9936 & Nicht Signifikant \\
\hline Zahnhälfte ${ }^{*}$ Reader & 0.8990 & Nicht Signifikant \\
\hline Zahnhälfte ${ }^{*}$ Gruppe ${ }^{*}$ Reader & 0.9830 & Nicht Signifikant \\
\hline voll & 0.1029 & Nicht Signifikant \\
\hline leer & 0.4893 & Nicht Signifikant \\
\hline
\end{tabular}


Bei Größe 40 ergaben sich im Paarvergleich folgende Resultate:

\begin{tabular}{|l|l|l|l|}
\hline Effekt & & $p-W e r t$ & Interpretation \\
\hline Gruppe 1 & Gruppe2 & $<.0001$ & Signifikant \\
\hline Gruppe 1 & Gruppe 3 & $<.0001$ & Signifikant \\
\hline Gruppe 2 & Gruppe 3 & $<.0001$ & Signifikant \\
\hline
\end{tabular}

Größe 50

\begin{tabular}{|l|l|l|}
\hline Effekt & $p-$ Wert & Interpretation \\
\hline Gruppe & $<.0001$ & Signifikant \\
\hline Reader & 0.8878 & Nicht Signifikant \\
\hline Gruppe ${ }^{\star}$ Reader & 0.7382 & Nicht Signifikant \\
\hline Zahnhälfte & $\mathbf{0 . 0 3 6 9}$ & Signifikant \\
\hline Zahnhälfte*Gruppe & 0.5624 & Nicht Signifikant \\
\hline Zahnhälfte*Reader & 0.5382 & Nicht Signifikant \\
\hline Zahnhälfte*Gruppe ${ }^{*}$ Reader & 0.8981 & Nicht Signifikant \\
\hline voll & 0.8734 & Nicht Signifikant \\
\hline leer & 0.3394 & Nicht Signifikant \\
\hline
\end{tabular}

Bei Größe 50 ergaben sich im Paarvergleich schließlich die folgenden Resulatate:

\begin{tabular}{|l|l|l|l|}
\hline Effekt & & $p$-Wert & Interpretation \\
\hline Gruppe 1 & Gruppe2 & $<.0001$ & Signifikant \\
\hline Gruppe 1 & Gruppe 3 & $<.0001$ & Signifikant \\
\hline Gruppe 2 & Gruppe 3 & $\mathbf{0 . 0 1 7 4}$ & Signifikant \\
\hline
\end{tabular}


Die Ergebnisse der Paarvergleiche lassen sich graphisch wie folgt darstellen:

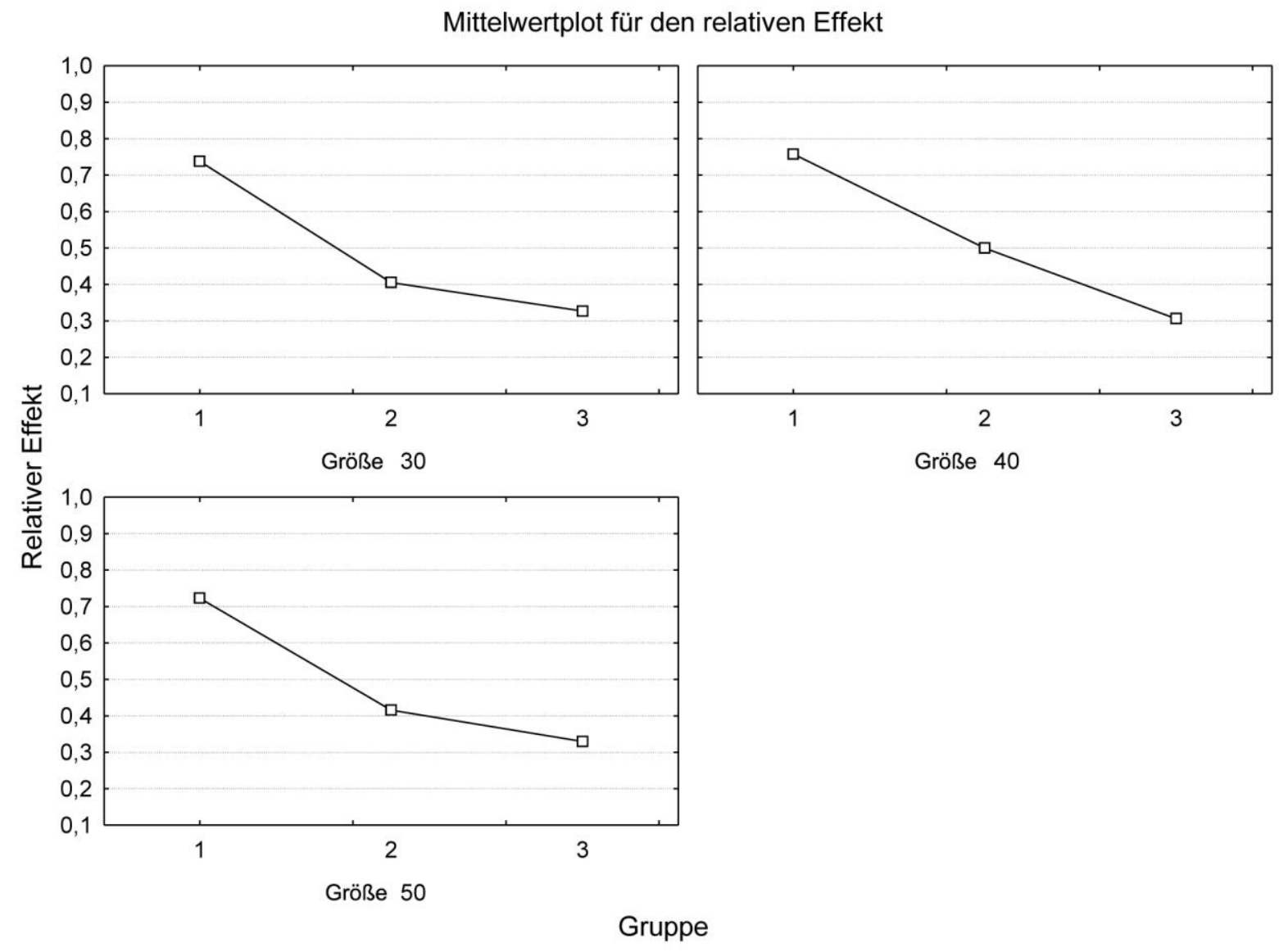




\section{Danksagung}

Herrn Prof. Dr. med. dent. Michael Hülsmann, Kommissarischer Direktor der Abteilung für Präventive Zahnmedizin, Parodontologie und Kariologie im Zentrum Zahn-, Mund- und Kieferheilkunde der Medizinischen Fakultät der Universität Göttingen, gilt mein herzlicher Dank für die Überlassung des Themas.

Sehr herzlich danken möchte ich Frau Dr. med. dent. Tina Rödig, Oberärztin in der Abteilung für Präventive Zahnmedizin, Parodontologie und Kariologie der Universität Göttingen, für die engagierte und zuverlässige Betreuung und Unterstützung dieser Arbeit.

Für die freundliche Einweisung im Labor und für die Unterstützung bei der praktischen Durchführung der Arbeit danke ich Frau Grzyb.

Für die statistische Auswertung danke ich Frau Katharina Lange und Herrn Frank Konietschke aus der Abteilung für medizinische Statistik der Universität Göttingen. 


\section{Curriculum Vitae}

Am 04.05.1968 wurde ich, Mohammad Bagher Sedghi Shabestari, in Teheran/Iran als erstes Kind von Afsar Shariat Panahi und Hassan Sedghi Shabestari geboren. Meine Schwester Solmaz Sedghi Shabestari kam am 21.05.1977 zur Welt.

Am 28.02.2002 erwarb ich die deutsche Staatsangehörigkeit.

1987 legte ich mein Abitur am Hadaf-Gymnasium in Teheran ab. Von März 1988 bis Juni 1988 absolvierte ich ein Geologiestudium an der Universität Asad (Iran). Von Juni 1988 bis Dezember 1988 lebte ich zum Erlernen der türkischen Sprache in der Türkei. 1989 kam ich nach Deutschland und lebte bis 1991 in Nidda. In den Jahren von 1992 bis 1994 vertiefte ich meine Deutschkenntnisse, um dann von 1995 bis 1997 das Studienkolleg für ausländische Studierende in Kassel zu besuchen. Dort erwarb ich 1997 die Hochschulreife für Deutschland.

Von 1997 bis 1998 studierte ich Zahnmedizin an der Medizinischen Hochschule Hannover. Von 1998 bis 2004 setzte ich mein Studium der Zahnmedizin an der Georg-August-Universität Göttingen fort. Die naturwissenschaftliche Vorprüfung absolvierte ich im März 2000. Im März 2002 legte ich die zahnärztliche Vorprüfung ab. Im November 2004 erhielt ich meine Approbation als Zahnarzt.

Von Mai 2005 bis April 2006 arbeitete ich als Assistenzzahnarzt in der Zahnarztpraxis Peter Seelke in Kreiensen.

Von Juni 2006 bis Juni 2007 war ich als Assistenzzahnarzt in der oralchirurgischen Gemeinschaftspraxis Dr. Simon, Dr. Becker und Dr. Hakim in Minden beschäftigt. Im August 2007 begann ich mit der praktischen Arbeit an der vorliegenden Dissertation.

Von September 2007 bis Januar 2008 arbeitete ich in einer Teilzeitanstellung als Zahnarzt in der Zahnarztpraxis Dr. Hadenfeld in Bovenden/Göttingen. Von April 2008 bis April 2009 arbeitete ich in einer Teilzeitanstellung als Zahnarzt in der Zahnarztpraxis Dr. Ernst und Partner in Fulda.

Seit Juni 2009 arbeite ich als Zahnarzt im Mondzorg-Centrum in Maastricht. 